\author{
UNIVERSIDADE DE SÃO PAULO \\ FACULDADE DE ODONTOLOGIA DE BAURU
}

ROBERTA HEIFFIG HANDEM

\title{
AVALIAÇÃO DA REABSORÇÃO RADICULAR EXTERNA CONSECUTIVA AO USO DO SISTEMA AUTOLIGÁVEL DAMON
}



ROBERTA HEIFFIG HANDEM

\section{AVALIAÇÃO DA REABSORÇÃO RADICULAR EXTERNA CONSECUTIVA AO USO DO SISTEMA AUTOLIGÁVEL DAMON}

Dissertação apresentada a Faculdade de Odontologia de Bauru da Universidade de São Paulo para obtenção do título de Mestre em Ciências no Programa de Ciências Odontológicas Aplicadas, na área de concentração Ortodontia.

Orientador: Prof. Dr. Marcos Roberto de Freitas

Versão Corrigida 
Handem, Roberta Heiffig

H191a Avaliação da reabsorção radicular externa consecutiva ao uso do Sistema Autoligável Damon- Bauru, 2012

$111 \mathrm{p} ; \mathrm{Il} ; 30 \mathrm{~cm}$

Dissertação (Mestrado) -- Faculdade de Odontologia de Bauru.

Universidade de São Paulo.

Orientador: Prof. Dr. Marcos Roberto de Freitas

Nota: A versão original desta dissertação encontra-se disponível no Serviço de Biblioteca e Documentação da Faculdade de Odontologia de Bauru - FOB/USP.

Autorizo exclusivamente para fins acadêmicos e científicos, a reprodução total ou parcial desta dissertação, por processos fotocopiadores e outros meios eletrônicos.

Bauru, 28 de novembro de 2012.

Assinatura:

Projeto de pesquisa aprovado pelo Comitê de Ética em Pesquisa da Faculdade de Odontologia de Bauru, Universidade de São Paulo, em 12 de março de 2012 
FOLHA DE APROVAÇÃO 



\section{ROBERTA HEIFFIG \#ANDEM}

14 de Janeiro de 1986

Bauru- SP

Filiação

2004-2007

2008-2010

2008-2011

2010-2012
Nascimento

José Roberto Handem

Regina Helena Heiffig Handem

Curso de Odontologia pela Universidade do Sagrado Coração USC - Bauru/SP

Especialização em Imaginologia e Radiologia Odontológica no Hospital de Reabilitação de Anomalias Crânio Faciais de Bauru- Centrinho- USP.

Especialização em Ortodontia no COPH- Bauru.

Curso de Pós-graduação em Ortodontia, ao nível de mestrado, pela Faculdade de Odontologia de Bauru- Universidade de São Paulo. 

"O que sabemos é uma gota, o que ignoramos é um oceano..."

Isaac $\mathcal{N}$ ewton 



\section{DEDICATÓRIA ESPECIAL}

Dedico este trabalho ao meu avô Xaquib Handem (in memorian) que me ajudou na minha formação profissional e pessoal...

Com ele eu aprendi.....

Que otimismo é a palavra-chave para vivermos melhor...

Que não devemos desistir jamais dos nossos sonhos, Gasta corrermos atrás...

Que nos dias ruins devemos pensar que o amanhã é outro dia, e que dias melhores virão...

Que a família está em primeiro lugar...

Que Deus está em nossas vidas, em todos os momentos do dia...

Que devemos escutar mais e falar menos...

Que ajudar ao próximo é uma das coisas mais belas da vida...

Admiração eterna!saudades meu vô querido.... 



\section{$\mathcal{A}$ Deus,}

Agradeço por estar comigo em todos os momentos e que me faz seguir em frente...Pelos anjos da guarda que me envia para guiar cada passo que dou...me direcionando pro caminfo certo, com saúde e paz. 



\section{DEDICATÓRIA}

Dedico as minhas conquistas aos meus pais... José Roberto e Regina, e minha irmã Renata

Pela minha vida regada de amor e carinho...

Que se doaram por mim, sem pedir nada em troca..

Pela educação dada, pelos valores ensinados...

Pela força e estimulo em cada etapa da minha vida...

$\mathcal{F}$ aço isso tudo pra vocês e por vocês....que são tudo na minha vida!

Palavras não expressam o tamanho do meu amor e da minha gratidão....

Amo vocês!

$\mathcal{A}$ minha bonequinha e afilhada Maria $\mathcal{E} d u a r d a . .$.

Que trouxe alegria para a família..e que enche a "Dinda"de amor...

Ao meu noivo, Rafael...

Que traz paz ao meu coração...que entrou na minha vida para mudá-la...e muda-la para melhor...desde o começo conheci o verdadeiro significado de companheirismo, respeito, admiração, carinfio e amor...Obrigada por me apoiar em tudo que faço...por acreditar em mim e nos meus projetos! Cada dia tenho mais certeza do homem maravilhoso que Deus me enviou. $\dot{E}$ com você que quero sonhar sempre...que quero formar uma família linda..que quero me divertir muito....e passar o resto da vida ... Te amo muito!! 

Minfa Profunda Gratidão:

Aos meus avós Diva,Gessyr e Yvette....por todo amor e carinho...pelos exemplos de pessoas de caráter...de humildade...que sempre me deram alegrias....e que me enchem de orgulho!!

Aos meus tios Paulo e Gislaine pelas palavras de incentivo...e por estarem sempre ao meu lado...

Aos meus primos Paulinho, Renato, Rheder, e Raquel por dividirem comigo todas as minhas conquistas....

$\mathcal{A}$ minha sogrinfia querida..Selma..que é um doce de mulher..e que tem um astral maravilhoso!

Aos meus cuntrados... Rodolfo, Reynaldo, Alexandra, Ivana, Marcio e Ana Maria... pelas palavras de incentivo e por tornarem minha vida mais feliz....

As crianças da família.... Maria Eduarda,Gabriel, Valentina, João Pedro, Luca, Valentina, Vinicius...obrigada por alegrar a minha vida...a pureza de vocês fazem tudo valer a pena... 



\section{Agradecimentos Especiais}

Obrigada ao meu orientador D r.M arcos Roberto de Freitas,

Por ter sido sempre muito paciente...

Obrigada pela confiança depositada em mim...

Pelos ensinamentos de forma simples e objetiva de sua

experiência clinica e acadêmica...

Sinto muito orgulho por ter sido meu ortodontista quando eu era criança....

$\mathcal{A} \mathcal{D}$ outora Karina Freitas,

Imensurável a gratidão por tudo que me ajudou neste trabalho...

Pela paciência....em me socorrer nas estatísticas e na busca da minfia amostra..

Por ser pra mim exemplo de pessoa, mãe e profissional...

Mulfer com um astral contagiante...

Que se tornou pra mim acima de tudo uma amiga!!

Serei eternamente grata....

Desejo a você tudo o que há de melhor nessa vida! 



\section{Agradecimentos}

Meus sinceros agradecimentos...

Ao Prof. Dr. Guilherme Janson

Que não mede esforços para nos tornarmos excelentes mestres...jamais esquecerei o seu jeito critico e determinado em alcançar os seus objetivos... Obrigada pela paciência em me receber e tirar as minhas dúvidas ao longo desse mestrado...obrigada pela amizade...sinto-me hon rada em tê-lo como professor e tenfio convicção de que valeu muito a pena ter sido sua aluna!

Ao Prof. Dr. Darwin Vaz de Lima

Muito obrigada por todo carinfio e atenção no decorrer desta pesquisa... por ter me ensinado muitas coisas novas...por estar sempre disposto a ajudar...por ter me recebido em sua casa com uma receptividade maravilhosa...com uma família que pra mim é exemplo de união, amor e respeito.guardo no meu coração com muito carinfo...Admiro muito o seu trabalho..o seu jeito de ensinar e a sua simplicidade...

Ao Prof. Dr. José Fernando Castanfa Henriques

Que me ensinou muito nos seminários, que contribui para o meu crescimento pessoal e por estar sempre disposto a me ajudar... muito obrigada!

Aos demais professores Dr.Arnaldo Pinzan, Dra.Daniela Gamba Garib, Dr. Renato Almeida pelo exemplo de profissionais e pela valiosa contribuição para o meu crescimento profissional! 

Aos funcionários do departamento...

Luiz Sergio Vieira..pela paciência...amizade..e ensinamentos...admiro muito o seu trabalfo e espero um dia ter metade de sua destreza manual com os fios..rs...

Neide...pela amizade....pelas boas risadas...e por estar sempre pronta a ajudar..

Verinfa...por toda atenção dada...pelo carinho e amizade...

Cléo...pela ajuda diária nas clinicas e amizade.

As colegas da limpeza....muito obrigada pelo carinfio..

Ao meu colega...

Daniel Boné....obrigada por toda atenção..por me ajudar no meu trabalho...sempre com um astral muito bom...obrigada meu amigo corinthiano!

Aos meus amigos do Mestrado....

Cintia Junqueira, Daniela $\mathcal{P}$ upulim, Marília Yatabe, Lucas $\mathcal{M}$ endes, Lucas Silva, Larissa Bressane, Fernanda Pinelli, Váleria Bezerra, Thais Rocha, Fernando Trigueiro, Caroline

Bronfman...muito obrigada por tornar essa caminhada mais fácil e mais divertida...Aprendi muito com cada um de vocês....D esejo do fundo do meu coração que vocês sejam muito felizes e que tenham uma vida acadêmica de muito sucesso!!

Agradecimento especial as minhas colegas de mestrado Valéria e Marília

Obrigada pela paciência... por estarem sempre prontas a me ouvir...pelo companheirismo..Vá..por dividir comigo a amostra dessa pesquisa...e pelas muitas risadas que demos...E Espero que vocês sejam muito felizes...

Aos funcionários da biblioteca... pela presteza e carinfio..

$\mathcal{A}$ bolsa capes pela concessão de bolsa.

$\mathcal{A}$ todos aqueles que, de alguma maneira contribuíram para a realização desta pesquisa! 



\section{RESUMO}

A reabsorção radicular apical constitui um efeito indesejável, porém frequente, do tratamento ortodôntico e por este motivo, várias técnicas e materiais, tal como o aparelho autoligável Damon têm sido desenvolvido visando facilitar a prática clinica e diminuir esse efeito deletério. O propósito deste estudo foi comparar o grau de reabsorção radicular externa em casos tratados com o aparelho autoligável Damon e com o aparelho pré-ajustado convencional. A amostra constitui de 52 casos, sendo 25 do grupo 1, tratados com o aparelho autoligável Damon, com idade média inicial de 16,04 anos e idade média final de 18,06 anos e com tempo de tratamento médio de 2,02 anos; e 27 do grupo 2, tratados com o aparelho pré-ajustado convencional, com idade média inicial de 16,77 anos, idade média final de 18,47 anos e com tempo de tratamento médio de 1,70 anos. Foram avaliadas as radiografias periapicais dos incisivos superiores e inferiores ao final do tratamento ortodôntico. Os dois grupos foram compatibilizados quanto às idades inicial e final, tempo de tratamento, distribuição por gêneros, tipo de má oclusão e protocolo de tratamento sem extrações. A reabsorção radicular foi avaliada pelo escore de Levander e Malmgren. Os dados relacionados à reabsorção radicular foram comparados pelo teste não paramétrico de Mann-Whitney. Os resultados mostraram que não houve diferença significante nos graus de reabsorção radicular entre os dois grupos. Graus de reabsorção radicular semelhantes podem ser esperados ao final do tratamento com o aparelho autoligável Damon e o aparelho pré-ajustado convencional.

Palavras-chaves: reabsorção radicular, movimentação dentária, radiografia periapical. 



\section{ABSTRACT \\ EVALUATION OF EXTERNAL ROOT RESORPTION CONSEQUENT TO THE USE OF SELF-LIGATED DAMON SYSTEM}

The apical root resorption is an undesirable effect, but frequent in orthodontic treatment and for this reason, several techniques and materials, such as self-ligated Damon appliance have been developed to facilitate clinical practice and decrease it. The purpose of this study was to compare the degree of external root resorption in patients treated with the self-ligated Damon appliance and the conventional preadjusted appliance. The sample comprised 52 cases, 25 in group 1, treated with the self-ligated Damon appliance, with mean initial age of 16.04 years, mean final age of 18.06 years, and mean treatment time of 2.02 years; and 27 in group 2, treated with the conventional preadjusted appliance, with a mean initial age of 16.77 years, mean final age of 18.47 years and mean treatment time of 1.70 years. It was evaluated the periapical radiographs of the maxillary and mandibular incisors at the end of orthodontic treatment. The two groups were matched regarding the initial and final ages and treatment time, gender distribution, type of malocclusion and treatment protocol without extractions. The root resorption was assessed by the score of Levander and Malmgren. Data related to root resorption were compared by the nonparametric Mann-Whitney test. The results showed no significant difference in the degree of root resorption between the two groups. Similar degrees of resorption can be expected after the treatment with the Damon self-ligated appliance and the conventional preadjusted appliance.

Key-words: root resorption, tooth movement, periapical radiograph. 



\section{LISTA DE FIGURAS}

Figura 1 - Classificação de Levander e Malmgren (1988) para avaliação do grau de reabsorção.

Figura 2 - Russel Lock ((ARAÚJO; MALTAGLIATI, 2008)..................................37

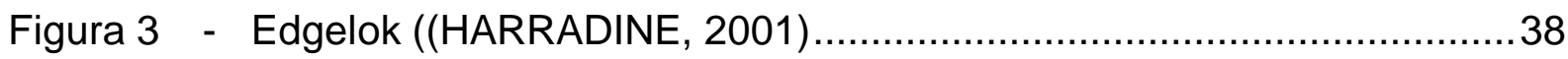

Figura 4 - Braquete Mobil-lock (Forestadent) (BERGER, 1990)..........................39

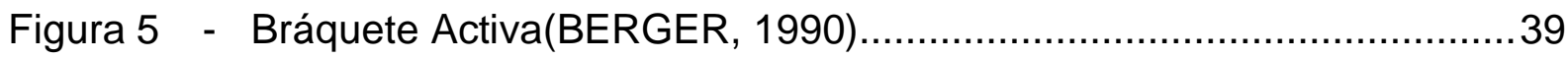

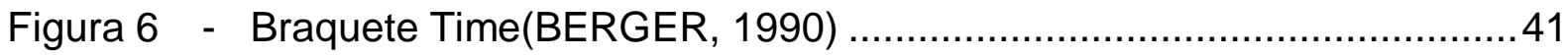

Figura 7 - Braquete Damon SL(BERGER, 1990) ……………………......... 41

Figura 8 - Braquete Twin-lock(BERGER, 1990) …....................................... 41

Figura 9 - Braquete In Ovation-R(GAC, 2003) ............................................. 41

Figura 10 - Braquete Smart Clip....................................................................

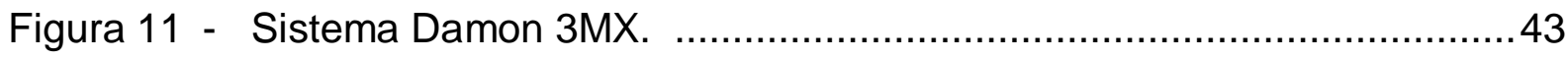

Figura 12 - Plano de Andrews/fonte: Andrews, 1989.(ANDREWS, 1989)

Figura 13 - Linha tangente á face vestibular do dente (JUNIOR, DA SILVA URSI, 2006).

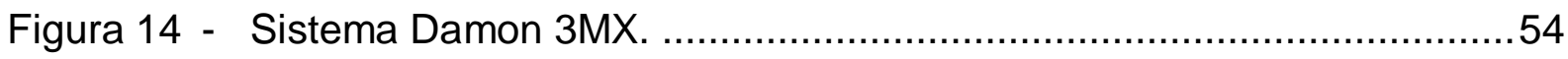

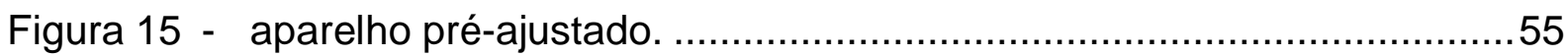

Figura 16 - Classificação dos graus de reabsorção segundo MALMGREN.

Figura 17 - Análise das imagens no programa Adobe Photoshop CS6.

Figura 18 - Ficha para anotação dos graus de reabsorção radicular.

Figura 19 - Índice de Irregularidade de Little (modificado) arco superior/ $\mathrm{A}+\mathrm{B}+\mathrm{C}+\mathrm{D}+\mathrm{E}$

Figura 20 - Índice de Irregularidade de Little arco inferior =

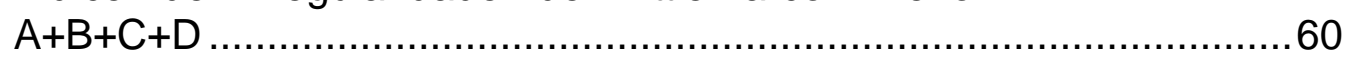

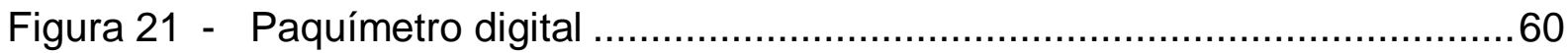

Figura 22 - Paquímetro paralelo ao plano oclusal. ..............................................61 



\section{LISTA DE TABELAS}

Tabela 1 - Avaliação do erro intra-examinador. Resultado do teste t dependente (erro sistemático) e do erro casual (Dahlberg) $n=15$.

Tabela 2 - Resultado do teste Kappa do erro intra-examinador quanto à avaliação do escore de Levander e Malmgren. $\mathrm{n}=120$ 66

Tabela 3 - Resultados do teste t independente entre os grupos $1 \mathrm{e}$ 2 para avaliar a compatibilidade entre os grupos nas idades inicial, final e tempo de tratamento.

Tabela 4 - Resultados do teste t independente entre os grupos $1 \mathrm{e}$ 2 para avaliar a compatibilidade entre os grupos do índice de irregularidade de Little.

Tabela 5 - Resultados do teste do qui-quadrado para avaliar a compatibilidade entre os grupos 1 e 2 na distribuição por gêneros.

Tabela 6 - Resultados do teste não-paramétrico de Mann-Whitney para a comparação entre os graus de reabsorção radicular entre os grupos 1 e 2 ao final (T2) do tratamento.

Tabela 7 - Escores encontrados no grupo 1 e grupo $2(n=52)$ 68

Tabela 8 - Porcentagem de pacientes que apresentaram: sem comprometimento radicular, reabsorção leve, moderada e extrema.

Tabela 9 - Grupo 1: número de escores apresentados em cada dente da maxilla.

Tabela 10- Grupo 1: número de escores apresentados em cada dente da mandíbula.

Tabela 11 - Grupo 2: número de escores apresentados em cada dente da maxilla

Tabela 12 - Grupo 2: número de escores apresentados em cada dente da mandíbula. 



\section{SUMÁRIO}

1 INTRODUÇÃO .17

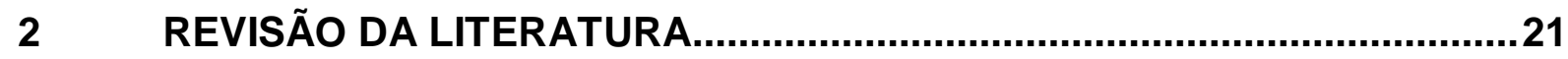

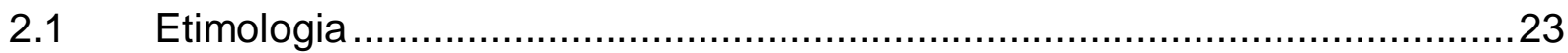

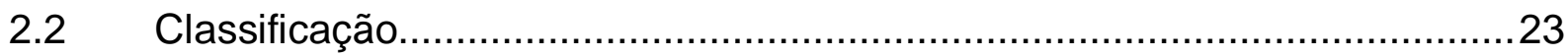

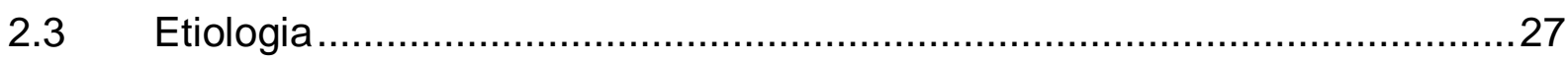

2.4 Como ocorre o processo de reabsorção radicular ........................................35

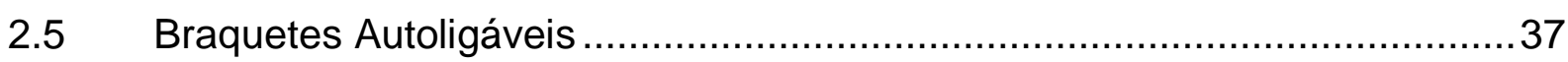

2.6 Aparelhos pré- ajustados (Técnica de Straight-Wire) …............................44

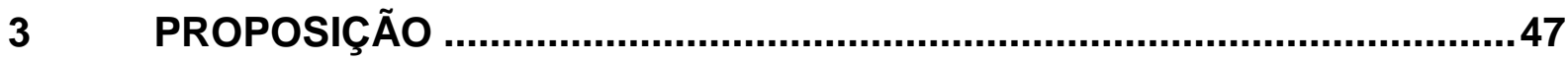

$4 \quad$ MATERIAL E MÉTODOS

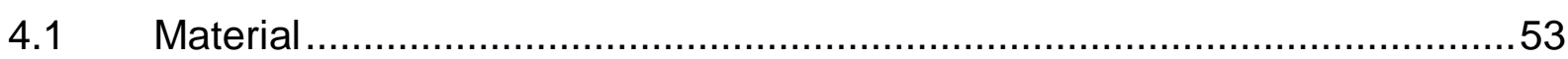

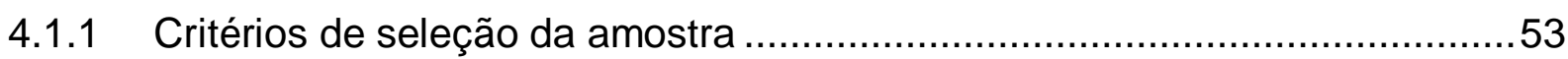

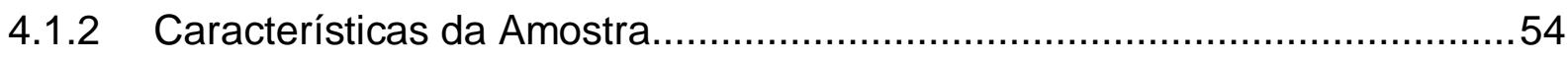

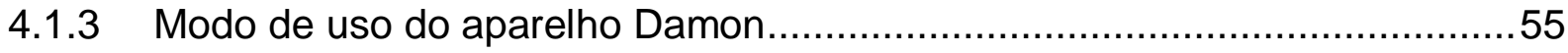

4.1.4 Modo de uso dos aparelhos pré-ajustados .............................................56

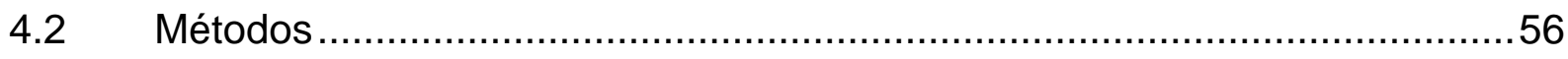

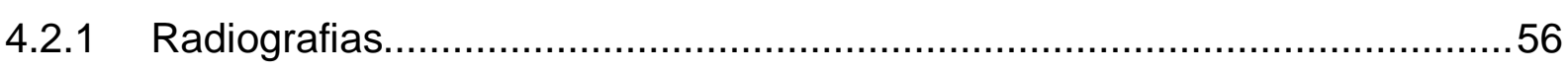

4.2.2 Índice de irregularidade de Little (modificado)........................................59

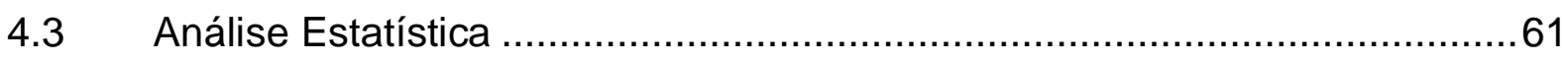

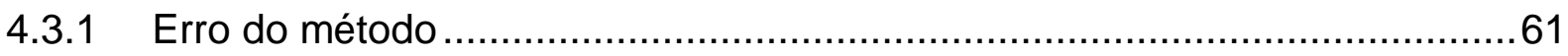

4.3.2 Análise estatística entre grupos e variáveis.............................................62

$5 \quad$ RESULTADOS

5.1 Quantidade de reabsorção radicular decorrente do

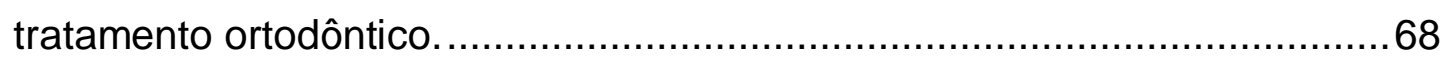

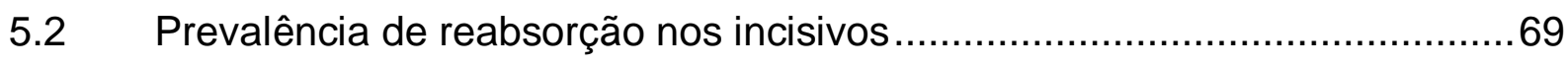





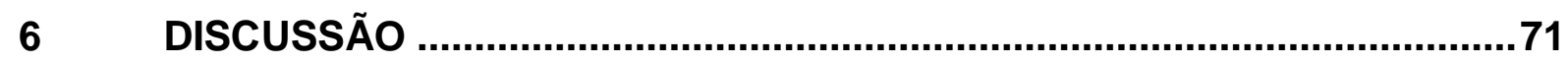

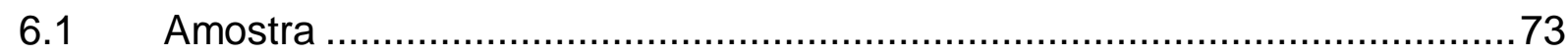

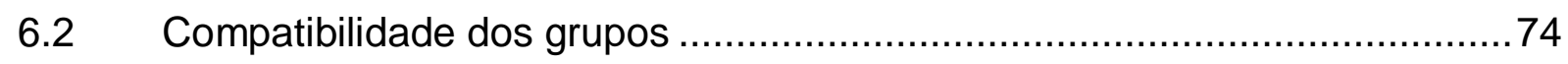

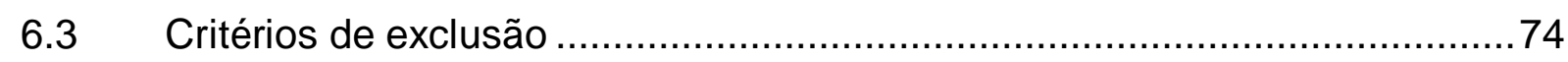

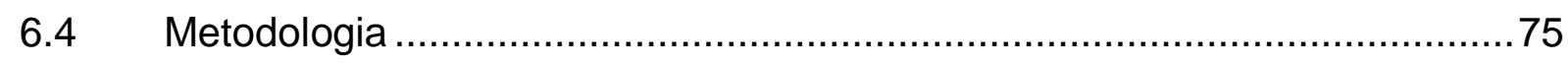

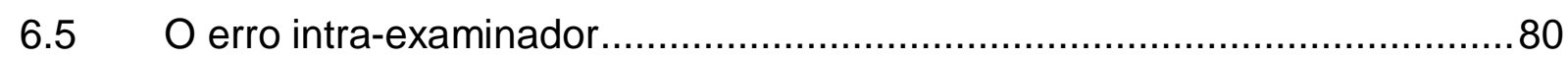

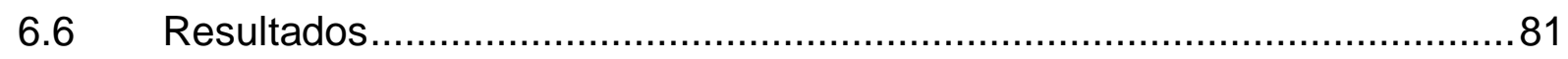

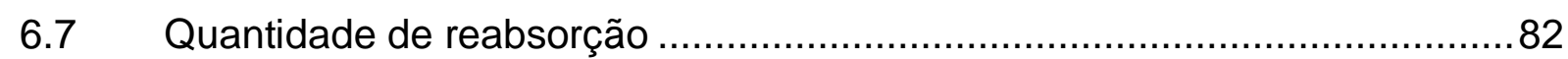

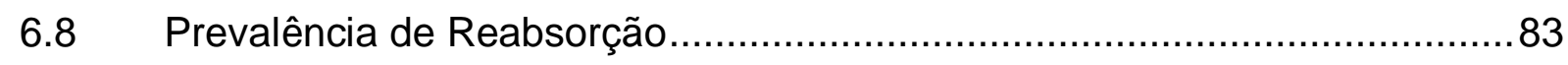

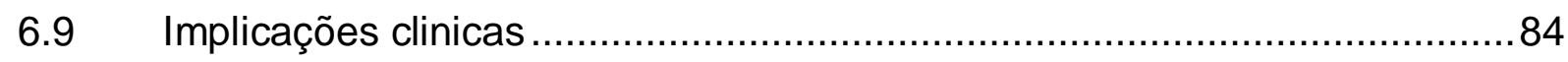

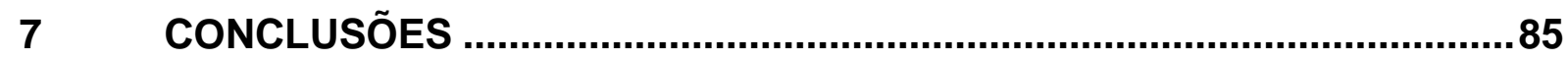

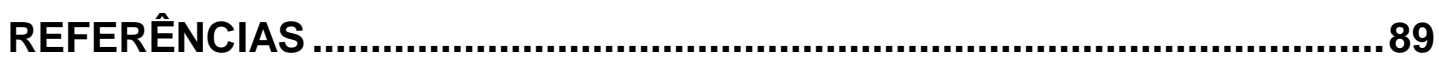

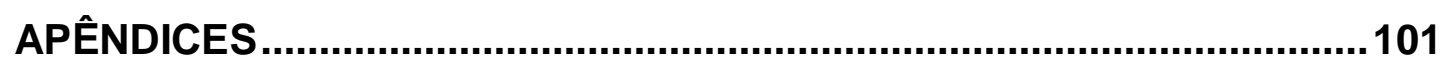

ANEXO 

1

Introdução 



\section{INTRODUÇÃO}

$\mathrm{Na}$ última década, tem havido um aumento significativo do número de sistemas de suporte de auto-ligavéis disponíveis para os ortodontistas. Atualmente, um líder de mercado é o Sistema Damon (Ormco, Glendora, Califórnia), que preconiza uma filosofia de tratamento baseada na utilização de um bracket autoligavel passivo e de níquel-titânio superelástico (DIBIASE et al., 2011).

Segundo os seus idealizadores, quando associados ao uso de fios superelásticos com formato mais expansivo permitem ao profissional a obtenção de excelentes resultados, sem necessidade de extração de pré-molares, além de propiciarem uma força "fisiológica" leve e contínua para movimentação dentária, gerando baixo nível de atrito e resultando em um tratamento finalizado em um menor período de tempo. (LENZA, 2008)

O que atrai o Sistema Damon é a promessa de excelência no tratamento de quase todos os pacientes, propondo casos sem extrações, não cirúrgico, sem expansão do palato, sem dor e tempo reduzido. (PECK S, 2008). O sistema Damon apresenta importante avanço em termos de robustez e facilidade de uso, com o seu crescimento rápido o mesmo merece uma análise da situação atual dessa classe de brackets. (HARRADINE, 2001)

Na literatura nota-se a escassez de artigos que relatam o grau de reabsorção radicular com o uso do sistema Damon. As reabsorções radiculares externas apicais advindas de movimentação ortodôntica é um problema iatrogênico. Acredita-se ser o resultado da combinação da biologia individual e dos efeitos das forças mecânicas ortodônticas (YOUNIS M, 2008).

O objetivo deste trabalho será verificar o grau de reabsorção radicular de pacientes submetidos a tratamento ortodôntico pelo sistema Damon comparado aos aparelhos convencionais. 



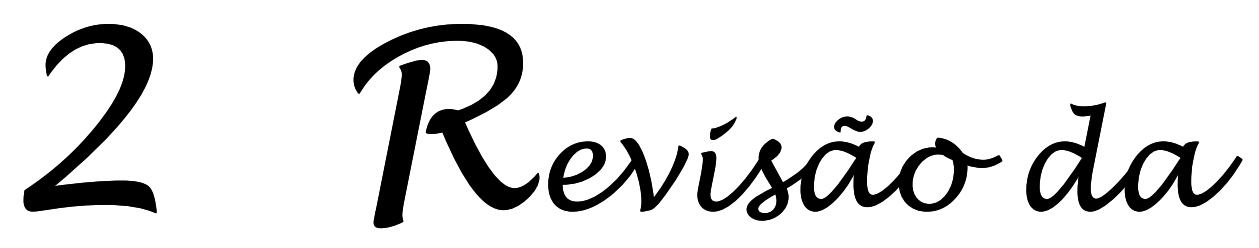

Literatura 



\section{REVISÃO DA LITERATURA}

\subsection{Etimologia}

A palavra reabsorção originou-se do latim, do verbo resorbere, que significa "de novo". Já sorbere significa "sorver, engolir, tragar", com o sentido de "engolir de novo, remover de novo". O termo absorção de origem também latim, advêm do verbo absorbere que indica a não finalização do processo. (BECKS H, 1932)

Controvérsias sempre existiram em relação ao termo que deveria ser utilizado para apontar a perda de substância dura que ocorre na região apical dos dentes decíduos e permanentes. Assim alguns autores apontavam como reabsorção enquanto outros absorção. (BECKS H, 1932). Ambos os termos ganhavam conceitos distintos no relatório anual do Comitê de Nomenclatura da American Dental Association (ADA), pois segundo o Comitê absorção significava retirada pelos tecidos de fluidos originários fora do corpo distinguindo-se de reabsorção que constituía da retirada de produtos ou tecidos originários no corpo. Visando uniformizar os termos Becks e Marshall, em 1932(BECKS H, 1932) padronizaram para reabsorção independentemente de ele ser utilizado para dentes permanentes, decíduos ou ainda para osso.

Em síntese, independentemente do conceito empregado para a reabsorção, é de grande relevância conhecer as suas causas e desenvolvimento.

\subsection{Classificação}

Bates, em 1956(BATES, 1856) foi o primeiro a descrever sobre a reabsorção radicular dos dentes permanentes e relacioná-la ao trauma do ligamento periodontal.Porém a reabsorção radicular oriunda da movimentação ortodôntica foi observada e descrita por Ottolengui em 1914(OTTOLENGUI, 1914), o autor já relatava que a polpa permanecia viva, enquanto as raízes eram reabsorvidas. 
Feiglin em 1936(FEIGLIN B, 1986) classificou a reabsorção radicular de três formas: em interna, externa e inflamatória. A reabsorção interna é aparentemente desencadeada por algum sinal inflamatório da polpa. $O$ trauma é sugerido como causa deste tipo de reabsorção, embora desconhecido o seu mecanismo. A reabsorção externa pode ser fisiológica quando ocorre em dentes decíduos, reabsorção dentária ortodôntica, quando advinda de um tratamento ortodôntico, reabsorção induzida por trauma, ou causada pela pressão de um dente adjacente não irrompido. A reabsorção inflamatória pode ser apical ou cervical. A apical ocorre apenas em dentes não vitais, enquanto na cervical, a polpa pode ou não ter vitalidade, caracterizando por uma pequena cavidade na margem cervical.

Andreasen, em 1985,(ANDREASEN, 1985) concluiu que a reabsorção radicular externa pode ser classificada em três tipos: a reabsorção de superfície causada por injúrias ao ligamento periodontal, podendo ser reparada se a causa for removida; a reabsorção inflamatória, podendo ser causada pela combinação entre as agressões ao ligamento periodontal e a superfície radicular. E o terceiro tipo a reabsorção por substituição, a fusão entre superfície radicular e osso; se esta fusão torna-se permanente ou transitória esta é determinada pelo tamanho inicial desta anquilose.

Após quatro anos Tronstad L(1988)(TRONSTAD, 1988a) descreve a reabsorçao inflamátoria como aquela que ocorre quando a pré-dentina ou précemento torna-se mineralizado ou, no caso do pré-cemento, é mecanicamente danificada ou raspada. É visto na parede do canal radicular (reabsorção interna) e na superfície externa da raiz (reabsorção cervical externa) e pode ser transitória ou progressiva. Quando a reabsorção inflamatória é progressiva torna-se uma área desnuda de uma superfície radicular interna ou externa, há estimulação de longa duração adicional de reabsorção das células, como aumento da pressão no tecido, infecções, ou doenças sistêmicas. A reabsorção por substituição é visto em dentes anquilosados que se tornaram incorporados no osso. Não é um resultado de um processo de doença, mas ocorre como um "erro" porque as células envolvidas na remodelação do osso não são capazes de distinguir entre o tecido dental e ósseo. 
Em 1993, PUCHE(PUCHEL.R, 1993) classificou as reabsorções em reversíveis e irreversíveis, sendo as reversíveis causadas pela compressão do ligamento periodontal, resultante de uma carga oclusal excessiva, e as irreversíveis em diferentes situações: na reabsorção fisiológica dos dentes decíduos para posteriormente serem substituídos pelos permanentes, na reabsorção de incisivos laterais superiores durante a erupção dos caninos, na reabsorção provocada pelo movimento fisiológico dos dentes e na reabsorção idiopática.

De acordo com a classificação de Goldson e Henrikson (1975) (GOLDSON; HENRIKSON, 1975) as reabsorções radiculares classificam-se em nove tipos, quanto à irregularidade da superfície apical, sendo elas:

1.Contorno radicular irregular, provavelmente causado pela reabsorção;

2.Reabsorção radicular como reabsorção oblíqua no terço apical da raiz. A superfície de reabsorção ou superfícies não ultrapassa a linha média do dente;

3.Reabsorção radicular apical menor que $2 \mathrm{~mm}$. A superfície de reabsorção ultrapassa a linha média do dente.

4. Idem a 3 combinada com a reabsorção oblíqua no terço apical da raiz;

5. Reabsorção radicular apical de $2 \mathrm{~mm}-1 / 3$ da raiz

6. Idem a 5 combinada com a reabsorção obliqua no terço apical da raiz;

7. Reabsorção radicular, $1 / 3$ a $2 / 3$ da raiz

8. Reabsorção radicular maior que $2 / 3$ da raiz

9. Raiz curta, arredondamento da raiz apical.

Em relação à magnitude da reabsorção radicular Malmgrem e colaboradores em 1982 (MALMGREN O, 1982)classificaram em quatro graus diferentes:

1.Contorno apical irregular

2.Reabsorção apical com menos de $2 \mathrm{~mm}$ de redução do comprimento radicular

3. Reabsorção apical com mais de $2 \mathrm{~mm}$ a $1 / 3$ de redução do comprimento original 
4. Reabsorção apical com redução maior que um terço do comprimento da raiz original.

A classificação mais utilizada em relação à movimentação dentária é a de Levander e Malmgren (1988)(LEVANDER; MALMGREN, 1988), (figura 1) em que os autores classificam as reabsorções de acordo com a gravidade, em: ausente, leve (contorno apical irregular), moderada (pequena perda radicular, com o ápice exibindo um contorno praticamente reto), acentuada (perda de quase um terço do comprimento radicular) e extrema (com perda de mais de um terço do comprimento radicular).

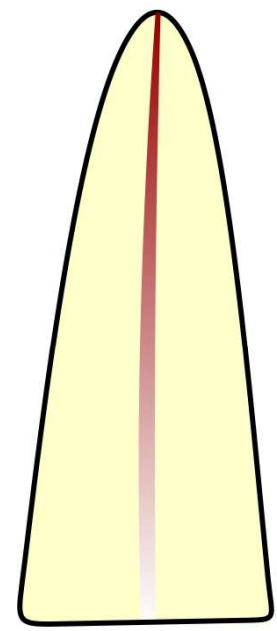

0

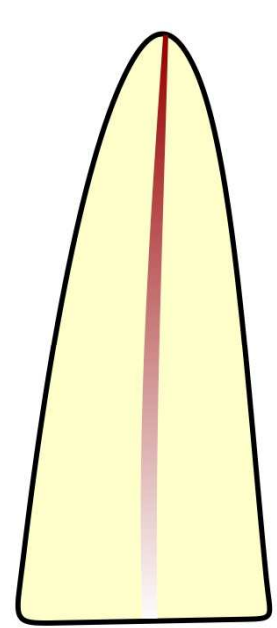

1

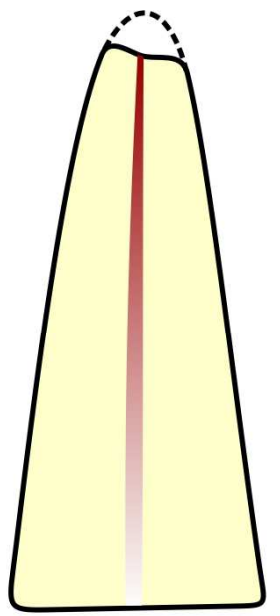

2

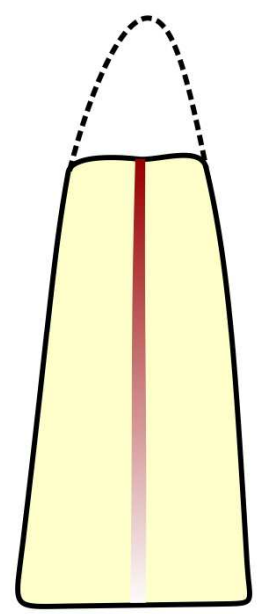

3

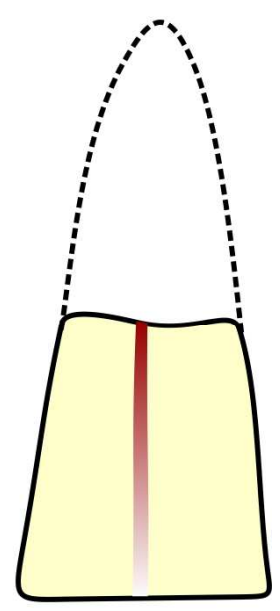

4

Figura 1 - Classificação de Levander e Malmgren (1988) para avaliação do grau de reabsorção.

De uma forma bem ampla, a reabsorção pode ser classificada em fisiológica, quando ocorre nos dentes decíduos, e patológica a que ocorre nos dentes permanentes (MARSHALL, 1935). 


\subsection{Etiologia}

Muitas são as causas das reabsorções radiculares descritas na literatura. A seguir serão descritas os fatores que relacionados às movimentações ortodônticas podem causar ou se relacionar com a reabsorção radicular.

\section{Genética}

A genética apesar de não comprovada parece influenciar na reabsorção radicular. No trabalho de Harris et al em 1997(HARRIS; KINERET; TOLLEY, 1997) estudou-se uma amostra que constituía de 103 pares de irmãos tratados com a mesma técnica por um ortodontista. Comprimentos de raiz e coroas foram medidos ao início e final do tratamento. Os autores relataram que independente da gravidade da má oclusão, há correlação entre os níveis de reabsorção radicular ocorrido entre pacientes irmãos. Os mecanismos de hereditariedade possível são o modo autossômico dominante, o modo autossômico recessivo e o modo poligênico. (FILHOA; DA SILVA FILHOB, NEWMAN, 1975).

Estudos sobre esta relação não são conclusivos, porém alguns estudos mostraram que as mulheres apresentaram maior reabsorção radicular em relação aos homens(KJÆER, 1995, MASSLER; PERREAULT, 1954). Entretanto, outros trabalhos relatam não haver diferença entre homens e mulheres em relação à reabsorção radicular. (BECK; HARRIS, 1994, BLAKE; WOODSIDE; PHAROAH, 1995a, LINGE; LINGE, 1983, SAMESHIMA; SINCLAIR, 2004, SAMESHIMA; SINCLAIR, 2001).

\section{Hábitos}

A reabsorção radicular ocorre como uma função normal do envelhecimento e desde comportamentos alterados tal como o bruxismo podem acelerar a reabsorção, mesmo na ausência de tratamento. (HARRIS; BUTLER, 1992).

Odenrick e Brattstrom (1983)(ODENRICK; BRATTSTRÖM, 1983), com o objetivo de determinar a incidência de onicofagia na população e sua possível 
correlação com a reabsorção radicular apical decorrente do tratamento ortodôntico aplicaram um questionário a 340 jovens de ambos os sexos, com idade de 13 a 15 anos. Foram avaliadas radiografias periapicais de incisivos e caninos. As raízes foram analisadas por 2 examinadores e classificadas em 0 quando não havia reabsorção; 1 quando o contorno do ápice apresentava-se irregular; 2 quando havia uma reabsorção de menos de $2 \mathrm{~mm} ; 3$ quando a reabsorção era de $2 \mathrm{~mm}$ a um terço de raiz e, finalmente, 4 para reabsorções de até dois terços de raiz. Um grupo foi constituído de 21 pacientes onicófagos tratados ortodonticamente e o outro, de 21 pacientes tratados ortodonticamente, os quais nunca haviam roído suas unhas. Todos os pacientes, em ambos os grupos, demonstraram alguma reabsorção após 0 tratamento, porém os autores encontraram um índice de reabsorção radicular significantemente mais alto nos pacientes onicófagos, previamente ao tratamento.

\section{Morfologia Radicular}

Em relação à morfologia das raízes de acordo com Levander e Malmgren (1988)(LEVANDER; MALMGREN, 1988) uma maior predisposição a reabsorção radicular é encontrada em raízes com morfologia radicular em forma de pipeta, a dilaceração das raízes, e raízes curtas. Um trabalho similar também foi descrito após duas décadas por Sameshima (2004)(SAMESHIMA; SINCLAIR, 2004), em que o autor concluiu que a pior reabsorção foi observada em incisivos laterais superiores $\mathrm{e}$ em dentes com formatos radiculares anormais (pipeta, pontudo ou dilacerado).

Em 1995 um estudo realizado por Kjaer(KJÆER, 1995) objetivou identificar as características morfológicas dos pacientes que submetidos ao tratamento ortodôntico sofreram reabsorções radiculares severas. Foi feita análise radiográfica de 107 pacientes, com presença de um ou mais dentes com reabsorção superior a um terço do comprimento radicular. $\mathrm{Na}$ dentadura decídua, foram registradas as características morfológicas, como padrões anormais de reabsorção da raiz do dente decíduo durante a erupção do dente permanente, a infra-oclusão e a morfologia dentária. Já na dentadura permanente avaliou-se a morfologia da raiz e da coroa. Foi relatada a presença de grande número de raízes curtas, estreitas e com forma de pipeta, além de raízes com dilaceração. Concluiu-se uma grande associação 
entre as características morfológicas e a tendência de reabsorção radicular durante o tratamento ortodôntico.

Após três anos outro trabalho(THONGUDOMPORN; FREER, 1998) foi realizado a fim de investigar a associação entre anomalias dentárias, morfologia radicular e a reabsorção radicular durante o tratamento ortodôntico. Foram selecionados 111 casos tratados, nos quais foram avaliados: agenesia, impactação, erupção ectópica, invaginação, incisivos laterais conóides, raízes com forma de pipeta ou estreitas, raízes curtas ou arredondadas e taurodontismo. A invaginação nos incisivos superiores indicou estar presentes em $26,1 \%$, raízes curtas ou arredondadas $23,4 \%$, raízes com forma de pipeta ou estreitas $20,7 \%$, erupção ectópica 14,4\%, 9,9\% nas anomalias: impactaçao, incisivos laterais conóides e taurodontismo, 8,1\% de agenesia e 1,8\% de dilaceração. Os autores puderam concluir que os pacientes que apresentavam algum tipo de anomalia morfológica dentária apresentaram níveis de reabsorção radicular mais alto quando em comparação com pacientes que não apresentam nenhum tipo. Para o clinico é importante se ater a morfologia radicular, a fim de se precaver de problemas futuros.

Filho A (1998) (FILHOA; DA SILVA FILHOB) ressalta a importância de considerar a situação radicular em pacientes que já sofreram tratamento ortodôntico, considerando tipo e tempo do tratamento ortodôntico, de preferência avaliando a documentação inicial.

\section{Fatores sistêmicos}

Phillips em 1955 (PHILLIPS, 1955) indicou que os fatores metabólicos e genéticos podem ser sugeridos como responsáveis pela reabsorção radicular, porém apenas pelos registros publicados até aquele momento eram insuficientes para validar tal afirmação.

Pereira (1995)(PEREIRA, 1995) pesquisou a relação entre a movimentação dentária induzida e o uso de anticoncepcionais hormonais por via bucal e a gravidez. A amostra constou de 35 ratas Wistar, com idades entre 90 e 120 dias, divididas em 7 grupos: três de ratas prenhas, dois de ratas recebendo anticoncepcional e 2 grupos controle, um com e outro sem movimentação dentária. Os resultados da 
análise microscópica dos tecidos envolvidos mostraram um padrão constante em todos os grupos experimentais, não permitindo qualquer interferência quanto a uma alteração decorrente das ratas prenhas ou do uso de anticoncepcional. O mesmo foi obtido na avaliação dos resultados dos traçados dos contornos ósseos e radiculares envolvidos na movimentação dentária, bem como das áreas do ligamento periodontal. Assim o autor concluiu que não há interferência do uso de anticoncepcionais hormonais, por via bucal e da gravidez na remodelação óssea periodontal durante a movimentação dentária induzida e que esses fatores não predispõem os dentes ao fenômeno da reabsorção.

Nishioka et al. Em 2006 (NISHIOKA et al., 2006) realizaram um estudo para determinar se havia associação entre a reabsorção radicular excessiva e os fatores do sistema imunológico. Foram avaliados os registros de 60 pacientes japonêses submetidos a tratamento ortodôntico (18 homens, idade média 17,7 anos; 42 mulheres, idade média 16,4 anos) e 60 controles baseados no sexo, duração do tratamento, e tipo de má oclusão. Os resultados mostraram que a incidência de alergia e morfologia radicular anormal foi mais alta significantemente no grupo com reabsorção radicular. A incidência de asma também tendeu a ser maior no grupo com reabsorção radicular. Destes resultados, concluíram que a alergia, a morfologia radicular anormal, e a asma podem ser fatores de risco para o desenvolvimento de reabsorção radicular anormal durante a movimentação dentária ortodôntica.

No trabalho de Furquim em 2002 (FURQUIM, 2002) foram analisadas as características morfológicas dentárias e maxilares, bem como determinado o perfil hormonal, crônico, enzimático e glicêmico de todos os pacientes. Foram observados 3 grupos de 70 pacientes cada, sendo 70 pacientes sem tratamento ortodôntico, 70 pacientes com tratamento ortodôntico sem reabsorção dentária e 70 com reabsorção dentária. Os resultados revelaram que pacientes tratados ortodonticamente com e sem reabsorção dentária apresentaram o mesmo perfil sistêmico e endocrinológico que os pacientes sem tratamento ortodôntico. 


\section{$\underline{\text { Reabsorção radicular associada à movimentação }}$}

Oppenheim em 1944 após estudos da interpretação histológica do movimento dentário ortodôntico descreveram que as reabsorções dependem da duração e intensidade da força. As alterações patológicas observadas após várias semanas de movimento no terço apical da polpa depende do deslocamento grande do ápice. Todos os danos a membrana periodontal, osso, cemento e polpa provavelmente poderia ser evitado pelo uso de forças de curta duração, seguido por períodos de descanso de duração ainda mais longa.(OPPENHEIM, 1944)

Harry e Sims em 1982 (HARRY; SIMS, 1982) utilizaram a microscopia eletrônica para verificar os efeitos da força intrusiva sobre a raiz dentária. Eles relataram uma notável reabsorção radicular quando utilizada as forças intrusivas comparadas ao grupo controle.

No ano de 1957 Kaare Reitan(REITAN, 1957) estudou o uso das forças em ortodontia. Analisou a variação individual dos tecidos, o tipo de força aplicada e os princípios mecânicos. $\mathrm{O}$ autor concluiu que a existência de um período inicial necessário após a aplicação da força, para atingir um estágio de proliferação celular e promover a alteração tecidual depende de uma série de fatores, tais como a idade do paciente e as características anatômicas da raiz. Com relação ao tipo de força aplicada, distinguiram-se as forças como do tipo intermitente e contínua. As forças intermitentes podem determinar a formação de áreas hialinas de maior extensão e de curta duração, quando comparada com as forças contínuas.

Em 1981, Ronnerman e Larsson (LARSSON; RÖNNERMAN, 1981) realizaram um estudo piloto em 23 pacientes tratados com a técnica de Canto, antes imediatamente após, três e dez anos após o término do tratamento. Radiografias periapicais dos incisivos foram realizadas e examinadas. Os pacientes foram divididos em 4 grupos: o grupo A foi formado por 5 pacientes com má oclusão de Classe II, divisão 1, tratados com Ativador; o grupo B constituiu-se de 9 pacientes, 8 Classe II, divisão 1 e um Classe II, divisão 2, tratados com 4 extrações; o grupo C foi formado por 5 pacientes Classe II, divisão 1, tratados com extrações apenas no arco superior e, finalmente, o grupo D, por 4 pacientes com má oclusão de Classe I e com 
apinhamento, tratados com extrações em ambos os arcos. Os autores encontraram reabsorção radicular apical nos incisivos superiores, na extensão de 1 a $3 \mathrm{~mm}$, em $39 \%$ dos casos. Não foram encontradas reabsorções apicais de mais de $3 \mathrm{~mm}$ e em $61 \%$ dos casos, nenhuma reabsorção ou reabsorção de menos de $1 \mathrm{~mm}$ foi observada.

Linge e Linge (1983) (LINGE; LINGE, 1983) em seu estudo no qual constava uma amostra de 719 pacientes tratados ortodonticamente, consideram 0 encurtamento radicular um efeito colateral do tratamento ortodôntico, irreversível, de difícil previsão e que pode ser severo o suficiente para colocar em dúvida o benefício deste tratamento. Observaram que a utilização de arcos retangulares e elásticos de Classe II foram fatores relacionados com a reabsorção, porém não associaram a quantidade de reabsorção radicular apical com o gênero e a quantidade de trespasse vertical e horizontal.

A fim de avaliar a qualidade dos tratamentos ortodônticos realizados na Universidade de Lund, em Malmo, em um período de 10 anos, Ahlgren em 1993, (AHLGREN, 1993) examinou os registros radiográficos de 480 pacientes tratados na clínica de pós-graduação. Metade dos casos foram tratados com aparelho fixo e a outra metade, com aparelhos removíveis. O diagnóstico foi feito através de radiografias periapicais e panorâmicas. As alterações radiculares com menos de 1 $\mathrm{mm}$ não foram consideradas. A reabsorção radicular foi encontrada em praticamente todos os casos tratados com aparelhos fixos. Entretanto, a quantidade de encurtamento radicular foi pequena, usualmente de $1 \mathrm{a} 3 \mathrm{~mm}$, nunca excedendo a um terço do comprimento radicular, sendo que os incisivos superiores foram os dentes mais vulneráveis. $O$ autor verificou a não ocorrência de reabsorção radicular nos casos tratados com aparelhos removíveis.

Analisando a reabsorção dos incisivos centrais superiores de pacientes com mordida aberta ou com sobremordida, Harris e Butler (1992) observaram nos 32 pacientes com mordida aberta que as raízes dos incisivos apresentavam-se mais curtas em relação às dos pacientes com sobremordida, mesmo antes do tratamento ortodôntico. (HARRIS; BUTLER, 1992). 
Martins et al em 1994 observaram que a reabsorção radicular ao término do tratamento ortodôntico, cessa com a remoção do aparelho, na maioria dos dentes observados, e nos poucos que apresentaram alguma progressão, não foi contínua, ocorrendo apenas uma remodelação apical. Os autores ainda aconselharam o ajuste oclusal, após seis meses do término do tratamento e o controle por 2 ou 3 anos, das reabsorções mais evidentes .(MARTINS; CANSANÇÄO; FERNANDEZ SANCHEZ, 1994).

Em relação ao diagnóstico das reabsorções radiculares a radiografia periapical como método é o mais empregado, a gama de trabalhos descritos na literatura (AHLGREN, 1993, FURQUIM, 2002, NISHIOKA et al., 2006, SAMESHIMA; SINCLAIR, 2004) se deve a relação custo beneficio, principalmente em relação às telerradiografias e radiografias panorâmicas, que apresentam uma confiabilidade inferior. (SANTOS et al., 2007). Ainda como vantagem Sameshima e Asgarifar (2001) e Sameshima et al. (2001) afirmaram que as radiografias periapicais apresentam as dilacerações de forma claramente visível quando comparadas com as panorâmicas, das quais são praticamente impraticáveis.(SAMESHIMA; SINCLAIR, 2004, SAMESHIMA; SINCLAIR, 2001)

No estudo de Rego M. V. N. N em 2004 conclui-se que os dentes mais susceptíveis a reabsorção radicular são: incisivos laterais superiores,incisivos centrais superiores, incisivos inferiores, raiz distal dos primeiros molares inferiores e segundos pré-molares inferiores, segundos pré-molares superiores, molares superiores e inferiores.(REGO et al., 2004)

Em um trabalho realizado por Heimisdottir et al. (2005) os autores chamam atenção para o diagnóstico apenas através de radiografias. Em seu trabalho discutiu-se algumas dificuldades associadas com a avaliação da reabsorção radicular através de radiografias. Um relato de caso foi descrito para elucidar tal problema. Uma menina com onze anos de idade apresentava uma reabsorção radicular marcante dos incisivos laterais maxilares, ocasionada pelos caninos permanentes impactados. Os incisivos precisavam ser extraídos. Vários meses antes das extrações, um canino havia sido cirurgicamente exposto para remover a pressão da raiz do incisivo. Os incisivos laterais foram analisados histologicamente, 
e as descobertas histológicas foram comparadas com aquelas dos primeiros prémolares mandibulares dos pacientes, os quais tinham sido extraídos. Os resultados demonstraram que a reabsorção dos incisivos laterais foi mais grave do que era esperado a partir das radiografias. A reabsorção estendia-se para a polpa. Assim, concluíram que a gravidade da reabsorção radicular de incisivos laterais não pode ser julgada com precisão a partir de radiografias somente. (HEIMISDOTTIR; BOSSHARDT; RUF, 2005).

Para avaliar se seria possível identificar previamente ao tratamento ortodôntico fatores que permitissem que o clinico pudesse prever a incidência, localização e gravidade da reabsorção radicular Sameshima e Sinclair (2004) realizaram radiografias periapicas boca toda de uma amostra de 868 pacientes que realizaram tratamento com aparelho fixo. Foi analisada com precisão a reabsorção radicular apical de molar a molar de ambos os arcos. Os resultados mostraram que a reabsorção ocorre principalmente nos dentes anteriores da maxila, atingindo uma média de 1,4 milímetros. A pior reabsorção foi observada em incisivos laterais superiores e em dentes com formatos radiculares anormais (pipeta, pontudo ou dilacerado). Os pacientes adultos mostraram mais reabsorção que as crianças no segmento anterior da mandíbula. Pacientes com sobressaliência aumentados mostram maior reabsorção radicular. (SAMESHIMA; SINCLAIR, 2004).

Em relação ao tratamento das reabsorções El-Bialy et al. (2004) mostraram um método clinicamente aceitável para tratar a reabsorção radicular. A utilização de ultrassom de baixa intensidade, baseado em pesquisas prévias que demonstram que o ultrassom pode aumentar a cura de vários tipos de tecidos conjuntivos traumatizados e estimular a formação de tecidos dentais. Assim os autores avaliaram o processo de cura da reabsorção radicular induzida ortodonticamente em seres humanos. Pacientes que procuravam tratamento ortodôntico (12 pacientes) participaram deste estudo. Para cada paciente, molas ativadas foram utilizadas nas pontas dos primeiros molares superiores com um nível inicial de força de 50 gramas; as molas foram checadas semanalmente para assegurar níveis contínuos de força. Um curto período de ultrasom de baixa intensidade foi aplicado em um lado da boca de cada paciente e o outro lado da boca foi utilizado como controle. Depois de quatro semanas, os pré-molares experimentais de todos os pacientes foram 
extraídos, e os pré-molares de seis pacientes foram estudados através de microscopia eletrônica de varredura (MEV); os pré-molares de outros seis pacientes foram estudados histologicamente $\mathrm{O}$ estudo MEV demonstrou uma diminuição estatisticamente significativa nas áreas de reabsorção e no número de lacunas de reabsorção nos pré-molares que foram expostos ao ultrassom. O exame histológico mostrou a cura da superfície radicular absorvida através da hipercementose.(ELBIALY; EL-SHAMY; GRABER, 2004).

\subsection{Como ocorre o processo de reabsorção radicular}

Quando uma força ortodôntica é aplicada a um dente ocorre um estresse biológico no ligamento periodontal, e consequentemente ao osso alveolar e cemento. Porém se o osso e o cemento apresentassem comportamento biológico similar, ambos deveriam ser igualmente reabsorvidos. (BREZNIAK; WASSERSTEIN, 2002). A explicação para a alta resistência á reabsorção radicular tem se dado a camada de pré-cemento e cementoblastos que recobrem todo o cemento.(BECK; HARRIS, 1994, EMSLIE, 1978). De acordo com Consolaro 2002 (CONSOLARO, 2002) os cementoblastos, ao contrário dos osteoblastos, não possuem receptores para mediadores sistêmicos, como prostaglandinas, leucotrienos, interleucinas, entre outros; que são acumulados nas áreas de compressão do ligamento periodontal contra o osso alveolar. Pode-se dizer assim que: "os cementoblastos são "surdos" para os mediadores da reabsorção óssea, atuando assim como guardiões da integridade da raiz".

Entretanto, essa proteção biológica não impede que a reabsorção radicular ocorra, pois pode haver lesão ou destruição parcial da camada de revestimento de pré-cemento (TRONSTAD, 1988). Caso um agente físico local promova uma lesão dessa camada de revestimento, os clastos obtêm acesso aos tecidos mineralizados do dente, iniciando assim o processo de reabsorção. Durante esse processo é formada uma zona degenerada e acelular (zona de necrose estéril), que é resultante da compressão do ligamento periodontal e de seus componentes com redução do suporte nutricional. (REITAN, 1957, 1964). 
Há um teoria conhecida como teoria da auto-imunidade, a mesma está associada ao processo de reabsorção em que indica que a dentina é protegida internamente pelos odontoblastos e externamente pelo esmalte. $\mathrm{O}$ cemento intermediário ou proteína "esmalte-like", (que é uma fina camada de proteína de matriz orgânica, produzida pela bainha de Hertwig) durante a formação da raiz protege a dentina da exposição direta às células do futuro ligamento periodontal. A fragmentação da bainha de Hertwig não expõe dentina, porque antes de fragmentarse, ela forma o cemento intermediário que a protege. Na odontogênese normal, não há exposição de dentina ao sistema imune. Por este motivo, se houver exposição de dentina na região do ligamento periodontal, esta será reconhecida como proteína estranha. Na movimentação dentária, o cemento, em função da sua fragilidade e de sua fina camada, a dentina é rapidamente exposta. Assim sempre que houver dentina exposta haverá reabsorção. $\mathrm{Na}$ área desnuda de dentina, os osteoclastos chegam rapidamente e os osteoblastos, somente horas após. A remoção da força faz com que os osteoclastos cedam lugar aos osteoblastos, promovendo o reparo, originado pela migração de cementoblastos sobre a superfície reabsorvida(JONES; BOYDE, 1988).

A contínua aplicação de força ortodôntica faz com que o processo de reabsorção continue mesmo após toda a zona hialinizada ter sido eliminada. Entretanto, se a força ortodôntica for interrompida, ou cair abaixo de certo nível, as lacunas de reabsorção serão reparadas. (RYGH, 1977)

No processo de reparação da reabsorção radicular as dimensões originais do dente não são restabelecidas, o que resulta normalmente em redução do seu comprimento. Com movimentos ortodônticos do dente no alvéolo, uma microlesão forma-se no tecido periodontal, provocando ou exacerbando a inflamação, tendo a uma regularização do ápice, promovendo assim diminuição do comprimento radicular. (DE LUCA CANTO, 1997) 


\subsection{Braquetes Autoligáveis}

A incorporação de braquetes autoligavéis já existe a um longo tempo em ortodontia, os mesmos possuem uma face vestibular que pode ser aberta ou fechada, sem o uso de amarrações metálicas ou elásticas e que mantêm o fio dentro da canaleta. O primeiro sistema de braquetes autoligáveis foi descrito foi o Russell Lock' edgewise em 1935(STOLZENBERG, 1935) (figura 2). Esses consistiam de um dispositivo fabricado com uma rosca interna e o sistema de fixação do fio era um parafuso achatado, que se encaixava nessa rosca e permitia graduar a força sobre o arco. O autor descreveu na literatura que o uso de amarrilhos para fixação do arco era dispensável na Ortodontia.

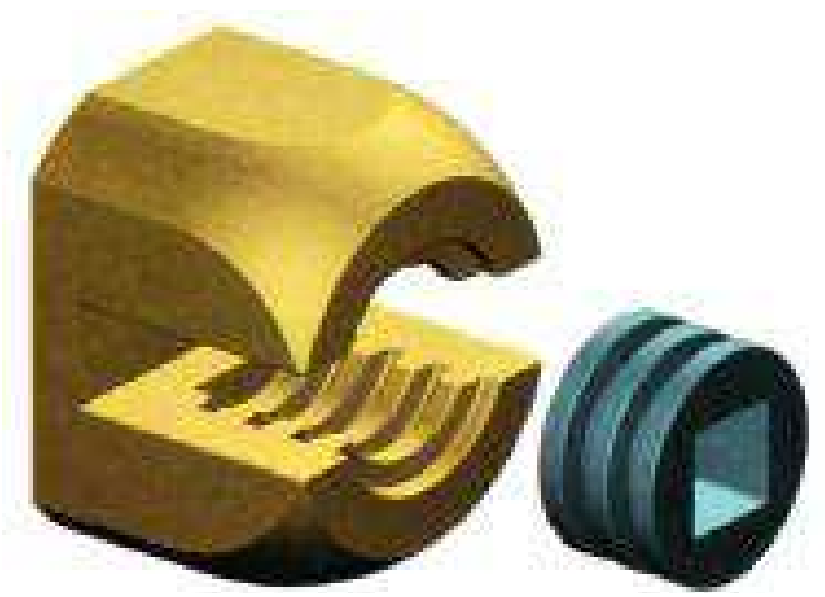

Figura 2 - Russel Lock ((ARAÚJO; MALTAGLIATI, 2008)

Somente em 1972 (WILDMAN et al., 1972) surgiu outro dispositivo, idealizado por Wildman chamado Edgelok (Ormco Corp., EUA), e patenteado pela Ormco(BERGER, 2000), em que apresentava uma tampa por vestibular para fechar e abrir a canaleta do braquete (figura3). Era considerado como um sistema passivo, visto que se baseava na relação do arco com a canaleta para controle do dente e não era armazenada energia no próprio braquete. 


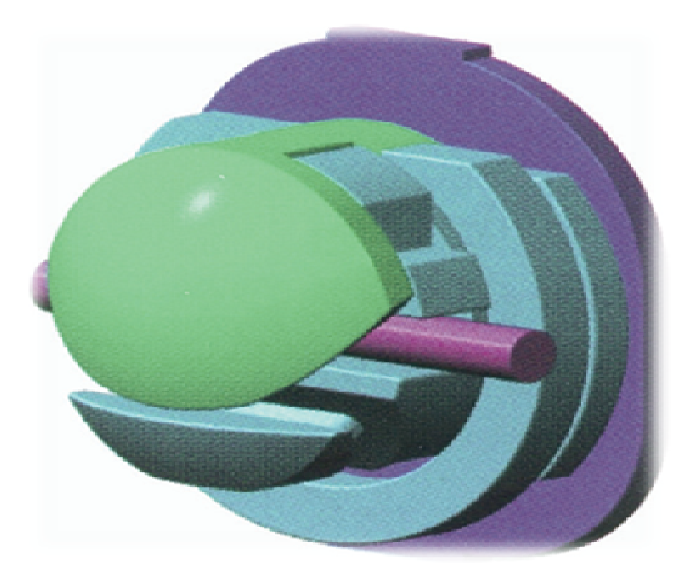

Figura 3 - Edgelok ((HARRADINE, 2001)

O que diferencia o sistema de braquetes convencionais dos autoligados é que nos autoligados os dentes não são presos por meio de ligaduras elásticas ou metálicas e o próprio braquete tem um sistema de fechamento que deixa o fio livre dentro da canaleta, possuindo uma trava para fechamento e abertura. (DAMON, 1998). Os benefícios imprevisíveis dos bráquetes autoligados foram as suas baixas resistências friccionais, ou seja, a redução do atrito gerado entre o fio e o bráquete, o que colaborou para o desenvolvimento desses braquetes(HEMINGWAY et al., 2001).

Podemos definir a friç̧ão como uma força atuando tangencialmente à superfície de dois corpos se movendo em contato. Quando um objeto em movimento contata outro, a fricção nas suas superfícies produz resistência para a direção de movimento, isto é, a fricção atua paralelamente e em oposição ao movimento. (LOFTUS et al., 1999).

$\mathrm{Na}$ década de 80 surgiu na Alemanha o Mobil-lock (Forestadent) (figura 4) que utilizava um instrumental para fechar e abrir a canaleta por meio da rotação de uma tampa semicircular do bráquete dos dentes anteriores, chamado de Speed(BERGER, 2000). Era necessário um instrumento rotatório para abrir e fechar a canaleta, porém, assim como o Edgelok, esse sistema apresentava controle de rotação muito pobre(HARRADINE, 2001). O braquete apresentava um design mais estético e menor, assim com distância interbraquetes maior. O mesmo apresentava uma redução no acúmulo de alimentos. Esse sistema se diferenciava dos anteriores por apresentar uma tampa que deslizava no sentido vertical para fechamento da 
canaleta. Outra vantagem dessa tampa é ter sido confeccionada, originalmente, com aço inoxidável e, hoje em dia, ela apresenta uma liga de níquel-titânio fina e resiliente, que a torna extremamente flexível. (BERGER, 2000).

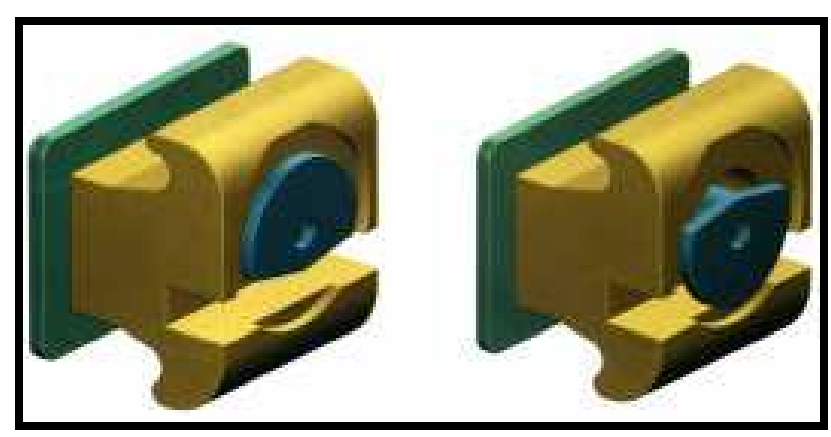

Figura 4 - Braquete Mobil-lock (Forestadent).(BERGER, 1990)

Assim, o fio inserido na canaleta está sob ativação constante, resultando em movimentos dentários precisos e controlados. Essa tampa superelástica é capaz de orientar o fio até que ele esteja completamente ajustado dentro na canaleta, evitando, portanto movimentações indesejadas subsequentes de rotação, inclinação e torque durante qualquer tipo de movimentação dentária. $O$ braquete permite colocação de ganchos e acessórios. Como uma grande vantagem estudos demonstraram que a redução do tempo de trabalho na clínica ortodôntica é de até quatro vezes em relação aos sistemas convencionais com elásticos(BERGER; BYLOFF, 2001).

Logo após o Speed foi lançado em 1986 bráquete Activa (figura 5), que foi originalmente desenhado por Irwin Pletcher, com o principal objetivo de acelerar o processo de fixação do arco aos bráquetes. A comercialização desses bráquetes não seguiu adiante, devido à facilidade com que os pacientes abriam sua tampa.

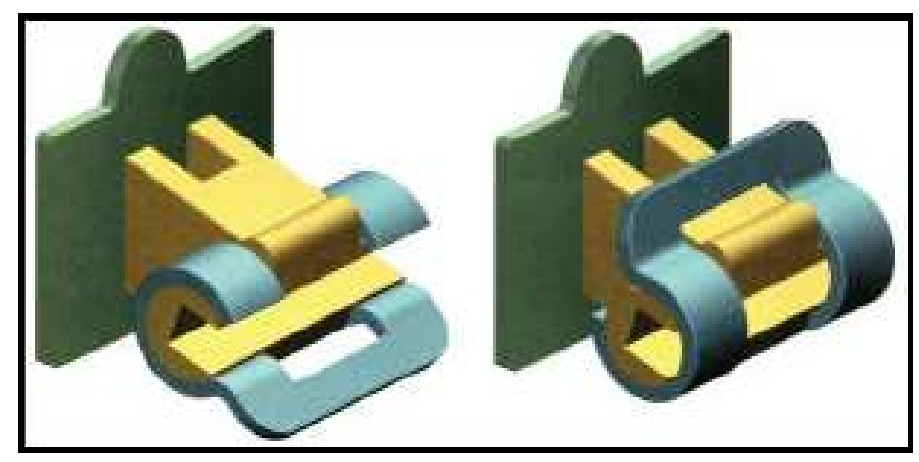

Figura 5 - Bráquete Activa(BERGER, 1990) 
$\mathrm{Na}$ década de 90 foi lançado o braquete Time (Adenta) (figura 6) este se assemelhava ao Speed na aparência e na maneira ativa de atuação. Seu tamanho era semelhante ao dos braquetes convencionais e a tampa que abre na canaleta no sentido ocluso-gengival era curva e menos rígida do que a dos primeiros sistemas, mesmo sendo de aço inoxidável. (BERGER, 2000). Logo em seguida, a American Orthodontics (EUA) lançou o braquete com tampa ativa chamado Sigma, concomitantemente com o lançamento dos sistemas passivos Damon SL I (Ormco Corp., EUA)(BERGER, 2000, DAMON, 1998) (figura 7). A "A"-Company, em 1998, lançou mais um braquete passivo chamado Twin-lock (figura 8), semelhante ao edgewise geminado, porém possuía uma tampa que se movia no sentido oclusal com o auxílio de um instrumento universal. (BERGER, 2000). Um sistema foi proposto pela GAC, um de seus últimos lançamentos (figura 9) o In-Ovation-R, com controle dos sistemas geminados tamanho mini, apresenta formato rombóide e com as demais características dos sistemas autoligados. Durante o alinhamento e nivelamento, utilizando-se fios redondos e de menor calibre, os braquetes são considerados passivos, pois a tampa está distante do fio dentro da canaleta. À medida que se aumenta o calibre do arco e se passa a usar fios retangulares, o contato justo do fio com a tampa o torna ativo. (GAC, 2003). Em 1999 surgiu o Damon SL 2 que são braquetes edgewise geminados com uma tampa lisa e retangular deslizante entre as aletas. Nos braquetes do arco dentário superior, a tampa desliza no sentido incisal e, nos do arco inferior, no sentido gengival. Seu design permite um rápido nivelamento devido à reduzida fricção entre o braquete e a canaleta, desta forma permitindo aos dentes deslizarem mais facilmente. No sistema Damon SL I havia a desvantagem de muitas quebras da trava deslizante, já no sistema Damon SL II houve uma melhora nessa imperfeição, diminuindo o número de quebras (HARRADINE, 2001). 


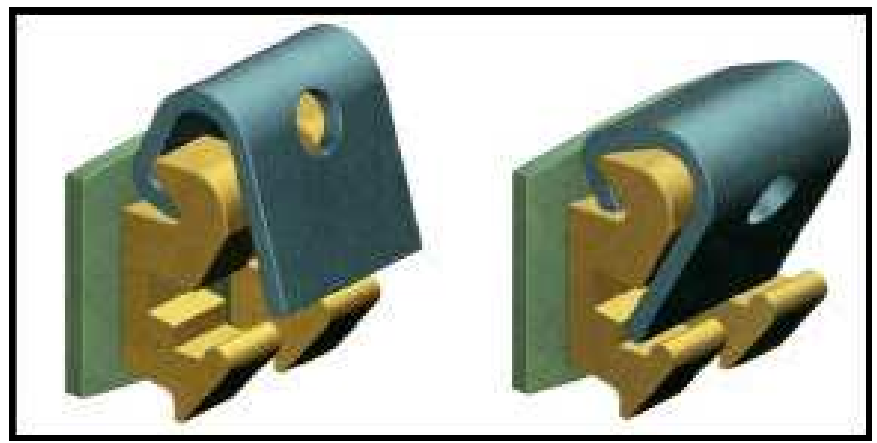

Figura 6 - Braquete Time(BERGER, 1990)

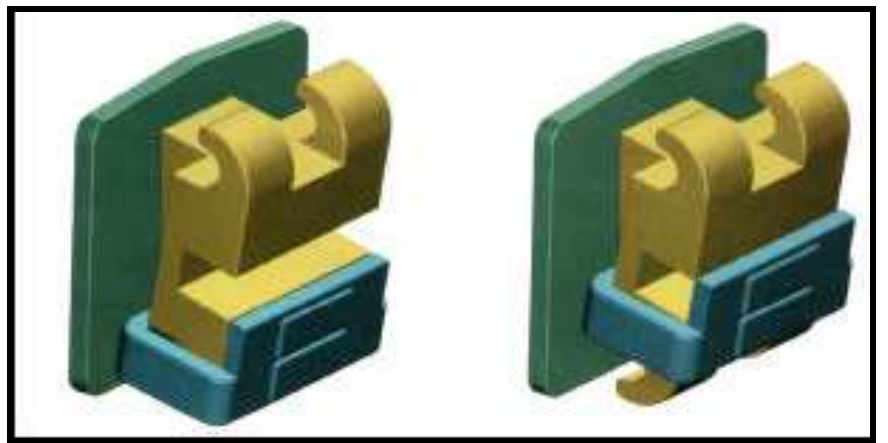

Figura 7 - Braquete Damon SL(BERGER, 1990)

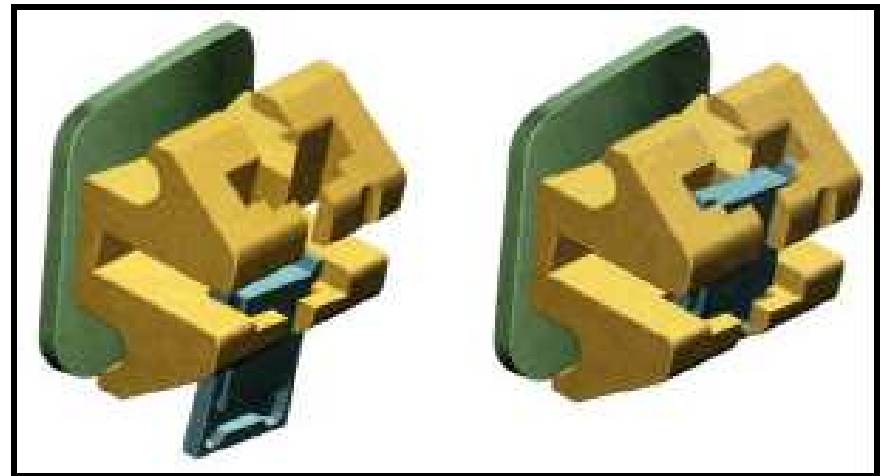

Figura 8 - Braquete Twin-lock(BERGER, 1990)
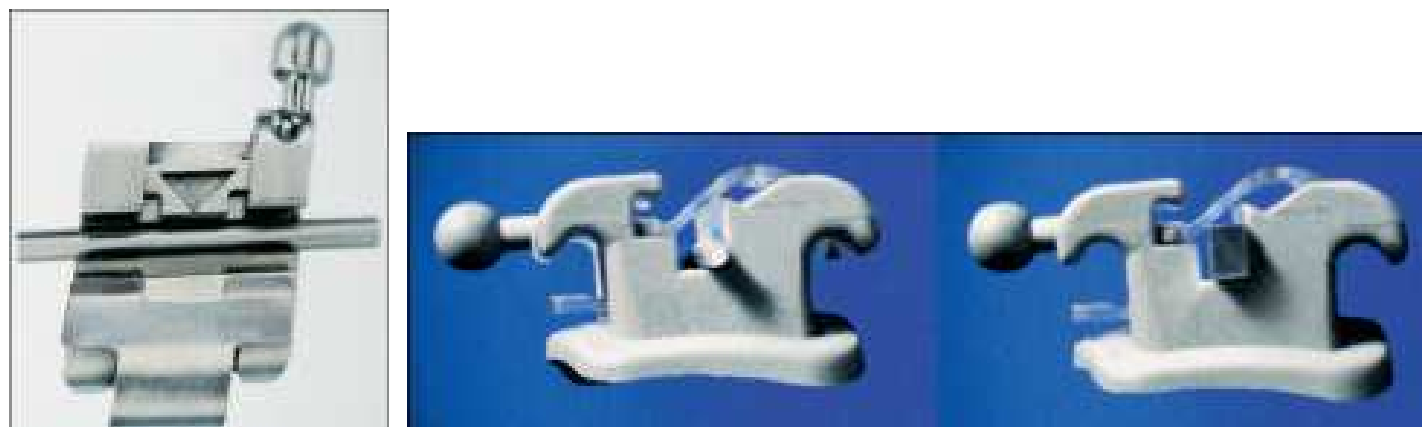

Figura 9 -: Braquete In Ovation-R(GAC, 2003) 
O primeiro sistema autoligado estético foi o Oyster (Gestenco International $A B$, Suécia), surgiu no século $X X I$, feito de fibra de vidro reforçada por um polímero, dando transparência ao braquete. A tampa fecha sobre a canaleta no sentido cervico-oclusal, funcionando de forma ativa. Pode-se remover a sua tampa e o braquete funciona como um sistema tradicional, sendo necessária a utilização de amarrilhos metálicos ou elásticos para manter o fio dentro da canaleta. (HARRADINE, 2001).

Em 2004, surgiu o Damon III, considerado semiestético, com um mecanismo fácil e seguro para abertura e fechamento da trava; porém, ele apresentava três problemas significativos: descolagem frequente, separação do metal com a porcelana, e fratura da aleta(HARRADINE, 2001). Ressalta-se, ainda, que, se um paciente almeja um braquete estético associado à ligadura elástica também esteticamente aceitável, a escolha do Damon III não seria a melhor opção. Em 2006, surgiu o In-Ovation C (GAC International, EUA)(ALPERN, 2008), também autoligado ativo. Nesse mesmo período, o sistema Damon lançou o Damon MX(HARRADINE, 2001), no qual dividia o tratamento em quatro fases:1 (arco redondo de alta tecnologia), 2 (arco retangular de alta tecnologia), 3 (maior mecânica) e 4 (finalização e detalhamento).

E mais recentemente foi lançado da 3M Unitek (EUA), o sistema autoligado SmartClip $^{T M}$ Self-ligating (figura 10). Esse sistema apresenta as seguintes características: contém dois clipes na lateral para prender o fio dentro da canaleta, segue os conceitos da biomecânica de deslizamento do aparelho ortodôntico MBT Versátil; aplicação de forças leves e uso do fio retangular de último calibre 0,019 " x 0,025" na canaleta 0,022" x 0,028", além de preconizar uma sequencia de fios semelhante à do tratamento convencional, com pequena mudança na fase do alinhamento e nivelamento para fios de nitinol superelásticos, em relação aos de nitinol (TREVISI, 2007). 


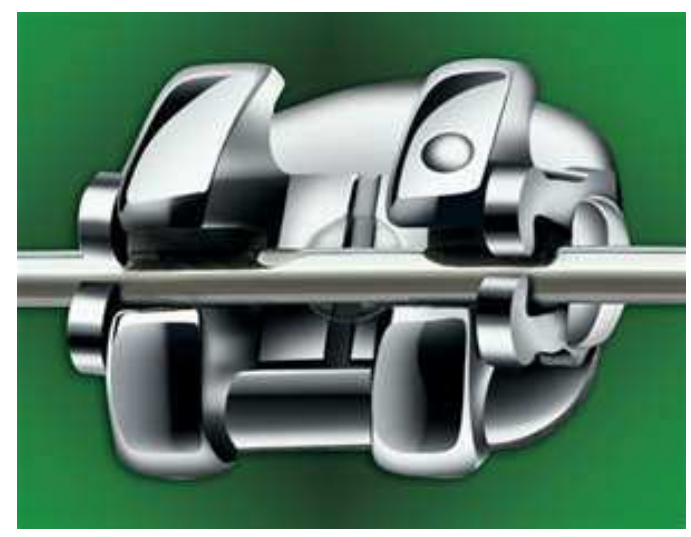

Figura 10 - Braquete Smart Clip

(Fonte: http://www.oss-orthodontics.com/Treatment/Types-of-Braces.aspx)

O que atrai o Sistema Damon (figura 11) é a promessa de excelência no tratamento de quase todos os pacientes, propondo casos sem extrações, não cirúrgico, sem expansão do palato, sem dor e tempo de tratamento reduzido. (PECK, 2008).

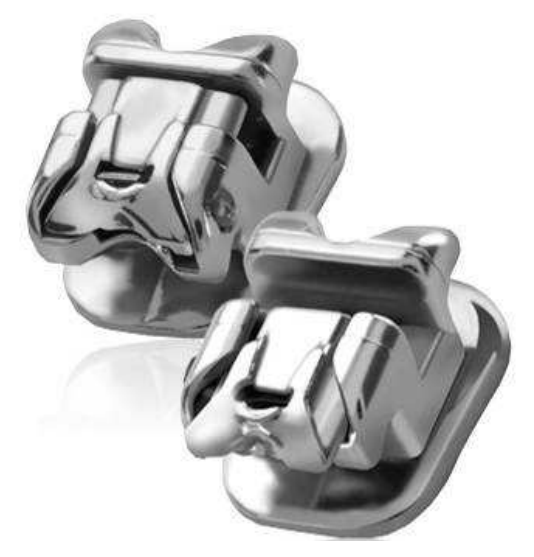

Figura 11 - Sistema Damon 3MX.

(fonte: http://www.ormco.com/index/damon-products-damon3mx-2).

Loftus et al.(LOFTUS et al., 1999) em seu estudo avaliou o atrito dos braquetes metálicos convencional, cerâmico convencional, autoligado Damon SL e cerâmico com canaleta metálico durante mecânica de deslizamento com elástico em cadeia. Os resultados mostraram não haver diferença entre as forças de atrito do bráquete Damon, dos bráquetes metálicos convencionais e do com canaleta metálica. Os bráquetes totalmente cerâmicos apresentaram um atrito significativamente maior. 
Thorstenson et al. (2001) avaliaram a resistência de deslizamento comparando os braquetes autoligados com os convencionais, em diferentes ângulos. Os autores observaram que a resistência ao deslizamento dos autoligados era menor do que os convencionais devido à baixa magnitude de atrito. (THORSTENSON; KUSY, 2001).

Damon em 1998 ressaltou que o suprimento sanguíneo tem importância fundamental para uma eficiente movimentação dentária, considerando não haver dúvidas de que as forças leves e contínuas são melhores. (DAMON, 1998).

\subsection{Aparelhos pré- ajustados (Técnica de Straight-Wire)}

Antes de abordar sobre os aparelhos pré-ajustados é de suma importância lembrar que o conceito de Edward Hartley Angle de 1925 perdura até os dias atuais, em que se baseia em um fio retangular que preenche total ou parcialmente o interior de um braquete, também retangular. Desde então, a partir desse principio muitas modificações foram feitas por outros estudiosos. A evolução desta mecânica é conhecida como mecânica Straight-Wire. Para se alcançar o desenvolvimento de um aparelho totalmente programado primeiro foi definido o que seria o ideal. E para isso Andrews em 1972 definiu a partir do exame da coroa clinica dos dentes de portadores de oclusão normal, os objetivos que deveriam ser buscados para se alcançar uma oclusão ótima. E isso foi descrito no artigo "As seis chaves da oclusão normal". As "seis chaves" consistiam em: 1) Relação dos molares - os primeiros molares permanentes superiores devem mostrar três pontos de contato evidentes com os dentes antagonistas; a superfície distal da crista marginal do primeiro molar permanente superior contacta e oclui com a superfície mesial da crista marginal mesial do segundo molar permanente inferior; a cúspide mésio-vestibular do primeiro molar permanente superior oclui dentro do sulco existente entre a cúspide mésiovestibular e a mediana do primeiro molar inferior e a cúspide mésio-palatina do primeiro molar permanente superior adapta-se à fossa central do primeiro molar permanente inferior; 2) Angulação das coroas - a porção cervical do longo eixo de cada coroa encontra-se distalmente à sua porção oclusal; 3) Inclinação das coroas a porção cervical do longo eixo da coroa dos incisivos superiores encontra-se por 
lingual à superfície incisal, aumentando a inclinação lingual progressivamente na região posterior; 4) Rotações - não deve haver rotações dentárias indesejáveis; 5) Contatos interproximais - não deve haver espaços interproximais; 6) Curva de Spee - deve apresentar-se plana ou suave. (ANDREWS, 1972)

Segundo o autor, o braquete deveria ser posicionado exatamente no centro vertical da coroa (figura 12) (JÚNIOR; DA SILVA URSI, 2006)

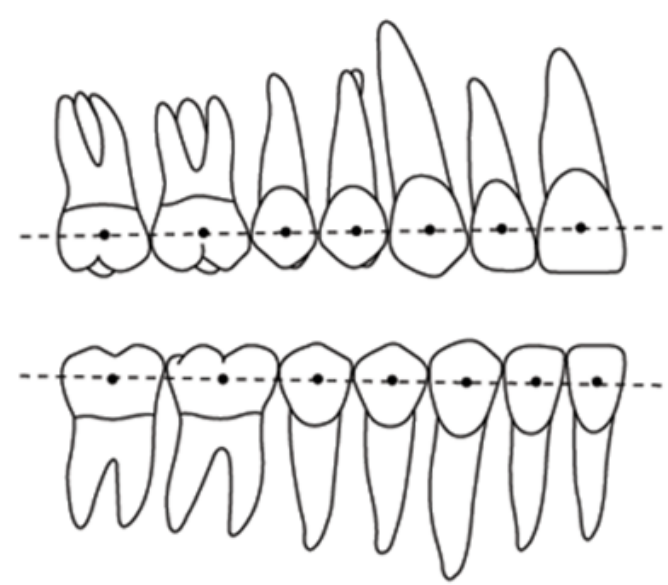

Figura 12 - Plano de Andrews/fonte: Andrews, 1989.(ANDREWS, 1989)

Os braquetes foram criados de tal modo que quando os dentes estivessem idealmente posicionados as canaletas estariam coincidentes com o plano de Andrews, em que a superfície com a qual o plano médio transverso de cada coroa coincidirá, quando os dentes estiverem idealmente posicionados. (CAPELOZZA FILHO et al., 1999)

Andrews visava uma linha de referência para medir a magnitude da variação do posicionamento dentário nos sentidos vestíbulo lingual e mésio distal. Para isso o autor comparou as variações das posições dentárias com uma linha perpendicular ao plano que cortava o ponto central do EVCC (eixo vertical da coroa clinica) de todos os dentes. Em relação à angulação essas eram medidas por meio da diferença em graus entre o eixo vertical da coroa clinica (EVCC) e a linha perpendicular ao plano de Andrews. Os torques eram obtidos pela diferença entre uma linha tangente á face vestibular do dente e a mesma perpendicular (figura 13) (JÚNIOR; DA SILVA URSI, 2006). 


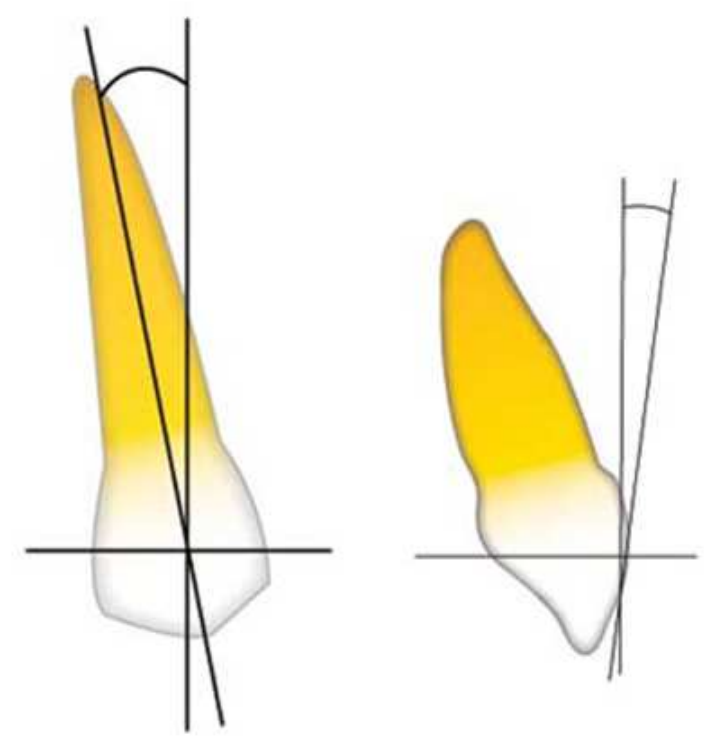

Figura 13 - Linha tangente á face vestibular do dente (JUNIOR, DA SILVA URSI,2006).

Andrews desenvolveu o sistema de braquetes pré-ajustados, no qual as características de normalidade de cada dente foram incorporadas aos braquetes ortodônticos, de natureza totalmente tridimensional e que já possuíam no seu desenho as características ideais de cada elemento dentário (1aㅡ $2^{\underline{a}}$ e $3^{\text {a }}$ ordens), para uma oclusão normal, proporcionando assim facilidade na mecânica e na confecção dos arcos. (ANDREWS, 1989). O autor ainda observou que alguns dentes eram afetados com os movimentos de translação, com angulações e rotações de suas coroas. Os dentes mais afetados eram caninos, pré-molares e molares. A fim de neutralizar esses efeitos Andrews incorporou ao desenho dos braquetes características inversas a esse movimento que os mesmos tenderiam a fazer durante a translação. Podemos dividi-los em a) Braquetes Standart; b) Braquetes de translação mínima; c) Braquetes de translação média; d) Braquetes de translação máxima; variando assim seus torques e angulações específicos para cada caso. Para tratamentos onde seriam necessários movimentos de translação Andrews criou prescrições distintas para casos de falta ou excesso de espaço. Além disso, o autor ainda criou braquetes distintos de incisivos superiores e inferiores nos casos de compensações dento-alveolares para más oclusões de Classe II e Classe III. 


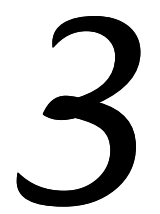

Proposiçãa 



\section{PROPOSIÇÃO}

O objetivo deste trabalho foi comparar o grau de reabsorção radicular externa em casos tratados com o aparelho autoligável Damon e com o aparelho pré-ajustado convencional. 



$$
\begin{array}{r}
4 \text { Materiale } \\
\text { Métodos } \\
\hline
\end{array}
$$





\section{MATERIAL E MÉTODOS}

\subsection{Material}

Para avaliar a reabsorção radicular decorrente do tratamento ortodôntico em pacientes tratados com o sistema Damon, foi compulsada a documentação clinica de 25 pacientes. Para comparação selecionou-se um grupo que utilizou a técnica dos aparelhos pré-ajustados. Sendo assim, podemos chamar de grupo 1 aquele composto por 25 pacientes tratados com o sistema Damon e de grupo 2 formado por 27 pacientes, os tratados com aparelhos pré-ajustados. O grupo 1 foi constituído de 9 pacientes tratados na Clinica de pós-graduação e Especialização em Ortodontia, da Faculdade de Odontologia de Bauru, da Universidade de São Paulo (FOB/USP) e de 16 pacientes tratados em clinica particular. O grupo 2 foi todo tratado na Clinica de pós-graduação e Especialização em Ortodontia, da Faculdade de Odontologia de Bauru, da Universidade de São Paulo (FOB/USP). Para tanto, foram selecionados 52 documentações disponíveis nos arquivos de Ortodontia da Faculdade e em clinica particular.

\subsubsection{Critérios de seleção da amostra}

Como requisito inicial, ressaltou-se a importância da completa documentação para determinar a idade, gênero, tipo de tratamento e existência das radiografias periapicais, da região dos incisivos superiores e inferiores, pré e pós-tratamento.

Com relação ao tipo de má oclusão a amostra constitui de pacientes Classe I de Angle, com apinhamento dentário de leve a moderado, estando na fase de dentadura permanente, com todos os dentes erupcionados. Foram excluídos os pacientes com más oclusões de Classe II e Classe III de Angle, agenesias ou perdas dentárias, dentes inclusos, dentes supranumerários, doença periodontal, com perda óssea vertical ou horizontal, lesão de furca e cálculo dentário, ou ainda que tenham sido submetidos a algum tratamento ortodôntico prévio. Não se realizou extrações dentárias em nenhum dos pacientes desta amostra. 
Foram eliminadas as radiografias que evidenciaram distorções ou falta de nitidez.

Não houve distinção de raça, sexo ou condições socioeconômicas e culturais. Não houve intervenção do uso de qualquer tipo de intervenção ortopédica.

Para avaliação da reabsorção, foram interpretadas as radiografias periapicais pré e pós-tratamento, dos incisivos superiores e inferiores. A escolha pela análise dos incisivos se deu pelo fato dos mesmos apresentarem maior prevalência de reabsorção. (FILHOA; DA SILVA FILHOB), 1996, (HEMLEY, 1941), (KALEY; PHILLIPS, 1991); (JANSON et al., 2000),(AHLGREN, 1993), (ALEXANDER, 1996).

\subsubsection{Características da Amostra}

Considerando-se os critérios acima descritos, a amostra foi composta por 52 documentações, dividida em dois grupos, apresentando as seguintes características em cada um deles:

Grupo 1: composta por 25 documentações de pacientes Classe I de Angle, com apinhamento moderado, sendo 13 pacientes do sexo masculino e 12 do sexo feminino; já tratados, com média de idade inicial de 16,04 anos e final de 18,06 anos. O tempo médio de tratamento foi de 2,02 anos. No qual foram utilizados braquetes ortodônticos individualizados, o Sistema Damon 3MX'M (figura 14), da prescrição padrão, cujo fabricante é a ORMCO - USA.

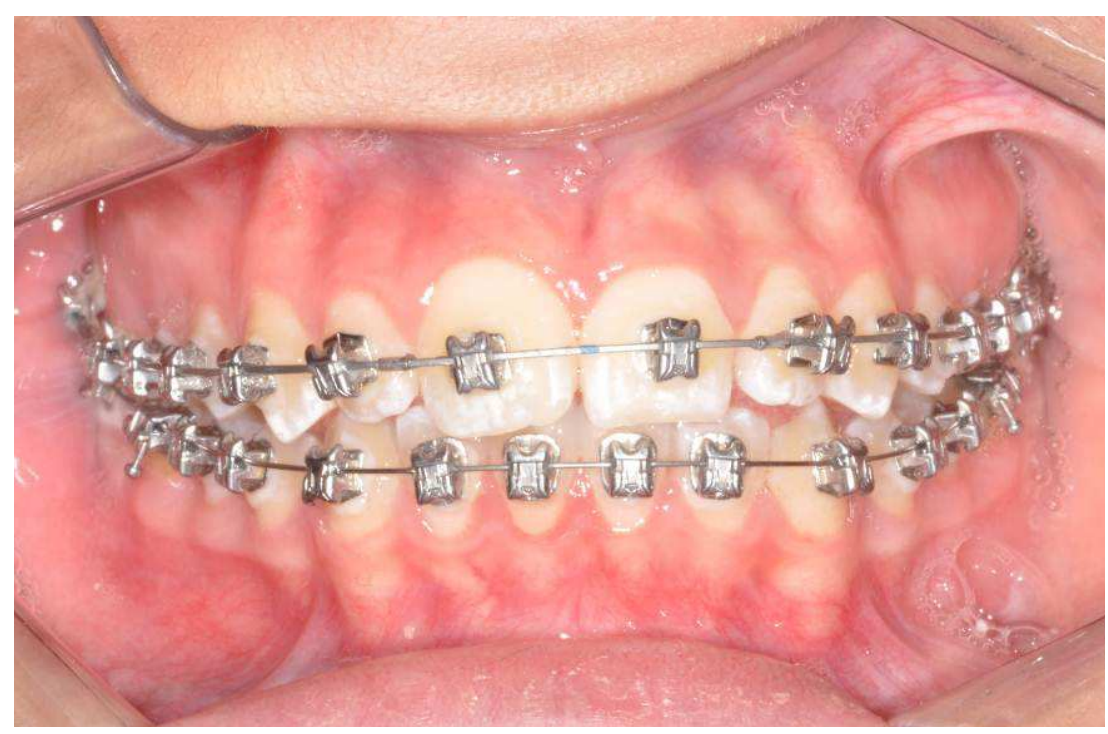

Figura 14 - Sistema Damon 3MX. 


\subsubsection{Modo de uso do aparelho Damon}

Foi considerado inicio do tratamento na data de instalação do aparelho. Foi realizado colagem direta dos bráquetes e tubos dos primeiros e segundos molares. Após a colagem de todos os dentes iniciou-se o alinhamento e nivelamento com fios de Nitinol termo ativados de secção redonda (.014" e .016") e retangular (.016"x.025", .018”x.025" e .019"x.025"). A evolução dos fios dependeu da necessidade de cada paciente. Após o final do alinhamento e nivelamento foi realizado o refinamento oclusal.

Grupo 2: composto por 27 documentações de pacientes Classe I de Angle, sendo 13 do gênero feminino e 14 do gênero masculino, com apinhamento moderado, com média de idade inicial de 16,77 anos e final de 18,47 anos. Os mesmos utilizaram aparelhos pré-ajustados (figura 15). O tempo médio de tratamento foi de 1,70 anos.

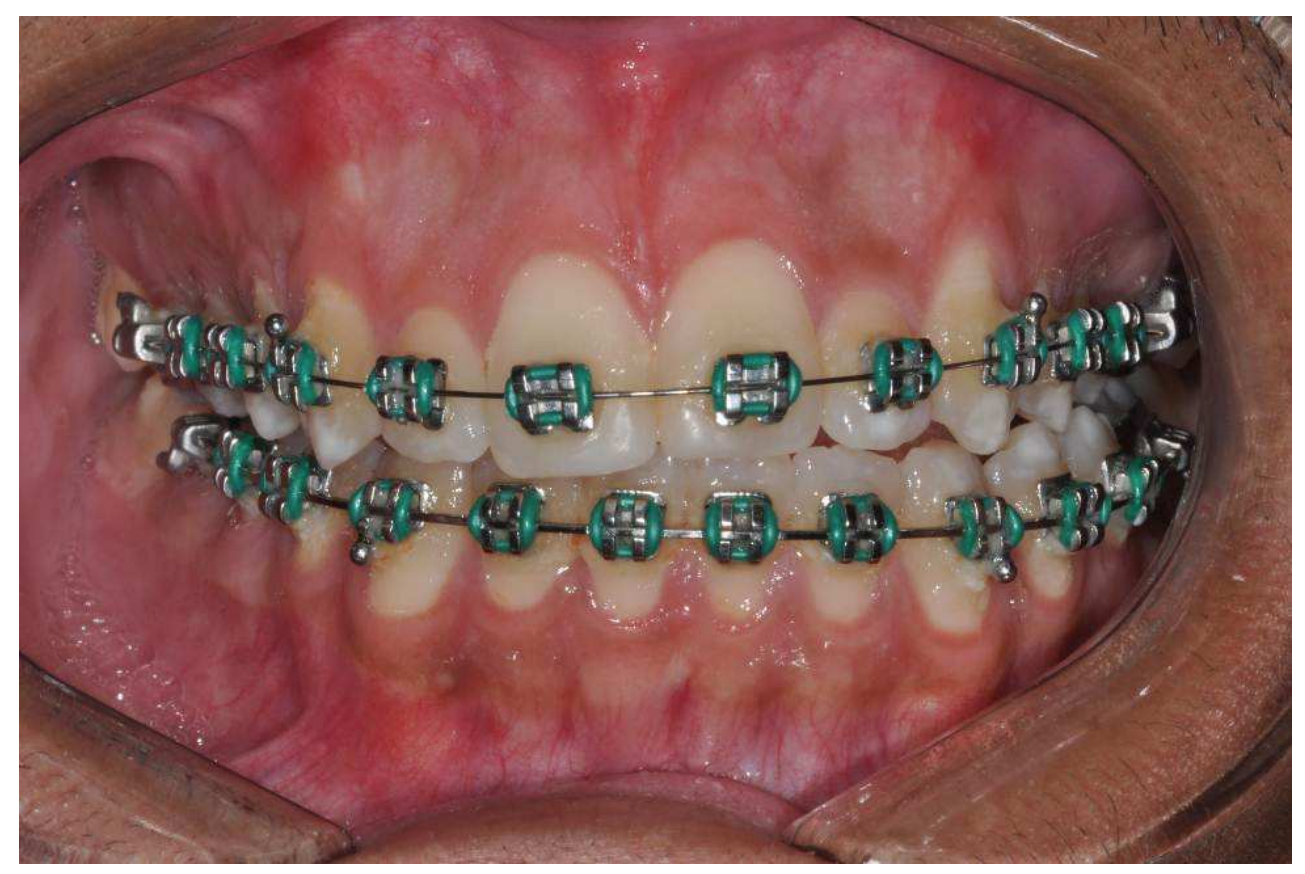

Figura 15 - aparelho pré-ajustado. 


\subsubsection{Modo de uso dos aparelhos pré-ajustados}

Iniciou-se o tratamento fazendo-se a bandagem dos primeiros molares e colagem direta de braquetes em todos os dentes. A sequência dos fios foi basicamente: alinhamento e nivelamento com 0.12"; 0.14"; 0.16" NiTi. Em seguida, fios de aço inoxidável 0.16"; 0.18" e 0.20". Após, passou-se para um arco de aço inoxidável de secção retangular com dimensões 019"x .025" e/ou 021"x025". A evolução ou sequência dos fios dependeu da necessidade de cada paciente. Após o final do alinhamento e nivelamento foi realizado o refinamento oclusal.

\subsection{Métodos}

\subsubsection{Radiografias}

As radiografias contidas nas documentações foram adquiridas por vários centros de documentação, sendo assim operadas por diferentes técnicos e aparelhos. Em relação ao processamento das radiografias, também podem ter ocorrido variações, portanto tornou-se inviável uma medição quantitativa do tamanho radicular. Assim, optou-se pela utilização do método de Levander e Malmgren (LEVANDER; MALMGREN, 1988) para estabelecer os níveis de reabsorção radicular, por meio de escores descritos a seguir (Figura 16):

- Grau 0- ausência de reabsorção radicular

- Grau 1- reabsorção leve, observando-se apenas contorno irregular, com raiz apresentando o seu comprimento normal

- Grau 2- reabsorção moderada, com pequena perda radicular e o ápice exibindo um contorno quase retilíneo

- Grau 3- reabsorção acentuada, com grande perda radicular, atingindo quase $1 / 3$ do seu comprimento

- Grau 4- reabsorção extrema, com perda maior que 1/3 do comprimento radicular 


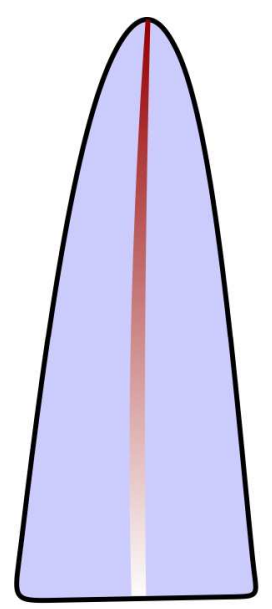

0

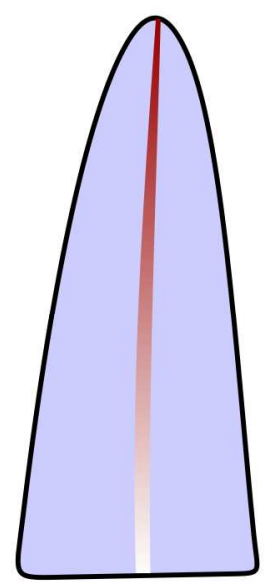

1

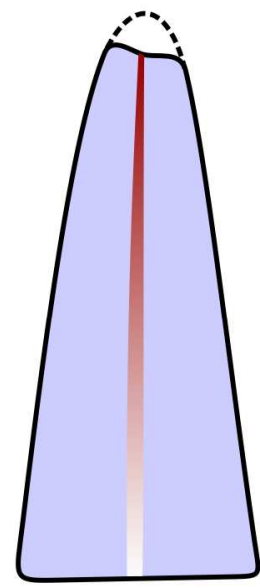

2

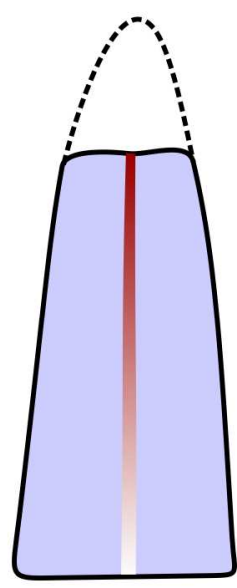

3

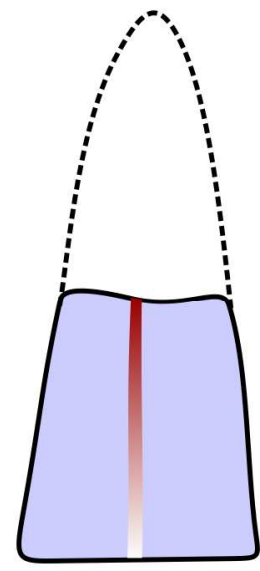

4

Figura 16 - Classificação dos graus de reabsorção segundo MALMGREN

Utilizando-se esse método proposto acima, foram obtidos para cada paciente oito escores referentes à avaliação do grau de reabsorção de cada um dos incisivos, totalizando 200 escores no grupo 1 e 216 escores no grupo 2.

As radiografias periapicais foram escaneadas em um escâner de slides $35 \mathrm{~mm}$ da Polaroid, o Sprint Scan 35 Plus3, com uma resolução de 675 dpi e escala de proporção de 1:1 (100\%). Posteriormente as imagens foram padronizadas e analisadas (Figura.17) e no programa Adobe Photoshop CS6, as imagens permitiram-se ser ampliadas em até 300\% sem perda de qualidade. As mesmas foram gravadas no modo "TIFF". Para facilitar a interpretação das imagens optou-se por manter a sala em ambiente escuro.

As radiografias periapicais pré-tratamento serviram de parâmetro para obtenção do grau de severidade da reabsorção radicular ocorrida. Comparando-se assim, com as radiografias pós-tratamento, em ambos os grupos. É importante salientar que as radiografias periapicais pré-tratamento não apresentaram nenhuma irregularidade apical; sendo este um critério de inclusão da amostra.

A classificação dos graus de reabsorção de cada dente foi anotada individualmente na ficha de cada paciente (Figura 18). Com o intuito de se evitar tendenciosidade, realizou-se a análise das radiografias sem saber a qual grupo as mesmas pertenciam. (estudo cego). 
Posteriormente, outras informações foram acrescentadas às fichas, como duração do tratamento, gênero e idade.

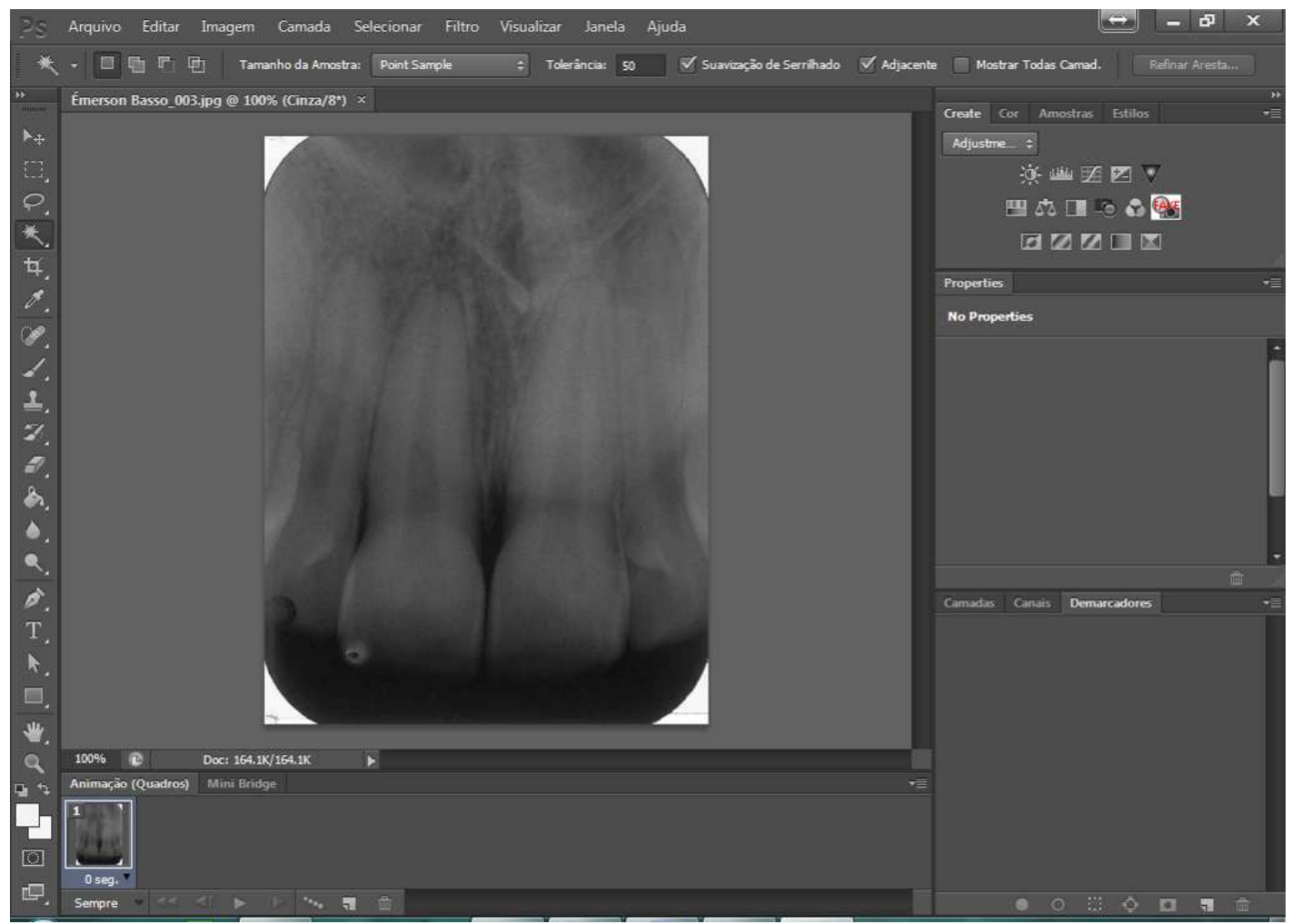

Figura 17 - Análise das imagens no programa Adobe Photoshop CS6

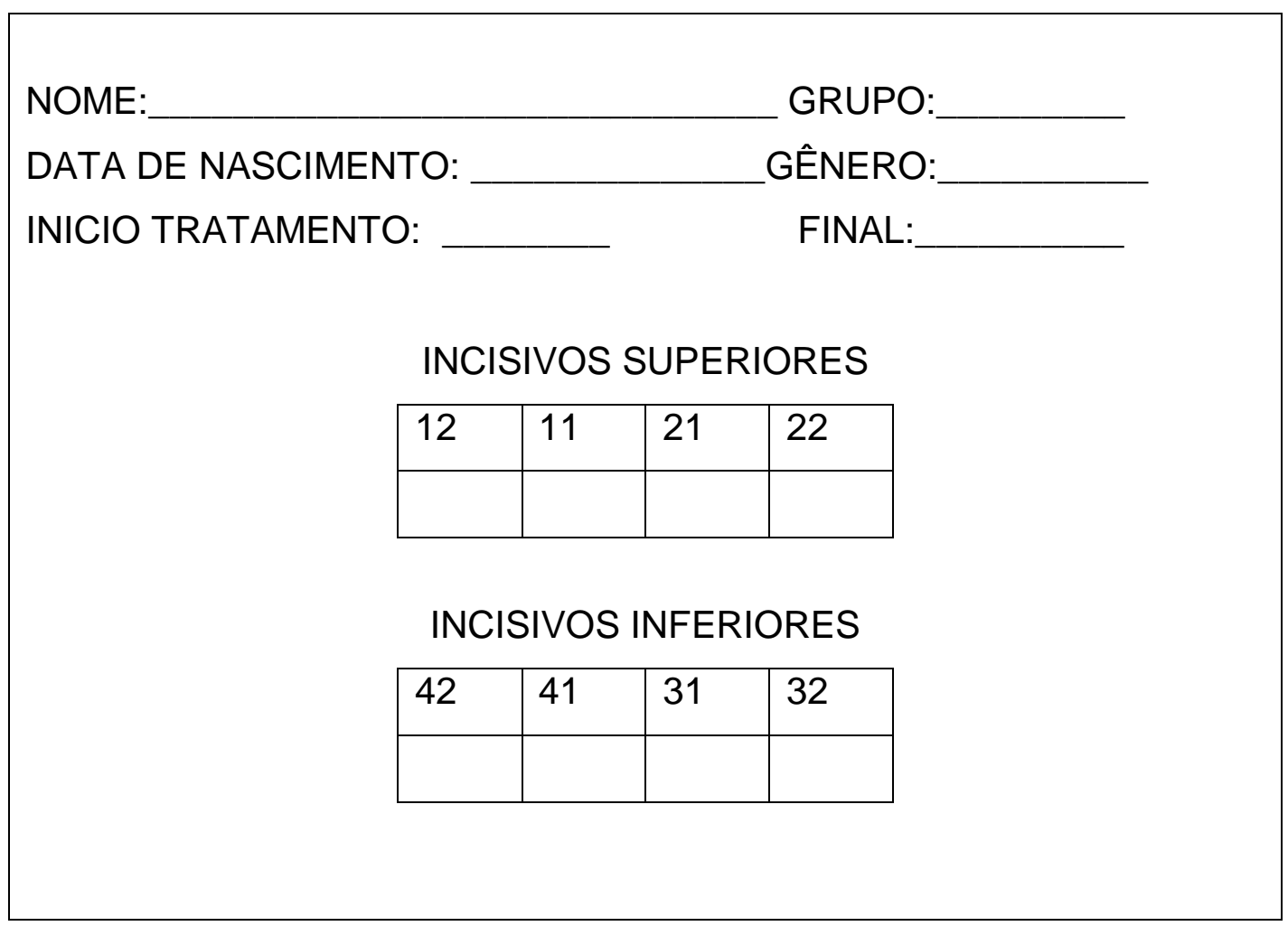

Figura 18 - Ficha para anotação dos graus de reabsorção radicular. 


\subsection{2 Índice de irregularidade de Little (modificado).}

Um dos critérios de inclusão da amostra foi que os pacientes de ambos os grupos apresentassem na análise de modelos um apinhamento superior e inferior moderado, ou seja, de no mínimo $3 \mathrm{~mm}$. Para isso, se fez necessário calcular o índice de irregularidade. O índice de Little (LITTLE, 1975) foi idealizado para avaliação do apinhamento dentário ântero-inferior. Devido a sua alta precisão e reprodutibilidade, a mesma metodologia foi empregada nesse estudo também para avaliar o apinhamento ântero-superior (GUIRRO et al., 2011). Podemos definir o índice de irregularidade como a somatória das distâncias lineares entre os pontos de contato anatômico dos dentes anteroinferiores (caninos e incisivos). Tal medida é representada pela distância para quais os pontos de contato devem ser movidos para um correto alinhamento. Ainda de acordo com Little (1975) mesmo os pontos de contato variando no sentido vertical, a correção dessas discrepâncias não afetará significantemente o comprimento do arco.

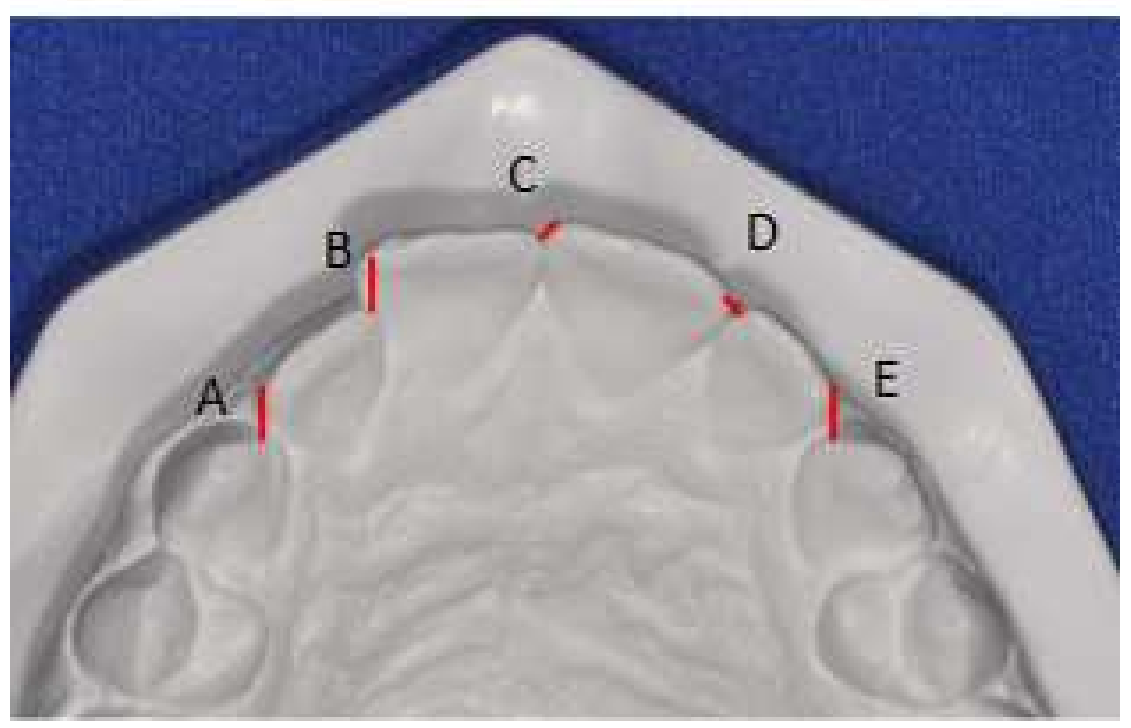

Figura 19 - Índice de Irregularidade de Little (modificado) arco superior/ A+B+C+D+E 


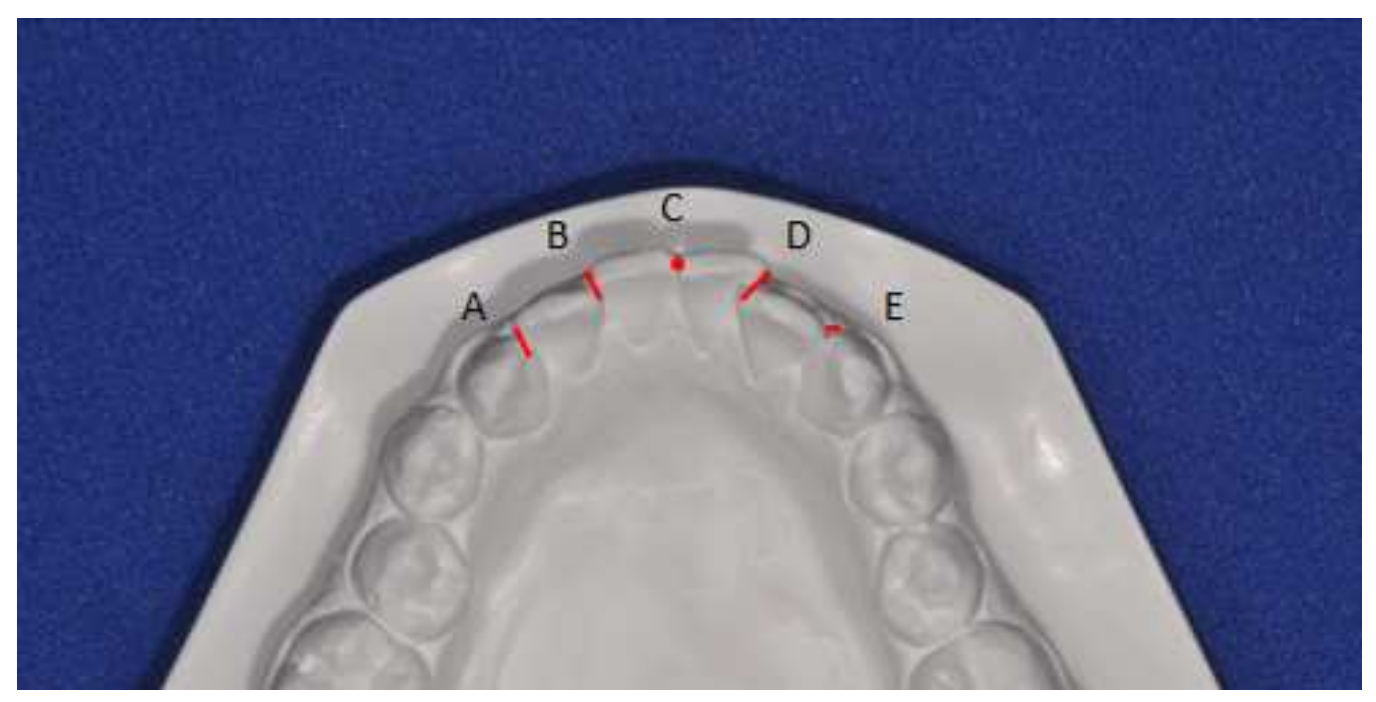

Figura 20 - Índice de Irregularidade de Little arco inferior $=A+B+C+D$

As medições dos modelos foram realizadas por meio de um paquímetro (figura 21) digital (Mitutoyo, Japão), com precisão de até $0,01 \mathrm{~mm}$. Para uma correta medição o paquímetro foi posicionado paralelo ao plano oclusal em todas as medições. (figura 22)

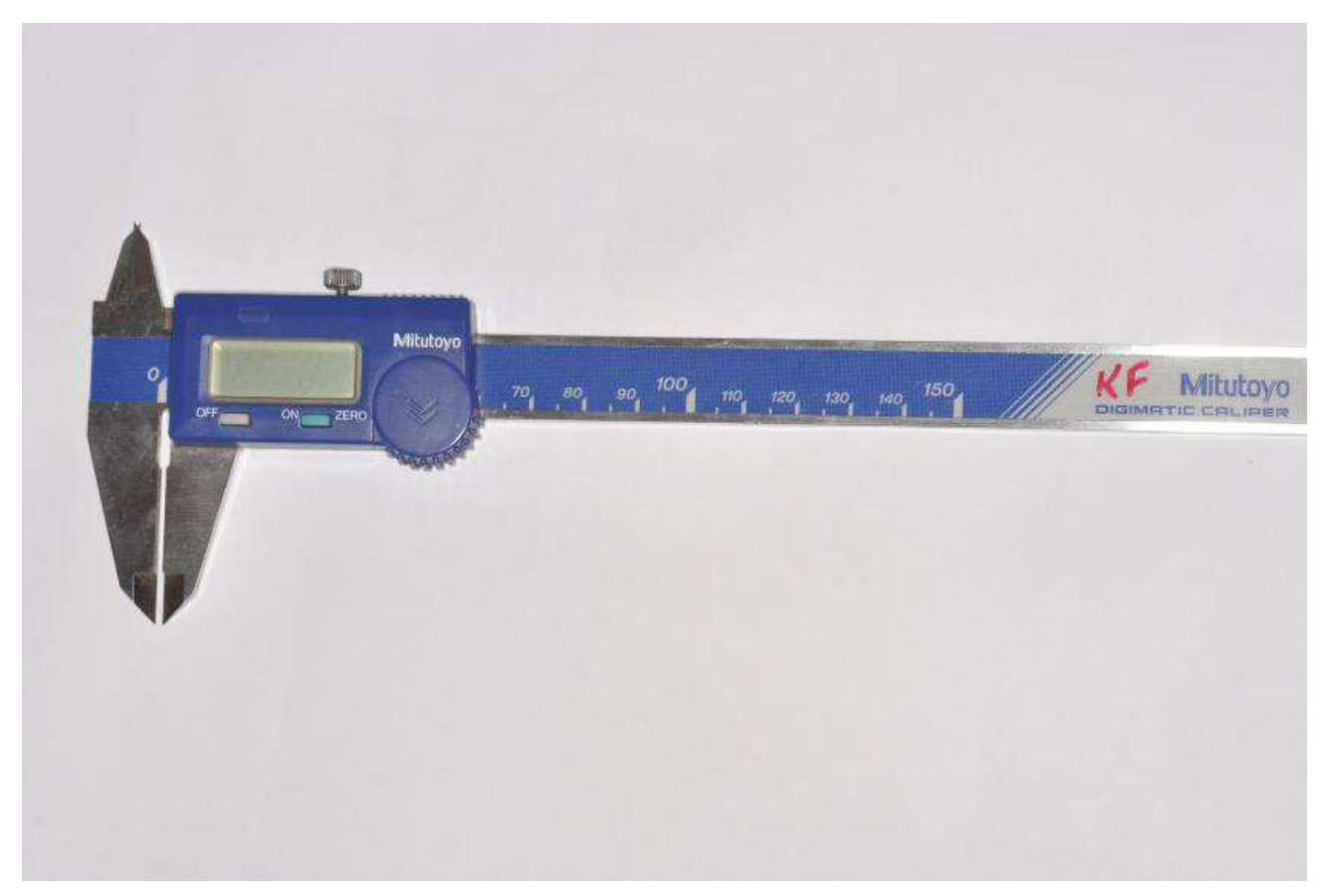

Figura 21 - Paquímetro digital 


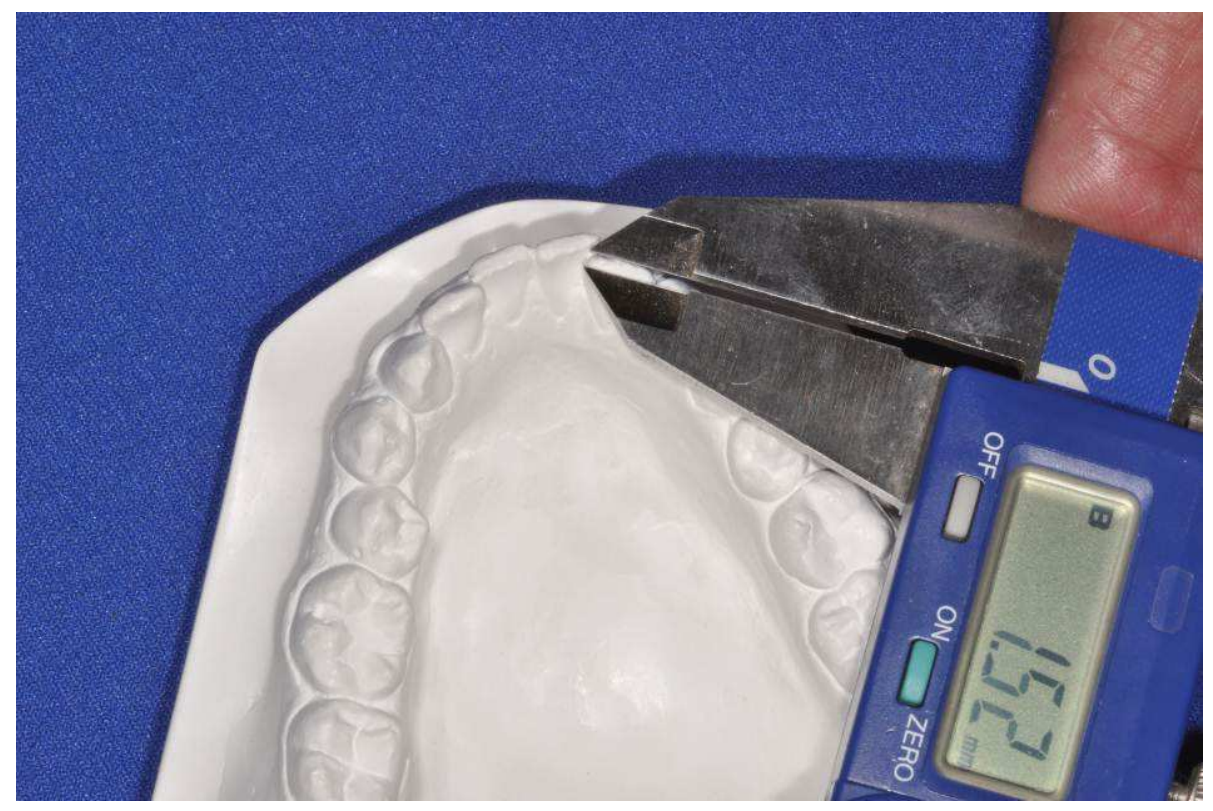

Figura 22 -: Paquímetro paralelo ao plano oclusal.

\subsection{Análise Estatística}

\subsubsection{Erro do método}

A fim de avaliar a confiabilidade intra-examinador das variáveis de ambos os grupos, foram selecionados 15 pacientes ao acaso; onde foram avaliados os modelos de gesso e as radiografias periapicais superiores e inferiores (totalizando 120 radiografias), após 30 dias, todo o processo foi repetido; obtendo-se assim as médias da primeira e segunda medição para verificar o erro sistemático. Portanto foi efetuado o teste $t$ pareado para amostras dependentes, pois a mesma unidade experimental foi mensurada em dois tempos distintos. Para o índice de irregularidade de Little foi aplicada a Fórmula de Dahlberg(DAHLBERG, 1940) para verificar o erro casual, onde será demonstrada na variação média entre a primeira e a segunda medição.

Após a avaliação do grau de reabsorção radicular através dos escores, foi aplicado o teste de coeficiente de Kappa. 


\subsubsection{Análise estatística entre grupos e variáveis}

- Para avaliar a compatibilidade dos grupos na distribuição dos gêneros será utilizado o teste não paramétrico qui-quadrado.

- Em relação à idade inicial e final, tempo de tratamento e índice de irregularidade de Little para avaliar a compatibilidade entre os grupos G1 e G2 será aplicado o teste $\mathrm{t}$ independente.

- Os escores obtidos em relação ao grau ou quantidade de reabsorção para o grupo 1 e grupo 2 foram comparadas por meio do teste não-paramétrico de Mann Whitney.

- Essas análises estatísticas foram realizadas pelo programa de computador Statistica for Windows (Statistica for Windows 7.0- Copyright Statsoft, Inc.2005).

- Os resultados foram considerados estatisticamente significantes para $p<0,05$. 


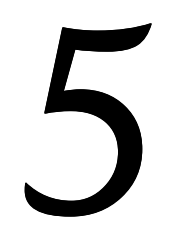

Resultados 



\section{RESULTADOS}

Após a análise apurada das radiografias e a posterior classificação dos graus de reabsorção radicular apical, os dados foram tabulados e submetidos à avaliação estatística. Os resultados estão apresentados sob a forma de tabelas. Os erros sistemático e casual, calculados a partir do teste t pareado e da fórmula de Dahlberg, estão apresentados na tabela 1. Os resultados mostraram pequeno e aceitável erro casual e sistemático.

Para testar o erro intra-examinador na análise das radiografias pelo escore de Levander e Malmgren utilizou-se o teste Kappa, está na tabela 2. Os resultados mostraram uma confiabilidade substancial.

A tabela 3 mostra os resultados do teste $t$ independente entre os grupos do aparelho convencional e do autoligável em relação às idades inicial e final e o tempo de tratamento. Os dois grupos mostraram-se compatíveis.

$O$ teste do teste $t$ independente entre os grupos 1 e 2 foi utilizado avaliar a compatibilidade entre os grupos nas variáveis do índice de irregularidade de Little, está na tabela 4. Os dois grupos mostraram-se compatíveis.

A comparação entre os dois grupos por gêneros (dimorfismo) foi realizada com o teste Qui-Quadrado e está na tabela 5. Os dois grupos mostraram-se compatíveis.

Na tabela 6 ilustra a comparação entre os graus de reabsorção radicular entre os dois grupos 1 e 2 ao início e ao final do tratamento e foi realizado o teste nãoparamétrico de Mann-Whitney. Podemos observar que a média entre os dois grupos foram bem similares; não mostrando resultados estatisticamente significantes. 
Tabela 1 - Avaliação do erro intra-examinador. Resultado do teste t dependente (erro sistemático) e do erro casual (Dahlberg). $n=15$.

\begin{tabular}{c|c|c|c|c|c|c}
\hline \multirow{2}{*}{ Variáveis } & \multicolumn{2}{|c|}{$1^{\text {a }}$ medição } & \multicolumn{2}{c|}{ 2a. medição } & \multicolumn{2}{c}{ Erro } \\
\cline { 2 - 7 } & Média & d.p. & Média & d.p. & Dalhberg & $\mathrm{P}$ \\
\hline $\begin{array}{c}\text { Little sup } \\
(\mathrm{mm})\end{array}$ & 5,00 & 1,45 & 4,98 & 1,38 & 0,08 & 0,533 \\
\hline $\begin{array}{c}\text { Little inf } \\
(\mathrm{mm})\end{array}$ & 5,47 & 2,09 & 5,43 & 1,91 & 0,36 & 0,781 \\
\hline
\end{tabular}

Tabela 2 - Resultado do teste Kappa do erro intra-examinador quanto a avaliação do escore de Levander e Malmgren. $n=120$

\begin{tabular}{c|c}
\hline Kappa geral & 0,749 \\
\hline P-valor geral & $<0,001$ \\
\hline $\begin{array}{c}\text { Kappa } \\
\text { Kntervalo de } 95 \% \text { de confiança do }\end{array}$ & Sup:0,869 \\
Inf:0,629 \\
\hline
\end{tabular}

Tabela 3 - Resultados do teste $t$ independente entre os grupos 1 e 2 para avaliar a compatibilidade entre os grupos nas idades inicial, final e tempo de tratamento.

\begin{tabular}{c|c|c|c|c|c}
\hline \multirow{2}{*}{$\begin{array}{c}\text { Variáveis } \\
\text { (anos) }\end{array}$} & \multicolumn{2}{|c|}{$\begin{array}{c}\text { Grupo 1-Damon } \\
\mathrm{N}=25\end{array}$} & \multicolumn{2}{c|}{$\begin{array}{c}\text { Grupo 2-Convencional } \\
\mathrm{N}=27\end{array}$} & $\mathrm{P}$ \\
\cline { 2 - 6 } & Média & d.p. & Média & d.p. & \\
\hline Idade Inicial & 16,04 & 5,20 & 16,77 & 5,32 & 0,623 \\
\hline Idade Final & 18,06 & 5,51 & 18,47 & 5,43 & 0,788 \\
\hline $\begin{array}{c}\text { Tempo de } \\
\text { Tratamento }\end{array}$ & 2,02 & 0,68 & 1,70 & 0,56 & 0,078 \\
\hline
\end{tabular}

Tabela 4 - Resultados do teste t independente entre os grupos 1 e 2 para avaliar a compatibilidade entre os grupos do índice de irregularidade de Little.

\begin{tabular}{c|c|c|c|c|c}
\hline \multirow{2}{*}{ Variáveis } & \multicolumn{2}{|c|}{$\begin{array}{c}\text { Grupo 1 - Damon } \\
\mathrm{N}=25\end{array}$} & \multicolumn{2}{c|}{ Grupo 2-Convencional } & \multirow{2}{*}{$\mathrm{P}$} \\
\cline { 2 - 5 } & Média & d.p. & Média & d.p. & \\
\hline $\begin{array}{c}\text { Little sup } \\
(\mathrm{mm})\end{array}$ & 6,60 & 3,68 & 5,13 & 1,66 & 0,065 \\
\hline $\begin{array}{c}\text { Little inf } \\
(\mathrm{mm})\end{array}$ & 6,36 & 2,93 & 5,40 & 1,60 & 0,144 \\
\hline
\end{tabular}


Tabela 5 - Resultados do teste do qui-quadrado para avaliar a compatibilidade entre os grupos 1 e 2 na distribuição por gêneros.

\begin{tabular}{|c|c|c|c}
\hline Gênero & Masculino & Feminino & Total \\
\hline 1 - Damon & 13 & 12 & 25 \\
\hline 2- Convencional & 15 & 12 & 27 \\
\hline Total & 28 & 24 & 52 \\
\hline $\mathbf{X}^{2}=\mathbf{0 , 0 6}$ & GL=1 & $\mathbf{P = 0 , 7 9 7}$ \\
\hline
\end{tabular}

Tabela 6 - Resultados do teste não-paramétrico de Mann-Whitney para a comparação entre os graus de reabsorção radicular entre os grupos 1 e 2 ao final (T2) do tratamento.

\begin{tabular}{c|c|c|c|c|c}
\hline \multirow{2}{*}{ Variáveis } & \multicolumn{2}{|c|}{ Grupo 1- Damon } & \multicolumn{2}{c|}{ Grupo 2-Convencional } & \multirow{2}{*}{$\mathrm{N}=27$} \\
\cline { 2 - 5 } & $\begin{array}{c}\text { Média } \\
\text { (Mediana) }\end{array}$ & $\begin{array}{c}\text { Desvio } \\
\text { interquartílico }\end{array}$ & $\begin{array}{c}\text { Média } \\
\text { (Mediana) }\end{array}$ & $\begin{array}{c}\text { Desvio } \\
\text { interquartílico }\end{array}$ & \\
\hline RRE 12 & $0,72(0,00)$ & 1,00 & $0,70(1,00)$ & 1,00 & 0,978 \\
\hline RRE 11 & $0,72(0,00)$ & 1,00 & $0,59(0,00)$ & 1,00 & 0,653 \\
\hline RRE 21 & $0,88(1,00)$ & 1,00 & $0,66(0,00)$ & 1,00 & 0,480 \\
\hline RRE 22 & $0,80(1,00)$ & 1,00 & $0,74(1,00)$ & 1,00 & 0,595 \\
\hline RRE 32 & $0,56(0,00)$ & 1,00 & $0,55(0,00)$ & 1,00 & 0,833 \\
\hline RRE 31 & $0,60(1,00)$ & 1,00 & $0,62(1,00)$ & 1,00 & 1,000 \\
\hline RRE 41 & $0,64(1,00)$ & 1,00 & $0,66(0,00)$ & 1,00 & 0,869 \\
\hline RRE 42 & $0,48(0,00)$ & 1,00 & $0,40(0,00)$ & 1,00 & 0,673 \\
\hline
\end{tabular}

No grupo 1, formado por pacientes tratados com o aparelho Damon, 200 dentes foram avaliados, dos quais 93 não apresentaram reabsorção radicular visível radiograficamente, 83 mostraram reabsorção leve, 20 reabsorção moderada, 4 reabsorção acentuada e nenhum reabsorção extrema (tabela 7)

No grupo 2, formado por pacientes tratados com aparelho convencional, 216 dentes foram avaliados, dos quais 114 não apresentaram reabsorção radicular visível radiograficamente, 74 mostraram reabsorção leve, 24 reabsorção moderada, 4 reabsorção acentuada e nenhum reabsorção extrema (tabela 8) 
Tabela 7 - Escores encontrados no grupo 1 e grupo $2(n=52)$

\begin{tabular}{|c|c|c|c|c|c|c|c|c|c|c|}
\hline \multirow{3}{*}{ Grupos } & \multicolumn{10}{|c|}{ Escores } \\
\hline & \multicolumn{2}{|c|}{0} & \multicolumn{2}{|r|}{1} & \multicolumn{2}{|r|}{2} & \multicolumn{2}{|r|}{3} & \multicolumn{2}{|c|}{4} \\
\hline & $\mathbf{N}$ & $\%$ & $\mathbf{N}$ & $\%$ & $\mathbf{N}$ & $\%$ & $\mathbf{N}$ & $\%$ & $\mathbf{N}$ & $\%$ \\
\hline Grupo 1 & 93 & $46,5 \%$ & 83 & $41,5 \%$ & 20 & $10 \%$ & 4 & $2 \%$ & 0 & $0 \%$ \\
\hline Grupo 2 & 114 & $52,7 \%$ & 74 & $34,2 \%$ & 24 & $11,1 \%$ & 4 & $1,85 \%$ & 0 & $0 \%$ \\
\hline
\end{tabular}

$\mathrm{N}=$ número de dentes.

\subsection{Quantidade de reabsorção radicular decorrente do tratamento ortodôntico.}

Nos 52 casos pertencentes à amostra, 416 dentes foram analisados. Do total dos dentes examinados, 207 (49,7\%) não apresentaram comprometimento radicular (grau 0), 157 (37,7\%) apresentaram reabsorção leve (grau 1), 44 (10,5\%) apresentaram reabsorção moderada, 8 (1,92\%) apresentaram reabsorção acentuada (grau 3) e nenhum paciente apresentou reabsorção extrema (grau 4). (tabela 8).

Avaliando a reabsorção encontrada, em relação ao número de pacientes, constatou-se que a maioria dos casos não apresentou comprometimento radicular, e uma porcentagem considerável apresentou uma quantidade de reabsorção, variando apenas entre leve e moderada. A reabsorção acentuada esteve presente em apenas um caso. E a reabsorção extrema não foi encontrada.

Tabela 8 - Porcentagem de pacientes que apresentaram: sem comprometimento radicular, reabsorção leve, moderada e extrema.

\begin{tabular}{c|c}
\hline Reabsorção & Porcentagem \% \\
\hline Sem comprometimento & $49,7 \%$ \\
\hline Leve & $37,7 \%$ \\
\hline Moderada & $10,5 \%$ \\
\hline Acentuada & $1,92 \%$ \\
\hline
\end{tabular}




\subsection{Prevalência de reabsorção nos incisivos}

Não houve entre os grupos, do ponto de vista estatístico uma maior reabsorção média dos dentes avaliados. Numericamente os valores observados foram:

No grupo 1: o dente que apresentou um maior número de escore 0 , ou seja sem comprometimento radicular, na maxila foram: dente 12 (incisivo lateral direitoILD) e dente 11 (incisivo central direito- ICD). $O$ dente que mais apresentou escore 1 foi o dente 22 (incisivo lateral esquerdo- ILE). O dente que mais apresentou escore 2 foi o dente 12 (incisivo lateral direito- ILD) . O dente que mais apresentou escore 3 foi os incisivo centrais. (tabela 9)

Na mandíbula: o dente que mais apresentou escore 0 foi o dente 42 (incisivo lateral direito- ILD). O dente que mais apresentou escore 1 foi 0 dente 41 (incisivo central direito- ICD). O dente que mais apresentou escore 2 foi o dente 32 (incisivo lateral esquerdo- ILE). Nenhum dente apresentou escore 3. (tabela 10).

No grupo 2: o dente que apresentou maior número de escore 0 na maxila foi: dente 11 (incisivo central direito- ICD) $O$ dente que mais apresentou escore 1 foi 0 dente 12 (incisivo lateral direito- ILD). O dente que mais apresentou escore 2 foram igualmente: o dente 11 (incisivo lateral direito- ILD), 21 (incisivo central direito ICD), 22 (incisivo lateral esquerdo- ILE). Todos os dentes em um caso apresentaram escore 3.(tabela 11)

Na mandíbula: o dente apresentou maior número de escore 0 foi o dente 42 (incisivo lateral direito- ILD). O dente que mais apresentou escore 1 foi o dente 31 (incisivo central esquerdo- ICE). O dente que mais apresentou escore 2 foi o dente 41 (incisivo central direito ICD). Nenhum dente apresentou escore 3. (tabela 12).

De modo geral, pôde-se observar que os dentes mais reabsorvidos foram os incisivos laterais superiores e os menos reabsorvidos foram os incisivos inferiores. 
Tabela 9 - Grupo 1: número de escores apresentados em cada dente da maxila

\begin{tabular}{c|c|c|c|c}
\hline \multicolumn{1}{|c|}{ Dentes } & ILD & ICD & ICE & ILE \\
\hline 0 & 13 & 13 & 11 & 8 \\
\hline 1 & 6 & 8 & 8 & 14 \\
\hline 2 & 6 & 2 & 4 & 3 \\
\hline 3 & 0 & 2 & 2 & 0 \\
\hline
\end{tabular}

Tabela 10 - Grupo 1: número de escores apresentados em cada dente da mandíbula.

\begin{tabular}{c|c|c|c|c}
\hline \multicolumn{1}{|c|}{ Dentes } & ILE & ICE & ICD & ILD \\
\hline 0 & 13 & 11 & 10 & 14 \\
\hline 1 & 10 & 13 & 14 & 10 \\
\hline 2 & 2 & 1 & 1 & 1 \\
\hline 3 & 0 & 0 & 0 & 0 \\
\hline
\end{tabular}

Tabela 11 - Grupo 2: número de escores apresentados em cada dente da maxila

\begin{tabular}{c|c|c|c|c}
\hline \multicolumn{1}{|c|}{ Dentes } & ILD & ICD & ICE & ILE \\
\hline 0 & 12 & 16 & 14 & 12 \\
\hline 1 & 12 & 7 & 9 & 11 \\
\hline 2 & 2 & 3 & 3 & 3 \\
\hline 3 & 1 & 1 & 1 & 1 \\
\hline
\end{tabular}

Tabela 12 - Grupo 2: número de escores apresentados em cada dente da mandíbula.

\begin{tabular}{c|c|c|c|c}
\hline \multicolumn{1}{|c|}{ Dentes } & ILE & ICE & ICD & ILD \\
\hline 0 & 16 & 13 & 14 & 17 \\
\hline 1 & 7 & 11 & 8 & 9 \\
\hline 2 & 4 & 3 & 5 & 1 \\
\hline 3 & 0 & 0 & 0 & 0 \\
\hline
\end{tabular}




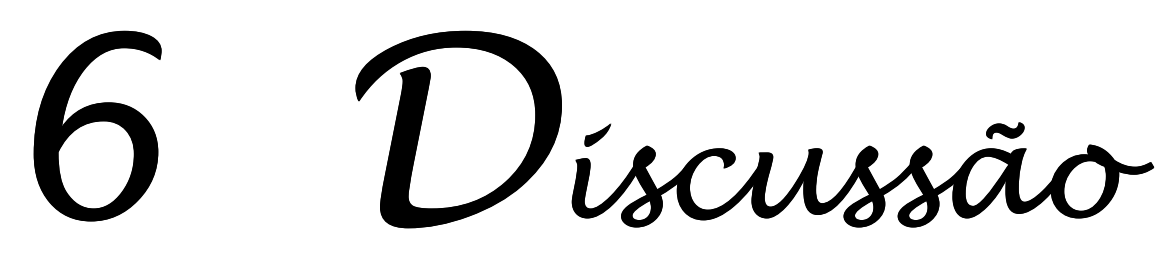





\section{DISCUSSÃO}

Para uma maior compreensão da discussão, este capitulo foi dividido em tópicos, abordando os principais temas decorrentes do presente estudo. Inicialmente iremos discutir as características e critérios das amostras. Posteriormente serão feitas considerações sobre a metodologia, e finalmente os resultados e suas implicações clinicas.

\subsection{Amostra}

A amostra tanto do grupo 1 como do grupo 2 foram constituídas de pacientes tratados por diferentes profissionais, assim muitas variáveis devem ser consideradas. Em relação ao número de pacientes, é difícil encontrar uma amostra considerável tratada e concluída por um único profissional. Alguns trabalhos descritos na literatura realizados com amostras de diferentes procedências não ressaltavam que esse fator pode interferir nos resultados. (BAUMRIND; KORN; BOYD, 1996, GOLDIN, 1989, JANSON et al., 2000, NEWMAN, 1975, VONDERAHE, 1973).

A amostra do grupo 1 tratado com o aparelho Damon foi composta de pacientes com má-oclusão de Classe I, com apinhamento dentário anterior de no mínimo 3mm superior e inferior; e os mesmos não realizaram extrações dentárias. A dificuldade em aumentar o número de pacientes desse grupo foi à ausência de radiografias periapicais ao final do tratamento, muitas vezes possuindo apenas radiografias panorâmicas. Visto também que é raro encontrar um número excessivo de pacientes finalizados com esse tipo de aparelho. Para comparar com um grupo controle, sendo este o grupo 2 (tratados com aparelho pré-ajustados) foi árdua a tarefa de encontrar pacientes que portassem essas mesmas características, e em muitos casos onde eram encontrados maiores apinhamentos foram solicitados extrações dentárias, fator esse que dificultou a seleção de um maior número de 
pacientes. Para o grupo 2 foram então selecionados 27 pacientes, seguindo esses mesmos critérios.

Em termos de casuística, torna-se difícil conseguir uma amostra de tamanho considerável. (KROGMAN, 1951) "Em pesquisa, pode-se visar à perfeição, porém a adequação constitui o padrão na maioria das vezes utilizado".

\subsection{Compatibilidade dos grupos}

Ao selecionar os dois grupos, um dos critérios de inclusão foram os pacientes apresentarem má-oclusão de Classe I. Isso se tornou importante para obtenção de um resultado mais fidedigno, evitando possíveis variáveis que pudessem interferir nos resultados deste estudo. Apesar dos cuidados ao selecionar apenas pacientes Classe I, alguns estudos(BAUMRIND; KORN; BOYD, 1996, BLAKE; WOODSIDE; PHAROAH, 1995b, HARRIS; KINERET; TOLLEY, 1997) ao comparar a natureza da má-oclusão com o risco de reabsorção radicular concluíram que a natureza da má oclusão não demonstrou determinar um maior ou menor risco de reabsorção radicular. Entretanto, as más oclusões graves necessitam de grande quantidade de movimentação e, consequentemente, o risco de reabsorção é maior.

\subsection{Critérios de exclusão}

Para compor uma amostra a fim de evitar suas variáveis, utilizamos rigorosamente alguns critérios de exclusão.

Optou-se por não utilizar os pacientes que apresentavam dentes tratados endodonticamente, isso se deu ao fato de que os graus de reabsorção diferem em dentes vitais e tratados endodonticamente(SPURRIER et al., 1990, WICKWIRE et al., 1974) Wickwire et al., em 1974(WICKWIRE et al., 1974), verificaram que os dentes tratados endodonticamente são mais suscetíveis à reabsorção, quando movimentados. Divergindo dos trabalhos de Spurrier et al., 1990(SPURRIER et al., 1990), e Mirabella \& Artun, 1995(MIRABELLA; ÅRTUN, 1995), que encontraram menos reabsorção nos dentes tratados endodonticamente, quando comparados aos 
dentes vitais, após movimentação dentária. Dentes com tratamento endodôntico poderiam, portanto, constituir variável com respostas imprevisíveis, dificultando a interpretação dos resultados.

Pacientes que apresentavam reabsorção radicular prévia foram excluídos. Estudos comprovaram que pacientes com reabsorção radicular prévia ao tratamento apresentam grande reabsorção radicular ao final(GOLDSON; HENRIKSON, 1975, OPPENHEIM, 2007). A incidência pode aumentar de $4 \%$ ao inicio do tratamento, para $77 \%$ ao seu término. (GOLDSON; HENRIKSON, 1975). Sendo assim, não foi necessário classificar o grau de reabsorção inicial, pois as radiografias iniciais serviram apenas para comparação e classificação das radiografias periapicais finais.

Pacientes que apresentavam bolsas periodontais, cáries, restaurações extensas, e/ou com histórico de trauma também foram eliminados, objetivando dessa forma minimizar as variáveis que pudessem interferir de alguma forma nos resultados.

As radiografias com distorções e falta de nitidez foram eliminadas, a fim de evitar um diagnóstico errôneo.

Os pacientes selecionados possuíam dentição permanente, com todos os dentes irrompidos. Segundo alguns autores (DESHIELDS, 1969, HORIUCHI; HOTOKEZAKA; KOBAYASHI, 1998, LINGE; LINGE, 1983) ocorre um crescimento residual dos incisivos até os 11 anos de idade, o que poderia encobrir a quantidade de reabsorção encontrada durante o tratamento.

\subsection{Metodologia}

O método para avaliar as reabsorções radiculares foram às radiografias periapicais, pois é o método mais utilizado pela maioria dos autores (BLAKE; WOODSIDE; PHAROAH, 1995b, DERMAUT; DE MUNCK, 1986, HARRIS; BUTLER, 1992, KETCHAM, 1927, LEVANDER; MALMGREN, 1988, LEVANDER; MALMGREN; ELIASSON, 1994, LINGE; LINGE, 1983, LINGE; LINGE, 1991, MARTINS; CANSANÇÄO; FERNANDEZ SANCHEZ, 1994, SPURRIER et al., 1990). 
As radiografias periapicais fornecem mais detalhes e nitidez que a radiografia panorâmica, além de ser um exame que expõe menos o paciente a radiação. As radiografias periapicais são muito superiores às panorâmicas, oclusais e cefalométricas laterais, para o estudo de estruturas radiculares (ALVARES; TAVANO).

A escolha por avaliar os incisivos se deu ao fato dos mesmos apresentarem comumente maior encurtamento, por serem os mais afetados. (AHLGREN, 1993, ALEXANDER, 1996, COPELAND; GREEN, 1986, HARRIS; BAKER, 1990) e por anatomicamente serem unirradiculares. É possível obter uma imagem radiográfica sem sobreposições, facilitando assim a sua visualização.

Em relação ao processamento das radiografias, as mesmas foram processadas por diversos centros de documentação, o que não possibilitou padronização de seu processamento. Por tornar inviável uma medição quantitativa do tamanho radicular; optou-se assim, por fazer uma analise qualitativa.

O método para avaliação utilizado nessa pesquisa proposto por LEVANDER; MALMGREN(LEVANDER; MALMGREN, 1988) classifica a reabsorção por escores. Esse método é muito utilizado por diversos autores, principalmente nos estudos da reabsorção radicular subsequente a movimentação ortodôntica. $O$ fato de não depender da padronização da radiografia inicial e por esta ser analisada por sua magnitude torna-se sua principal vantagem. Outro fator relevante é que os erros inter e intra-examinadores neste estudo mostraram excelente nível de concordância, reduzindo assim, a possibilidade de erro. Alguns autores não concordam com esse método(BLAKE; WOODSIDE; PHAROAH, 1995b) por utilizarem uma análise quantitativa, comparando as medidas das radiografias periapicais pré e pós tratamento(BAUMRIND; KORN; BOYD, 1996, COPELAND; GREEN, 1986, HARRIS; KINERET; TOLLEY, 1997, LINGE; LINGE, 1983, LINGE; LINGE, 1991).

Atualmente um dos melhores métodos para prever as reabsorções radiculares é através das radiografias periapicais, porém a sua aquisição e análise requer alguns cuidados importantes para permitir um diagnóstico adequado. $O$ fator menos favorável é o fato da radiografia periapical não ser tridimensional, pois não permite avaliar o ápice nos seus três planos do espaço. A tomografia computadorizada, por 
exemplo, nos permite avaliar nos cortes sagitais e transversais oblíquos. Alguns dentes podem ter a forma radicular triangular no sentido vestíbulo-lingual, não identificado nas radiografias periapicais. Assim sendo, a superposição de imagens radiográficas podem "ocultar" formas de ápices mais propensas à reabsorção como a forma e pipeta e dilacerada. A escolha do método através de radiografia periapical neste estudo foi por não existir uma amostra do aparelho convencional com tomografia computadorizada pré e pós-tratamento. A dose de radiação foi levada em consideração, visto que os pacientes dessa pesquisa eram pacientes jovens.

Todas as radiografias deste trabalho foram escaneadas e tratadas em programa especifico. As imagens digitalizadas podem ser de grande auxilio no diagnostico preciso em estágios mais iniciais, pois podem ser aumentadas em tamanho e em qualidade, e permitem visualização de fenômenos menores (CONSOLARO, 2005)

Felizmente apesar de frequente a reabsorção radicular decorrente do tratamento ortodôntico é rara a presença de sinais clínicos significantes. Sendo assim, os dentes comumente mostram-se sem mobilidade, sem escurecimento e com vitalidade pulpar (KETCHAM, 1927, STEADMAN, 1942).

Relacionando a reabsorção radicular com a perda da crista óssea, em 1986 KALKWARF; KREJCI; PAO(KALKWARF; KREJCI; PAO, 1986) observaram que nos estágios iniciais da reabsorção $3 \mathrm{~mm}$ de reabsorção equivalem a $1 \mathrm{~mm}$ de perda da crista óssea. E quando a perda de comprimento ultrapassa $2 \mathrm{~mm}$ de reabsorção passa a equivaler $1 \mathrm{~mm}$ de crista óssea. Isso mostra a pouca significância clinica da reabsorção radicular em seus estágios mais precoces. Favoravelmente muitos autores comprovaram que, na maioria das vezes a reabsorção é suave e cessa no momento em que a força ortodôntica é removida. (BAUMRIND; KORN; BOYD, 1996, BECK; HARRIS, 1994).

O método de Malmgren através de escores é também utilizado com o uso de tomografia computadorizada cone beam, como mostra o trabalho de MAKEDONAS, 2011(MAKEDONAS et al., 2011) em que foram avaliados 97 pacientes com uma máoclusão de Classe I, tratados com aparelho fixo e extração de pré-molares. O exame de tomografia computadorizada foi realizado antes e após 6 meses de tratamento. 
Foi encontrado contorno irregular na maioria dos dentes antes do tratamento, e as reabsorções foram registradas apenas com escore 2 (menos de $2 \mathrm{~mm}$ de reabsorção). Reabsorção severa foi encontrada em apenas 4 pacientes. A frequência mostrou-se principalmente nos incisivos da maxila, corroborando com a frequência desta pesquisa. Os autores ainda tentaram relacionar alguns fatores de risco que pudessem influenciar no grau de reabsorção, tais como: raízes com anomalias, pacientes com onicofagia e dentes traumatizados. Os resultados mostrarm que não houve correlação desses fatores de risco com o grau de reabsorção após 6 meses de tratamento ativo. Para evitar possíveis variáveis nesta pesquisa optamos por eliminar os pacientes que pudessem apresentar esses fatores de risco ou mesmo apresentar irregularidade apical pré-tratamento.

O mesmo autor realizou um estudo (MAKEDONAS et al., 2012) recente examinando 156 pacientes tratados com aparelho ortodôntico fixo e extração de quatro pré-molares. Foi realizada tomografia computadorizada antes do tratamento, após 6 meses e ao final do tratamento. $O$ índice de Malmgren foi novamente utilizado para descrever o grau de reabsorção. Os resultados mostraram: reabsorção radicular severa (maior que $2 \mathrm{~mm}$ ) encontrada em $25,6 \%$ dos pacientes ao final do tratamento. Reabsorção extrema foi encontrada em apenas um paciente. Os incisivos superiores foram os dentes mais afetados com a reabsorção. $O$ estudo ainda mostrou não haver correlação nas reabsorções observadas após 6 meses ou ao término do tratamento.

Como o presente trabalho LEITE V, CONTI et al, 2012(LEITE et al., 2012) comparou pacientes que realizaram tratamento com aparelho autoligável com aparelhos convencionais quanto à reabsorção radicular. Foram selecionados 19 pacientes com má oclusão de Classe l;(sendo 11 com o aparelho autoligável e 8 com o convencional(, dentição permanente completa e com apinhamento anterior de 3 a $5 \mathrm{~mm}$. Incisivos superiores e inferiores foram avaliados através de tomografia computadorizada cone beam e programas específicos foram utilizados para esta análise. As tomografias foram obtidas pré-tratamento e após 6 meses de tratamento ativo. Houve reabsorção em ambos os grupos, entretanto não houve diferença do grau de reabsorção em relação ao tipo de aparelho utilizado. Os autores utilizaram uma resolução de 0,4 voxel, uma resolução pouco nítida para avaliar detalhes das 
estruturas anatômicas. E o fato de mediram da borda incisal até o ápice radicular torna o trabalho menos confiável, visto que a borda incisal pode sofrer desgastes ou trauma ao longo do tratamento.

Com o intuito de comparar também o aparelho pré-ajustado e o aparelho convencional em relação a sua reabsorção, PANDIS, 2008 (PANDIS et al., 2008) analisou 96 pacientes, sendo 48 que utilizaram o aparelho Damon e 48 o aparelho convencional. O que difere do presente trabalho é a utilização de radiografia panorâmica para avaliar a reabsorção radicular. Os autores utilizaram a radiografia panorâmica antes e após o tratamento ortodôntico. Os incisivos superiores e inferiores foram medidos em seu comprimento e comparados no pré e póstratamento. Apesar de levar em consideração o grau de magnificação da radiografia panorâmica, a radiografia periapical como descrita anteriormente é superior em relação à qualidade de imagem e sobreposição das estruturas, tornando assim esse método mais passível de erros. Independente da técnica diagnostica os resultados não mostraram diferença estatisticamente significante quanto ao grau de reabsorção entre os dois grupos.

Apesar de não ser o objetivo de esse trabalho descrever as vantagens e benefícios de cada tipo de aparelho ortodôntico uma pesquisa publicada recentemente(KAWASHIMA-ICHINOMIYA et al., 2012) mostrou um relevante beneficio do aparelho pré-ajustado em relação ao aparelho convencional. Com o objetivo de investigar a quantidade de reabsorção radicular externa e liberação de interleucina-6 no fluido gengival em indivíduos tratados com o aparelho pré-ajustado sessenta pacientes foram divididos em dois grupos, sendo 30 pacientes tratados com aparelho convencional e 30 com o pré-ajustado. As reabsorções dos incisivos centrais superiores foram avaliadas através de radiografias periapicais tomadas antes e depois do tratamento ortodôntico. Houve diferença estatística quanto ao grau de reabsorção, apresentando menor grau nos pacientes que usaram os aparelhos pré-ajustados. O fluido gengival foi obtido através de método não invasivo usando tiras de papel de filtro, também obtidas pré e pós-tratamento. Após analises laboratoriais foram analisadas os níveis de interleucinas. Os níveis foram significantemente menores nos pacientes tratados com os aparelhos pré-ajustados 
em relação aos aparelhos convencionais. Portanto, os aparelhos pré-ajustados podem ser um sistema útil para a redução da inflamação e da reabsorção.

\subsection{0 erro intra-examinador}

Um teste de diagnóstico é preciso quando suas medições são consistentes. $A$ sua precisão é avaliada quando comparamos os resultados de repetidos pareceres sobre o mesmo objeto. Com o objetivo de tornar os resultados confiáveis, procurouse minimizar os erros dos métodos das mensurações. Portanto, as condições de exame foram padronizadas, assim como, ambiente, equipamento, período do dia, foram mantidas em todas as etapas das medições. (WENZEL; VERDONSCHOT, 1994).

A amostra foi reexaminada em 15 pacientes (30\% do seu total), escolhidos ao acaso. Assim, foram avaliados os oito incisivos, sendo quatro da maxila e quatro da mandíbula, totalizando uma análise de 120 dentes. Foi utilizado o coeficiente Kappa (K) ou Cohen's kappa para a obtenção dos valores de concordância(LANDIS; KOCH, 1977). Este coeficiente verifica a quantidade de concordância entre os dados categóricos em duas avaliações distintas subtraindo deste valor o número de concordâncias que possam ter ocorrido por mero acaso.

No presente trabalho a tabela 2 mostrou alta concordância da primeira medição para a segunda medição.

Em 1998 LEVANDER; MALMGREN; STENBACK(LEVANDER; MALMGREN; STENBACK, 1998) realizaram um estudo com o intuito de aumentar a precisão e a confiabilidade da metodologia de sua pesquisa. Para isso, eles realizaram novamente a avaliação de todas as radiografias da amostra. Os autores observaram similaridade das avaliações em 156 das 186 radiografias analisadas, o que corresponde a $83,87 \%$ de concordância. No presentes estudo das 120 radiografias avaliadas 103 mostraram similaridade, o que mostra bastante confiabilidade no presente estudo. 
Portanto, os resultados do presente estudo foram verificados como substancial a fidedignidade das medições. Os resultados foram consistentes, quando repetidos os testes.

\subsection{Resultados}

Os resultados demonstraram que não houve uma diferença estatisticamente significante entre os graus de reabsorção radicular entre os grupos 1 e 2 .

Apesar de não existir diferença estatisticamente significante entre os dois grupos experimentais quanto à quantidade de reabsorção, algumas considerações podem ser feitas.

A relação entre reabsorção radicular e tempo de tratamento tem se mostrado polêmico, visto que alguns estudos(BECK; HARRIS, 1994, LINGE; LINGE, 1983, MIRABELLA; ÅRTUN, 1995) não encontraram diferença significante quando relacionaram a reabsorção radicular ao tempo de tratamento. Diferentemente de outros trabalhos(BRIN et al., 2003, SAMESHIMA; SINCLAIR, 2001, TAITHONGCHAI; SOOKKORN; KILLIANY, 1996), em que os resultados mostraram que quanto maior o tempo de tratamento maior a probabilidade de reabsorção radicular.

Ao comparar os dois grupos levando-se em consideração a idade e tempo de tratamento (Tabela 3), foram identificado valores bastante próximos, denotando alta compatibilidade, eliminando dessa forma possíveis influências da idade na quantidade de reabsorção encontrada, apesar de o fator idade, entre 11,5 e 25 anos, segundo LINGE \& LINGE(LINGE; LINGE, 1991), não parecer refletirem um processo de envelhecimento significante para as estruturas radiculares.

Com o objetivo de avaliar a influência do tratamento sobre as estruturas radiculares, buscamos um segundo grupo o mais compatível possível no momento da seleção. Observou-se além das características da má-oclusão, a idade e o gênero. Com relação à idade, é possível notar alto grau de compatibilidade entre os dois grupos. 
O grupo 2 apresenta-se bem equilibrado com relação aos gêneros. Caso fosse acusada alguma divergência, esta não seria uma limitação para a presente investigação. Alguns trabalhos não encontraram correlação entre a quantidade de reabsorção radicular e a diferença na proporção entre os gêneros(KALEY; PHILLIPS, 1991, LINGE; LINGE, 1991, MCFADDEN et al., 1989, PARKER; HARRIS, 1998). Dois estudos, entretanto, concluíram que os pacientes do gênero feminino demonstraram maior grau de reabsorção(KJÆER, 1995, NEWMAN, 1975); divergindo com outro estudo em que pacientes do gênero masculino mostraram maior incidência e severidade (SPURRIER et al., 1990). Como os estudos de maior amostragem não evidenciaram diferenças pode-se assumir que não há diferenças significantes entre os gêneros(SAMESHIMA; SINCLAIR, 2001).

\subsection{Quantidade de reabsorção}

No presente estudo esperou-se encontrar um baixo grau de reabsorção radicular, pois além da amostra ser constituída de pacientes com apinhamento moderado, todos foram tratados sem extração. Os números mostraram que dos 52 casos $49,7 \%$ não apresentaram comprometimento radicular, ou seja, a maioria apresentou grau 0. Ficou claro também que a reabsorção radicular acentuada ou extrema é rara. No presente estudo o grau 3 esteve presente em apenas 1,92\% dos casos, enquanto que a extrema não esteve presente. Os resultados são parecidos também com os resultados de REMINGTON(REMINGTON et al., 1989), CANSANÇÃO(MARTINS; CANSANÇÄO; FERNANDEZ SANCHEZ, 1994), KALEY; PHILLIPS(KALEY; PHILLIPS, 1991) em que apresentaram poucas diferenças dos resultados de LEVANDER; MALMGREN(LEVANDER; MALMGREN, 1988), que encontraram reabsorção acentuada em $17 \%$ dos dentes.

Os resultados deste trabalho se difere de alguns autores como SILVA FILHO et al.(SILVA FILHO et al., 1993) que encontraram reabsorção em 100\% dos pacientes analisados, entretanto os autores relataram ser reabsorção leve e o tempo médio de tratamento foi de 2 anos e 3 meses, sendo superior a deste trabalho. $E$ com os de DESHILDS(DESHIELDS, 1969) que encontrou reabsorção em 99,08\% dos pacientes, levando em consideração que os autores avaliaram apenas os 
incisivos superiores, e foi utilizada a telerradiografia para avaliação dos incisivos, o que dificulta uma correta visualização dos ápices, devido a sobreposição das estruturas anatômicas.

No presente estudo apesar de não haver diferença estatística quanto ao grau de reabsorção, os valores numéricos mostraram na tabela 7 :

- O grupo 2 (aparelho convencional) obteve o maior número de escore 0 em relação ao grupo 2, ou seja sem comprometimento radicular.

- O grupo 1 apresentou um maior número de escore 1 (reabsorção leve) (83) em relação ao grupo 2 (74).

- Já em relação à reabsorção moderada (grau 2) o grupo 2 apresentou um maior número de escore (24) em relação ao grupo 1 (20).

- A reabsorção acentuada esteve presente nos dois grupos similarmente.

Esses resultados conferem que não há uma predileção de escores em ambos os grupos. Apesar de o grupo 2 ter apresentado um menor comprometimento radicular, nota-se na tabela 8 , que apesar de não significativo o apinhamento do grupo Damon mostrou-se maior.

\subsection{Prevalência de Reabsorção}

Os resultados encontrados no presente estudo foram semelhantes aos descritos na literatura (AHLGREN, 1993, ALEXANDER, 1996, BECK; HARRIS, 1994, KALEY; PHILLIPS, 1991), ou seja, encontramos maior reabsorção nos incisivos centrais superiores, seguidos dos laterais. E os incisivos inferiores também foram os menos reabsorvidos.

O presente trabalho apresentou maior frequência de reabsorção no arco superior, mostrando similaridade com outros estudos (BLAKE; WOODSIDE; PHAROAH, 1995b, JANSON et al., 2000, QUINTELLA, 2001). Essa frequência não 
foi encontrada no trabalho de MASSLER \& MALONE(MASSLER; MALONE, 1954), em que não houve diferença de reabsorção entre os arcos dentários.

Ao comparar três técnicas ortodônticas fixas JANSON e colaboradores (JANSON et al., 2000), utilizaram como no presente estudo o método de Malmgren para avaliar o grau de reabsorção radicular. Os autores verificaram que do total de dentes examinados, somente 2,25\% não apresentaram comprometimento radicular visível radiograficamente, ou seja, de grau 0 . O que se diferenciou bastante da investigação deste trabalho, em que dos 416 dentes analisados 207 não apresentaram comprometimento radicular. Porém este trabalho em que se investigou as três técnicas ortodônticas continha pacientes tratados com extrações, onde se fez necessário retração dos dentes anteriores e consequentemente um maior tempo de tratamento. O que é um fator relevante comparado a um tratamento sem extração e com pequenas movimentações.

\subsection{Implicações clinicas}

Os resultados desta pesquisa ao demonstrar que não há diferença estatisticamente significante nas reabsorções radiculares em ambos os grupos, seja dos pacientes tratados com o aparelho Damon ou dos tratados com os aparelhos convencionais; não podem servir de parâmetros para a escolha entre eles. Visto que os riscos iatrogênicos das estruturas radiculares ocorrem nos dois grupos. $O$ constante desenvolvimento e evolução dos materiais ortodônticos vêm proporcionando maior conforto para o profissional, caracterizado pela diminuição do tempo de cadeira e das consultas necessárias para troca dos fios. Os pacientes também têm sido favorecidos, já que esses novos materiais melhoram rapidamente a estética, em consequência da realização precoce do nivelamento e alinhamento, proporcionado pelo menor atrito entre o fio e o braquete. Essas características certamente prometem um grande futuro para a especialidade. Cabe ao clinico selecionar qual o tipo de aparelho é mais adequado, levando em consideração suas vantagens, desvantagens, tempo de tratamento e domínio da técnica. 



\section{CONCLUSÕES}

Após avaliação dos resultados obtidos neste trabalho e de acordo com a metodologia empregada para avaliação do grau de reabsorção radicular decorrente do uso dos aparelhos Damon e pré-ajustado, pode-se concluir que:

- Não há diferença no grau de reabsorção radicular quando comparados casos tratados com o aparelho autoligável Damon e pré-ajustado convencional. 

Referencias 



\section{REFERÊNCIAS}

Ahlgren J. A Ten-Year Evaluation of the Quality of Orthodontic Treatment. Swedish dental journal. 1993 17(5):201.

Alexander SA. Levels of Root Resorption Associated with Continuous Arch and Sectional Arch Mechanics. American Journal of Orthodontics and Dentofacial Orthopedics. 1996 110(3):321-4.

Alpern MC, editor Gaining Control with Self-Ligation2008: Elsevier.

ALVARES L, TAVANO O. Técnicas Radiográficas. Curso de radiologia em odontologia. 4(55-127.

Andreasen J. External Root Resorption: Its Implication in Dental Traumatology, Paedodontics,

Periodontics, Orthodontics and Endodontics. International endodontic journal. 1985 18(2):109-18.

Andrews L. Straight Wire: O Conceito Eo Aparelho. San Diego: LA Wells. 19894.

Andrews LF. The Six Keys to Normal Occlusion. Am J Orthod. 1972 62(3):296-309.

ARAÚJO CCM, MALTAGLIATI LÁ. Avaliação Das Inclinações Dentárias Obtidas No Tratamento Ortodôntico Com Braquetes Autoligados Utilizando Tomografia Computadorizada. COMPROMISSO FIRMADO. 2008412.

BATES SB, M. et al. Absorption. J Dent Sci. 1856 1(256.

Baumrind S, Korn EL, Boyd RL. Apical Root Resorption in Orthodontically Treated Adults. American Journal of Orthodontics and Dentofacial Orthopedics. 1996 110(3):311-20.

Beck BW, Harris EF. Apical Root Resorption in Orthodontically Treated Subjects: Analysis of Edgewise and Light Wire Mechanics. American Journal of Orthodontics and Dentofacial Orthopedics. 1994 105(4):350-61. 
Becks H MJ. Resorption or Absorption? J Am Dent 1932 1528-37.

Berger J. Self-Ligation in the Year 2000. Journal of Clinical Orthodontics. 2000 34(2):74-81.

Berger J, Byloff FK. The Clinical Efficiency of Self-Ligated Brackets. Journal of Clinical Orthodontics. 2001 35(5):304-10.

Berger JL. The Influence of the Speed Bracket's Self-Ligating Design on Force Levels in Tooth Movement: A Comparative in Vitro Study. American Journal of Orthodontics and Dentofacial Orthopedics. 1990 97(3):219-28.

Blake M, Woodside D, Pharoah M. A Radiographic Comparison of Apical Root Resorption after Orthodontic Treatment with the Edgewise and Speed Appliances. American Journal of Orthodontics and Dentofacial Orthopedics. 1995a 108(1):76-84.

Blake M, Woodside D, Pharoah M. A Radiographic Comparison of Apical Root Resorption after Orthodontic Treatment with the Edgewise and Speed Appliances. American journal of orthodontics and dentofacial orthopedics: official publication of the American Association of Orthodontists, its constituent societies, and the American Board of Orthodontics. 1995b 108(1):76.

Brezniak N, Wasserstein A. Orthodontically Induced Inflammatory Root Resorption. Part I: The Basic Science Aspects. The Angle Orthodontist. 2002 72(2):175-9.

Brin I, Tulloch J, Koroluk L, Philips C. External Apical Root Resorption in Class li Malocclusion: A Retrospective Review of 1-Versus 2-Phase Treatment. American Journal of Orthodontics and Dentofacial Orthopedics. 2003 124(2):151-6.

Capelozza Filho L, Silva Filho OG, Ozawa TO, Cavassan AO. Individualizaçäo De Braquetes Na Técnica De Straight-Wire: Revisäo De Conceitos E Sugestäo De Indicaçöes Para Uso; Brackets Individualization in Straight-Wire Technique: Concepts Review and Suggestions for Prescribed Use. Rev dent press ortodon ortop maxilar. 1999 4(4):87-106.

Consolaro A. Entrevista. Rev Dental Press Ortodon Ortop Facial 2002 7(3):7-16.

Consolaro A. Reabsorções Dentárias Nas Especialidades Clínicas; Dental Resorptions in Clinical Specialties: Dental Press; 2005. 
Copeland S, Green LJ. Root Resorption in Maxillary Central Incisors Following Active Orthodontic Treatment. American journal of orthodontics. 1986 89(1):51-5.

Dahlberg G. Statistical Methods for Medical and Biological Students. Statistical Methods for Medical and Biological Students. 1940

Damon DH. The Damon Low-Friction Bracket: A Biologically Compatible StraightWire System. Journal of clinical orthodontics: JCO. 1998 32(11):670.

de Luca Canto G. Estudo Comparativo Da Reabsorção Radicular Apical, Decorrente Do Tratamento Ortodôntico, Em Pacientes Tratados Com a Técnica Do Arco De Canto Simplificada, Do Arco Reto E Com a Terapia Bioeficiente 1997.

Dermaut L, De Munck A. Apical Root Resorption of Upper Incisors Caused by Intrusive Tooth Movement: A Radiographic Study. American Journal of Orthodontics and Dentofacial Orthopedics. 1986 90(4):321-6.

DeShields RW. A Study of Root Resorption in Treated Class li, Division I Malocclusions. The Angle Orthodontist. 1969 39(4):231-45.

DiBiase AT, Nasr IH, Scott P, Cobourne MT. Duration of Treatment and Occlusal Outcome Using Damon3 Self-Ligated and Conventional Orthodontic Bracket Systems in Extraction Patients: A Prospective Randomized Clinical Trial. American Journal of Orthodontics and Dentofacial Orthopedics. 2011 139(2):e111-e6.

El-Bialy T, El-Shamy I, Graber TM. Repair of Orthodontically Induced Root Resorption by Ultrasound in Humans. American Journal of Orthodontics and Dentofacial Orthopedics. 2004 126(2):186-93.

Emslie R. Some Considerations on the Role of Cementum in Periodontal Disease. Journal of clinical periodontology. 1978 5(1):1-12.

Feiglin B. Root Resorption. AustDent J. 1986 31(1):12-22.

FilhoA LC, da Silva FilhoB OG. (1998) V3, N1.Reabsorção Radicular Na Clínica Ortodôntica: Atitudes Para Uma Conduta Preventiva. Revista Dental Press De Ortodontia E Ortopedia Facial.

FilhoA LC, da Silva FilhoB OG. Reabsorção Radicular Na Clínica Ortodôntica: Atitudes Para Uma Conduta Preventiva. 
Furquim LZ. Perfil Endocrinológico De Pacientes Ortodônticos Com E Sem Reabsorções Dentárias Correlação Com a Morfologia Radicular E Da Crista Óssea Alveolar: Faculdade de Odontologia de Bauru, Universidade de São Paulo; 2002.

GAC. Innovation in Self-Ligating Brackets International Ortho World. Ortho World. 2003 v.36(n.2,):

Goldin B. Labial Root Torque: Effect on the Maxilla and Incisor Root Apex. American Journal of Orthodontics and Dentofacial Orthopedics. 1989 95(3):208-19.

Goldson L, Henrikson CO. Root Resorption During Begg Treatment: A Longitudinal Roentgenologic Study. American journal of orthodontics. 1975 68(1):55-66.

Guirro WJG, de Freitas KMS, de Freitas MR, Henriques JFC, Janson G, Canuto LFG. Recidiva Do Apinhamento Anterossuperior Nas Más Oclusões De Classe I E Classe li Tratadas Ortodonticamente Sem Extrações. 2011

Harradine NWT. Self-Ligating Brackets and Treatment Efficiency. Clinical orthodontics and research. 2001 4(4):220-7.

Harris EF, Baker WC. Loss of Root Length and Creastal Bone Height before and During Treatment in Adolescent and Adult Orthodontic Patients. American Journal of Orthodontics and Dentofacial Orthopedics. 1990 98(5):463-9.

Harris EF, Butler ML. Patterns of Incisor Root Resorption before and after Orthodontic Correction in Cases with Anterior Open Bites. American Journal of Orthodontics and Dentofacial Orthopedics. 1992 101(2):112-9.

Harris EF, Kineret SE, Tolley EA. A Heritable Component for External Apical Root Resorption in Patients Treated Orthodontically. American Journal of Orthodontics and Dentofacial Orthopedics. 1997 111(3):301-9.

Harry M, Sims M. Root Resorption in Bicuspid Intrusion. A Scanning Electron Microscope Study. The Angle Orthodontist. 1982 52(3):235.

Heimisdottir K, Bosshardt D, Ruf S. Can the Severity of Root Resorption Be Accurately Judged by Means of Radiographs? A Case Report with Histology. American Journal of Orthodontics and Dentofacial Orthopedics. 2005 128(1):106-9. 
Hemingway R, Williams R, Hunt J, Rudge S. The Influence of Bracket Type on the Force Delivery of Ni-Ti Archwires. The European Journal of Orthodontics. 2001 23(3):233.

Hemley S. The Incidence of Root Resorption of Vital Permanent Teeth. J Dent Res. $194120(20: 133-41$

Horiuchi A, Hotokezaka H, Kobayashi K. Correlation between Cortical Plate Proximity and Apical Root Resorption. American Journal of Orthodontics and Dentofacial Orthopedics. 1998 114(3):311-8.

Janson GRP, de Luca Canto G, Martins DR, Henriques JFC, de Freitas MR. A Radiographic Comparison of Apical Root Resorption after Orthodontic Treatment with 3 Different Fixed Appliance Techniques. American Journal of Orthodontics and Dentofacial Orthopedics. 2000 118(3):262.

Jones S, Boyde A. The Resorption of Dentine and Cementum in Vivo and in Vitro. Biological mechanisms of tooth eruption and root resorption Ohio: Columbus. 1988 335-54.

Júnior VSB, da Silva Ursi WJ. O Aparelho Pré-Ajustado: Sua Evolução E Suas Prescrições. 2006

Kaley J, Phillips C. Factors Related to Root Resorption in Edgewise Practice. The Angle Orthodontist. 1991 61(2):125-32.

Kalkwarf KL, Krejci RF, Pao Y. Effect of Apical Root Resorption on Periodontal Support. The Journal of prosthetic dentistry. 1986 56(3):317.

Kawashima-Ichinomiya R, Yamaguchi M, Tanimoto Y, Asano M, Yamada K, Nakajima R, et al. External Apical Root Resorption and the Release of Interleukin-6 in the Gingival Crevucular Fluid Induced by a Self-Ligating System. Open Journal of Stomatology. 2012 2(2):116-21.

Ketcham AH. A Preliminary Report of an Investigation of Apical Root Resorption of Permanent Teeth. International Journal of Orthodontia, Oral Surgery and Radiography. 1927 13(2):97-127.

Kjær I. Morphological Characteristics of Dentitions Developing Excessive Root Resorption During Orthodontic Treatment. The European Journal of Orthodontics. 1995 17(1):25. 
Krogman WM. Craniometry and Cephalometry as Research Tools in Growth of Head and Face. American journal of orthodontics. 1951 37(6):406-14.

Landis JR, Koch GG. The Measurement of Observer Agreement for Categorical Data. Biometrics. 1977 159-74.

Larsson E, Rönnerman A. Mandibular Dysfunction Symptoms in Orthodontically Treated Patients Ten Years after the Completion of Treatment. The European Journal of Orthodontics. 1981 3(2):89-94.

Leite V, Conti AC, Navarro R, Almeida M, Oltramari-Navarro P, Almeida R. Comparison of Root Resorption between Self-Ligating and Conventional Preadjusted Brackets Using Cone-Beam Computed Tomography. The Angle Orthodontist. 2012

Lenza MA. Braquetes Autoligáveis: Futuro Da Ortodontia? Revista Dental Press de Ortodontia e Ortopedia Facial. 2008 13(6):17-9.

Levander E, Malmgren O. Evaluation of the Risk of Root Resorption During Orthodontic Treatment: A Study of Upper Incisors. The European Journal of Orthodontics. 1988 10(1):30-8.

Levander E, Malmgren O, Eliasson S. Evaluation of Root Resorption in Relation to Two Orthodontic Treatment Regimes. A Clinical Experimental Study. The European Journal of Orthodontics. 1994 16(3):223-8.

Levander E, Malmgren O, Stenback K. Apical Root Resorption During Orthodontic Treatment of Patients with Multiple Aplasia: A Study of Maxillary Incisors. The European Journal of Orthodontics. 1998 20(4):427-34.

Linge BO, Linge L. Apical Root Resorption in Upper Anterior Teeth. The European Journal of Orthodontics. 1983 5(3):173-83.

Linge L, Linge BO. Patient Characteristics and Treatment Variables Associated with Apical Root Resorption During Orthodontic Treatment. American Journal of Orthodontics and Dentofacial Orthopedics. 1991 99(1):35-43.

Little RM. The Irregularity Index: A Quantitative Score of Mandibular Anterior Alignment. American journal of orthodontics. 1975 68(5):554-63. 
Loftus BP, Ârtun J, Nicholls JI, Alonzo TA, Stoner JA. Evaluation of Friction During Sliding Tooth Movement in Various Bracket-Arch Wire Combinations. American Journal of Orthodontics and Dentofacial Orthopedics. 1999 116(3):336-45.

Makedonas D, Lund H, Grondahl K, Hansen K. Root Resorption Diagnosed with Cone Beam Computed Tomography after 6 Months of Orthodontic Treatment with Fixed Appliance and the Relation to Risk Factors. Angle Orthod. 2012 Mar;82(2):196201.

Makedonas D, Lund H, Gröndahl K, Hansen K. Root Resorption Diagnosed with Cone Beam Computed Tomography after 6 Months of Orthodontic Treatment with Fixed Appliance and the Relation to Risk Factors. The Angle Orthodontist. 2011 82(2):196-201.

Malmgren O GL, Hill C, Orwin A, Petrini L, Lundberg M. Root Resorption after Orthodontic Treatment of Traumatized Teeth. Am J Orthod. 1982 82(6):487-91.

Marshall J. Physiologic and Traumatic Apical Resorption. J Amer dent Ass. 1935 22(

Martins DR, Cansançäo JM, Fernandez Sanchez J. Avaliaçäo Radiográfica Da Reabsorçäo Radicular, Consecutiva Ao Tratamento Ortodôntico (Cinco Anos Após a Remoçäo Dos Aparelhos); Radiographic Evaluation of Root Resorption Five Years after Orthodontic Treatment. Ortodontia. 1994 27(3):4-8.

Massler M, Malone AJ. Root Resorption in Human Permanent Teeth: A Roentgenographic Study. American journal of orthodontics. 1954 40(8):619-33.

Massler M, Perreault J. Root Resorption in the Permanent Teeth of Young Adults. J Dent Child. 1954 21(2):158-64.

McFadden WM, Engstrom C, Engstrom H, Anholm JM. A Study of the Relationship between Incisor Intrusion and Root Shortening. American Journal of Orthodontics and Dentofacial Orthopedics. 1989 96(5):390-6.

Mirabella AD, Årtun J. Prevalence and Severity of Apical Root Resorption of Maxillary Anterior Teeth in Adult Orthodontic Patients. The European Journal of Orthodontics. 1995 17(2):93-9.

Newman WG. Possible Etiologic Factors in External Root Resorption. American journal of orthodontics. 1975 67(5):522. 
Nishioka M, loi H, Nakata S, Nakasima A, Counts A. Root Resorption and Immune System Factors in the Japanese. The Angle Orthodontist. 2006 76(1):103-8.

Odenrick L, Brattström V. The Effect of Nailbiting on Root Resorption During Orthodontic Treatment. Eur J Orthod. 1983 5(185-8.

Oppenheim A. A Possibility for Physiologic Orthodontic Movement. American Journal of Orthodontics and Oral Surgery. 1944 30(6):277-328.

Oppenheim A. Tissue Changes, Particularly of the Bone, Incident to Tooth Movement. The European Journal of Orthodontics. 2007 29(suppl 1):i2-i15.

Ottolengui R. The Physiological and Pathological Resorption of Tooth Roots. Items of Interest. 1914 36(332-62.

Pandis N, Nasika M, Polychronopoulou A, Eliades T. External Apical Root Resorption in Patients Treated with Conventional and Self-Ligating Brackets. American Journal of Orthodontics and Dentofacial Orthopedics. 2008 134(5):646-51.

Parker RJ, Harris EF. Directions of Orthodontic Tooth Movements Associated with External Apical Root Resorption of the Maxillary Central Incisor. American Journal of Orthodontics and Dentofacial Orthopedics. 1998 114(6):677-83.

Peck S. So What's New? Arch Expansion, Again. The Angle Orthodontist. 2008 78(3):574.

Pereira AAC. Influência Da Gravidez E Dos Anticoncepcionais Na Reabsorção Radicular E Na Remodelação Óssea, Consequente À Movimentação Dentária Induzida: Avaliação Microscópica; Influence of Pregnancy and of Contraceptive in the Root Resorption and Bone Remodelation to Induced Tooth Movement: Microscopic Evaluation: Universidade de São Paulo. Faculdade de Odontologia de Bauru; 1995.

Phillips JR. Apical Root Resorption under Orthodontic Therapy*. The Angle Orthodontist. 1955 25(1):1-22.

PucheL.R. Reabsorcion Radicular Y Ortodoncia. Acta Odontol Venez. 1993 31(1):445.

Quintella CB. Avaliação Da Influência Do Guia De Erupção: Universidade de São Paulo. Faculdade de Odontologia de Bauru; 2001. 
Rego MVNN, Thiesen G, Marchioro EM, Berthold TB. Reabsorção Radicular E Tratamento Ortodôntico: Mitos E Evidências Científicas; Radicular Resorption and Orthodontic Treatment: Myths and Scientific Evidences. J bras ortodon ortop facial. 2004 9(51):292-309.

Reitan K. Some Factors Determining the Evaluation of Forces in Orthodontics. American journal of orthodontics. 1957 43(1):32-45.

Reitan K. Effects of Force Magnitude and Direction of Tooth Movement on Different Alveolar Bone Types*. The Angle Orthodontist. 1964 34(4):244-55.

Remington DN, Joondeph DR, Årtun J, Riedel RA, Chapko MK. Long-Term Evaluation of Root Resorption Occurring During Orthodontic Treatment. American Journal of Orthodontics and Dentofacial Orthopedics. 1989 96(1):43-6.

Rygh P. Orthodontic Root Resorption Studied by Electron Microscopy. The Angle Orthodontist. 1977 47(1):1-16.

Sameshima G, Sinclair P. Characteristics of Patients with Severe Root Resorption. Orthodontics \& craniofacial research. 2004 7(2):108-14.

Sameshima GT, Sinclair PM. Predicting and Preventing Root Resorption: Part I. Diagnostic Factors. American Journal of Orthodontics and Dentofacial Orthopedics. 2001 119(5):505-10.

Santos ECA, Lara TS, Arantes FM, Coclete GA, Silva RS. Análise Radiográfica Computadorizada Da Reabsorção Radicular Apical Após a Utilização De Duas Mecânicas Ortodônticas. Revista Dental Press de Ortodontia e Ortopedia Facial. 2007 12(1):48-55.

Silva Filho OG, Berreta EC, Cavassan AO, Capelozza Filho L. Estimativa Da Reabsorção Radicular Em 50 Casos Ortodônticos Bem Finalizados; Evaluation of Root Resorption in 50 Properly Treated Orthodontics Cases. Ortodontia. 1993 26(1):24-35.

Spurrier SW, Hall SH, Joondeph DR, Shapiro PA, Riedel RA. A Comparison of Apical Root Resorption During Orthodontic Treatment in Endodontically Treated and Vital Teeth. American Journal of Orthodontics and Dentofacial Orthopedics. 1990 97(2):130-4.

Steadman SR. Résumé of the Literature on Root Resorption*. The Angle Orthodontist. 1942 12(1):28-38. 
Stolzenberg J. The Russell Attachment and Its Improved Advantages. International Journal of Orthodontia and Dentistry for Children. 1935 21(9):837-40.

Taithongchai R, Sookkorn K, Killiany DM. Facial and Dentoalveolar Structure and the Predictionof Apical Root Shortening. American Journal of Orthodontics and Dentofacial Orthopedics. 1996 110(3):296-302.

Thongudomporn U, Freer TJ. Anomalous Dental Morphology and Root Resorption During Orthodontic Treatment: A Pilot Study. Aust Orthod J. 1998 15(3):162-7.

Thorstenson GA, Kusy RP. Resistance to Sliding of Self-Ligating Brackets Versus Conventional Stainless Steel Twin Brackets with Second-Order Angulation in the Dry and Wet (Saliva) States. American Journal of Orthodontics and Dentofacial Orthopedics. 2001 120(4):361-70.

TREVISI H. Smartclip: Tratamento Ortodôntico Com Sistema De Aparelho Autoligado-Conceito E Biomecânica. SmartClip: tratamento ortodôntico com sistema de aparelho autoligado-conceito e biomecânica. 2007

Tronstad L. Root Resorption-Etiology, Terminology and Clinical Manifestations. Dental Traumatology. 1988a 4(6):241-52.

Tronstad L. Root Resorption: A Multidisciplinary Problem in Dentistry. Biological mechanisms of tooth eruption and root resorption Ohio: Columbus. 1988b 293-301.

VONDERAHE G. Postretention Status of Maxillary Incisors with Root-End Resorption. The Angle Orthodontist. 1973 43(3):247-55.

Wenzel A, Verdonschot E. Some Considerations in the Evaluation of Diagnostic Tests in Dentistry. Dento maxillo facial radiology. 1994 23(4):179.

Wickwire NA, McNeil MH, Norton LA, Duell RC. The Effects of Tooth Movement Upon Endodontically Treated Teeth. The Angle Orthodontist. 1974 44(3):235-42.

Wildman A, Hice T, Lang H, Lee I, Strauch Jr E. Round Table-the Edgelok Bracket. J Clin Orthod. 1972 6(11):613-23.

Younis M IL, Soares RG, Salles AA. Ortodontia Frente Às Reabsorções

Apicais E Periapicais Prévias Ou Posteriores Ao Tratamento. Rev Endod Pesq Ensino. 2008 4(8):1-9. 
Apênalices 



\section{APÊNDICES}

Tabela A1: Gênero data de nascimento, inicio e final de tratamento do grupo 1.

\begin{tabular}{|llll|}
\hline \multicolumn{1}{c}{ Nome } & \multicolumn{1}{c|}{ DN } & \multicolumn{1}{c|}{ Inicio } & \multicolumn{1}{c|}{ Final } \\
\hline A S B & $26 / 04 / 1995$ & $23 / 06 / 2010$ & $02 / 11 / 2012$ \\
\hline A C Z. B & $30 a 9 m$ & $23 / 01 / 2009$ & $28 / 04 / 2012$ \\
\hline A F M & $23 / 04 / 1995$ & $9 / 2 / 2011$ & $02 / 11 / 2012$ \\
\hline A S P & $27 / 07 / 1996$ & $18 / 08 / 2010$ & $02 / 11 / 2012$ \\
\hline B S G & $5 / 2 / 1998$ & $17 / 02 / 2011$ & $02 / 11 / 2012$ \\
\hline B L & $24 / 03 / 1997$ & $15 / 11 / 2008$ & $11 / 11 / 2010$ \\
\hline C F & $21 / 10 / 1993$ & $5 / 5 / 2010$ & $2 / 5 / 2012$ \\
\hline C S F & 14 anos & $5 / 5 / 2010$ & $2 / 5 / 2012$ \\
\hline E M N & $22 / 12 / 1991$ & $20 / 08 / 2008$ & $19 / 09 / 2011$ \\
\hline E P R & $14 / 05 / 1998$ & $28 / 03 / 2011$ & $26 / 03 / 2012$ \\
\hline F E M S & $16 / 02 / 1996$ & $1 / 8 / 2010$ & $25 / 05 / 2012$ \\
\hline G V F & $28 / 06 / 1995$ & $14 / 04 / 2011$ & $9 / 8 / 2012$ \\
\hline G K. B S & $16 / 02 / 1996$ & $14 / 04 / 2010$ & $20 / 03 / 2012$ \\
\hline G N S & $20 / 12 / 1996$ & $15 / 02 / 2011$ & $02 / 11 / 2012$ \\
\hline G C A & $9 a 8 m$ & $10 / 11 / 2009$ & $7 / 5 / 2012$ \\
\hline I A Silva & $15 / 05 / 1984$ & $16 / 04 / 2008$ & $19 / 04 / 2011$ \\
\hline K G. M. C & $17 a 8 m$ & $12 / 2 / 2009$ & $19 / 06 / 2012$ \\
\hline L M L B & $8 / 2 / 1995$ & $22 / 02 / 2011$ & $02 / 11 / 2012$ \\
\hline L B. C. O & $10 a 4 m$ & $29 / 01 / 2008$ & $31 / 08 / 2010$ \\
\hline L F O & $16 / 11 / 1993$ & $17 / 11 / 2009$ & $9 / 1 / 2012$ \\
\hline M A. V. D & $12 / 1 / 1980$ & $20 / 04 / 2010$ & $23 / 07 / 2012$ \\
\hline P C F & $9 / 1 / 1999$ & $4 / 8 / 2010$ & $20 / 03 / 2012$ \\
\hline R C R & $2 / 1 / 1997$ & $28 / 11 / 2011$ & $02 / 11 / 2012$ \\
\hline R M C & $21 / 02 / 1998$ & $1 / 12 / 2011$ & $02 / 11 / 2012$ \\
\hline T T N & $10 / 8 / 1992$ & $4 / 5 / 2011$ & $6 / 8 / 2012$ \\
\hline & & & \\
\hline
\end{tabular}


Tabela A2: Gênero data de nascimento, inicio e final de tratamento do grupo 2.

\begin{tabular}{|lcccc|}
\hline \multicolumn{1}{|c}{ Nome } & Sexo & DN & Inicio & Final \\
\hline A. M. R & $\mathrm{F}$ & $26 / 02 / 1975$ & $28 / 09 / 2006$ & $28 / 11 / 2008$ \\
\hline A M. S. & $\mathrm{F}$ & $20 / 11 / 1987$ & $16 / 09 / 2009$ & $12 / 1 / 2011$ \\
\hline A Q. & $\mathrm{F}$ & $13 / 09 / 1986$ & $19 / 05 / 2000$ & $29 / 04 / 2001$ \\
\hline A S. M. & $\mathrm{M}$ & $14 / 10 / 1994$ & $21 / 05 / 2007$ & $27 / 01 / 2009$ \\
\hline C L. A. & $\mathrm{M}$ & $7 / 10 / 1985$ & $30 / 09 / 2005$ & $9 / 6 / 2008$ \\
\hline D C. J & $\mathrm{F}$ & $28 / 04 / 1975$ & $17 / 11 / 2009$ & $10 / 10 / 2011$ \\
\hline D D. S & $\mathrm{F}$ & $26 / 08 / 1987$ & $27 / 11 / 2004$ & $7 / 1 / 2006$ \\
\hline D L. V & $\mathrm{M}$ & $13 / 02 / 1991$ & $11 / 8 / 2007$ & $6 / 3 / 2009$ \\
\hline E O. M & $\mathrm{M}$ & $28 / 10 / 1990$ & $5 / 4 / 2004$ & $18 / 10 / 2005$ \\
\hline E L B & $\mathrm{M}$ & $13 / 05 / 1988$ & $24 / 09 / 2002$ & $13 / 08 / 2004$ \\
\hline F B O & $\mathrm{M}$ & $7 / 2 / 1983$ & $23 / 05 / 1998$ & $19 / 01 / 2000$ \\
\hline F S O & $\mathrm{M}$ & $3 / 2 / 1989$ & $17 / 09 / 2002$ & $19 / 04 / 2004$ \\
\hline G FS & $\mathrm{M}$ & $4 / 1 / 1996$ & $2 / 12 / 2008$ & $13 / 06 / 2011$ \\
\hline G C & $\mathrm{M}$ & $19 / 10 / 1988$ & $4 / 7 / 2002$ & $27 / 06 / 2003$ \\
\hline G S M & $\mathrm{F}$ & $14 / 10 / 1981$ & $24 / 07 / 1997$ & $23 / 02 / 1999$ \\
\hline J A & $\mathrm{M}$ & $21 / 07 / 1993$ & $1 / 6 / 2006$ & $25 / 06 / 2008$ \\
\hline K G O & $\mathrm{F}$ & $20 / 12 / 1990$ & $24 / 01 / 2004$ & $12 / 8 / 2005$ \\
\hline K M & $\mathrm{F}$ & $12 / 8 / 1986$ & $19 / 05 / 2000$ & $21 / 05 / 2001$ \\
\hline L F. P & $\mathrm{F}$ & $17 / 11 / 1995$ & $13 / 04 / 2010$ & $12 / 9 / 2011$ \\
\hline L F. D & $\mathrm{M}$ & $7 / 1 / 1991$ & $7 / 7 / 2007$ & $14 / 11 / 2009$ \\
\hline M M. F & $\mathrm{M}$ & $15 / 06 / 1987$ & $9 / 12 / 2002$ & $7 / 1 / 2005$ \\
\hline M A. M & $\mathrm{F}$ & $28 / 02 / 1984$ & $20 / 09 / 1999$ & $9 / 10 / 2000$ \\
\hline N F. A & $\mathrm{M}$ & $29 / 01 / 1990$ & $11 / 3 / 2004$ & $15 / 09 / 2005$ \\
\hline R G. F & $\mathrm{F}$ & $1 / 5 / 1989$ & $17 / 05 / 2004$ & $23 / 05 / 2007$ \\
\hline T R. B & $\mathrm{M}$ & $30 / 01 / 1991$ & $1 / 9 / 2006$ & $20 / 01 / 2009$ \\
\hline V P L & $\mathrm{F}$ & $10 / 2 / 1984$ & $12 / 11 / 2005$ & $1 / 6 / 2007$ \\
\hline V E. V & $\mathrm{F}$ & $9 / 10 / 1983$ & $23 / 01 / 2001$ & $26 / 11 / 2001$ \\
\hline
\end{tabular}


Tabela A3: Little superior e inferior do grupo 1 (G1) e grupo 2 (G2).

\begin{tabular}{|cccccc|}
\hline $\mathbf{G ~ 1}$ & Little Sup. & Little $\mathbf{~ I n f . ~}$ & G $\mathbf{~}$ & Little Sup & Little Inf. \\
\hline $\mathbf{1}$ & 9,24 & 12,97 & 1 & 6,66 & 9,15 \\
\hline $\mathbf{2}$ & 4,99 & 5,95 & 2 & 4,04 & 6,69 \\
\hline $\mathbf{3}$ & 14,21 & 7,56 & 3 & 7,73 & 4,36 \\
\hline $\mathbf{4}$ & 9,94 & 10,88 & 4 & 5,24 & 4,96 \\
\hline $\mathbf{5}$ & 9,76 & 10,25 & 5 & 4,24 & 8,04 \\
\hline $\mathbf{6}$ & 5,48 & 3,38 & 6 & 6,8 & 7,45 \\
\hline $\mathbf{7}$ & 3,01 & 5,78 & 7 & 4,21 & 3,24 \\
\hline $\mathbf{8}$ & 7,24 & 5,8 & 8 & 3,39 & 3,41 \\
\hline $\mathbf{9}$ & 3,89 & 3,49 & 9 & 6,18 & 7,55 \\
\hline $\mathbf{1 0}$ & 4,02 & 4,32 & 10 & 8,43 & 4,54 \\
\hline $\mathbf{1 1}$ & 4,12 & 6,48 & 11 & 3,38 & 4,4 \\
\hline $\mathbf{1 2}$ & 14,87 & 7,31 & 12 & 3,91 & 4,13 \\
\hline $\mathbf{1 3}$ & 3,66 & 7,7 & 13 & 4,35 & 7,03 \\
\hline $\mathbf{1 4}$ & 11,06 & 5,83 & 14 & 7,56 & 5,76 \\
\hline $\mathbf{1 5}$ & 3,46 & 2,98 & 15 & 5,23 & 5,73 \\
\hline $\mathbf{1 6}$ & 3,49 & 4,33 & 16 & 3,4 & 4,28 \\
\hline $\mathbf{1 7}$ & 3,12 & 5,04 & 17 & 4,4 & 7,21 \\
\hline $\mathbf{1 8}$ & 9,18 & 8,96 & 18 & 4,43 & 4,11 \\
\hline $\mathbf{1 9}$ & 3,45 & 3,52 & 19 & 5,97 & 5,79 \\
\hline $\mathbf{2 0}$ & 7,22 & 3,97 & 20 & 3,4 & 5,9 \\
\hline $\mathbf{2 1}$ & 3,0 & 3,72 & 21 & 7,87 & 3,22 \\
\hline $\mathbf{2 2}$ & 3,07 & 4,7 & 22 & 3,24 & 4,44 \\
\hline $\mathbf{2 3}$ & 8,76 & 13,32 & 23 & 4,45 & 4,45 \\
\hline $\mathbf{2 4}$ & 15,39 & 6,81 & 24 & 3,69 & 6,1 \\
\hline $\mathbf{2 5}$ & 3,47 & 4,1 & 25 & 4,83 & 3,0 \\
\hline & & & 26 & 3,69 & 5,76 \\
\hline & & & 27 & 7,89 & 5,16 \\
\hline & & & & \\
\hline
\end{tabular}


Tabela A4: Grau de reabsorção dos incisivos superiores e inferiores do grupo 1.

\begin{tabular}{|c|c|c|c|c|c|c|c|c|}
\hline & D12 & D11 & D21 & D22 & D32 & D31 & D41 & D42 \\
\hline 1 & 2 & 1 & 2 & 1 & 1 & 2 & 1 & 2 \\
\hline 2 & 2 & 3 & 3 & 2 & 0 & 1 & 1 & 0 \\
\hline 3 & 0 & 0 & 0 & 0 & 0 & 0 & 0 & 0 \\
\hline 4 & 0 & 0 & 0 & 0 & 0 & 0 & 1 & 0 \\
\hline 5 & 0 & 0 & 0 & 1 & 0 & 0 & 0 & $\overline{0}$ \\
\hline 6 & 0 & 0 & 1 & 1 & 0 & 0 & 0 & 0 \\
\hline 7 & 2 & 1 & 2 & 1 & 1 & 0 & 0 & 0 \\
\hline 8 & 1 & 2 & 1 & 1 & 2 & 0 & 1 & 1 \\
\hline 9 & 1 & 3 & 3 & 1 & 0 & 1 & 1 & 0 \\
\hline 10 & 0 & 0 & 0 & 0 & 0 & 0 & 0 & 0 \\
\hline 11 & 1 & 1 & 1 & 1 & 0 & 0 & 0 & 0 \\
\hline 12 & 0 & 0 & 1 & 0 & 0 & 1 & 1 & 0 \\
\hline 13 & 2 & 1 & 1 & 2 & 0 & 0 & 0 & 0 \\
\hline 14 & 0 & 0 & 0 & 0 & 1 & 1 & 0 & 0 \\
\hline 15 & 1 & 0 & 1 & 1 & 0 & 1 & 1 & $\overline{0}$ \\
\hline 16 & 2 & 1 & 2 & 1 & 2 & 1 & 2 & 1 \\
\hline 17 & 1 & 1 & 0 & 0 & 0 & 1 & 0 & 1 \\
\hline 18 & 0 & 0 & 0 & 1 & 1 & 1 & 1 & 1 \\
\hline 19 & 0 & 0 & 1 & 0 & 1 & 1 & 1 & 1 \\
\hline 20 & 0 & 1 & 1 & 1 & 1 & 1 & 1 & 1 \\
\hline 21 & 0 & 0 & 0 & 0 & 0 & 1 & 1 & 1 \\
\hline 22 & 2 & 2 & 2 & 2 & 1 & 1 & 1 & 0 \\
\hline 23 & 1 & 0 & 0 & 1 & 1 & 0 & 0 & 1 \\
\hline 24 & 0 & 1 & 0 & 1 & 1 & 0 & 1 & 1 \\
\hline 25 & 0 & 0 & 0 & 1 & 1 & 1 & 1 & 7 \\
\hline
\end{tabular}


Tabela A5: Grau de reabsorção dos incisivos superiores e inferiores do grupo 2.

\begin{tabular}{|lllllllllll|}
\hline & D12 & D11 & D21 & D22 & D32 & D31 & D41 & D42 \\
\hline $\mathbf{1}$ & 3 & 3 & 3 & 3 & 2 & 1 & 2 & 1 \\
\hline $\mathbf{2}$ & 1 & 0 & 0 & 0 & 0 & 0 & 0 & 0 \\
\hline $\mathbf{3}$ & 1 & 1 & 1 & 1 & 0 & 0 & 0 & 0 \\
\hline $\mathbf{4}$ & 1 & 1 & 1 & 1 & 0 & 1 & 0 & 0 \\
\hline $\mathbf{5}$ & 1 & 2 & 2 & 0 & 1 & 0 & 2 & 1 \\
\hline $\mathbf{6}$ & 1 & 0 & 1 & 0 & 1 & 1 & 1 & 1 \\
\hline $\mathbf{8}$ & 0 & 1 & 1 & 0 & 0 & 0 & 0 & 0 \\
\hline $\mathbf{9}$ & 1 & 1 & 0 & 0 & 0 & 1 & 0 & 0 \\
\hline $\mathbf{1 0}$ & 1 & 0 & 0 & 1 & 1 & 1 & 1 & 1 \\
\hline $\mathbf{1 1}$ & 1 & 1 & 0 & 1 & 0 & 1 & 1 & 0 \\
\hline $\mathbf{1 2}$ & 1 & 1 & 2 & 2 & 2 & 2 & 2 & 1 \\
\hline $\mathbf{1 3}$ & 0 & 0 & 1 & 0 & 1 & 2 & 1 & 0 \\
\hline $\mathbf{1 4}$ & 0 & 2 & 1 & 1 & 1 & 2 & 2 & 1 \\
\hline $\mathbf{1 5}$ & 2 & 0 & 0 & 1 & 2 & 1 & 1 & 2 \\
\hline $\mathbf{1 6}$ & 0 & 0 & 0 & 0 & 0 & 1 & 2 & 0 \\
\hline $\mathbf{1 7}$ & 1 & 0 & 1 & 1 & 0 & 0 & 0 & 0 \\
\hline $\mathbf{1 8}$ & 0 & 1 & 0 & 0 & 2 & 0 & 0 & 1 \\
\hline $\mathbf{1 9}$ & 0 & 0 & 0 & 1 & 1 & 0 & 0 & 0 \\
\hline $\mathbf{2 0}$ & 1 & 0 & 1 & 2 & 0 & 0 & 1 & 0 \\
\hline $\mathbf{2 1}$ & 0 & 0 & 0 & 0 & 0 & 0 & 0 & 1 \\
\hline $\mathbf{2 2}$ & 2 & 2 & 2 & 2 & 0 & 1 & 1 & 0 \\
\hline $\mathbf{2 3}$ & 0 & 0 & 0 & 1 & 1 & 0 & 0 & 0 \\
\hline $\mathbf{2 4}$ & 0 & 0 & 0 & 1 & 0 & 1 & 0 & 0 \\
\hline $\mathbf{2 5}$ & 1 & 0 & 1 & 1 & 0 & 0 & 0 & 1 \\
\hline $\mathbf{2 6}$ & 0 & 0 & 0 & 0 & 0 & 0 & 0 & 0 \\
\hline $\mathbf{2 7}$ & 0 & 0 & 0 & 0 & 0 & 0 & 0 & 0 \\
\hline & & & & & & & & \\
\hline
\end{tabular}





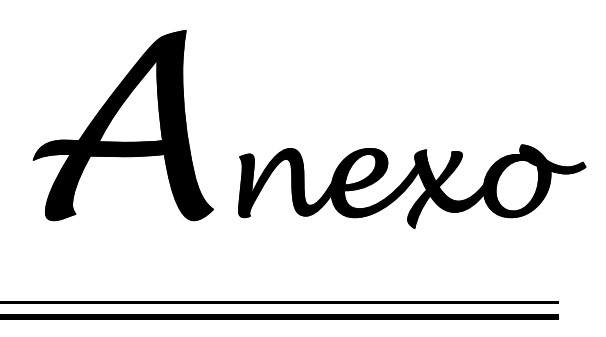



ANEXO

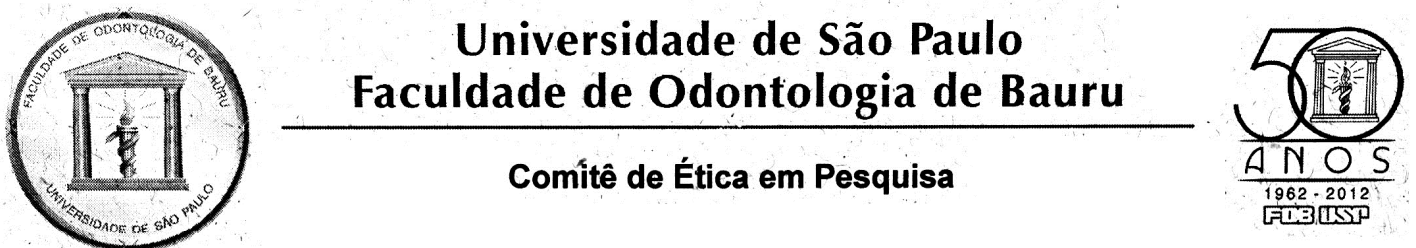

Processo $n^{\circ}$ 083/2011

Bauru, 12 de março de 2012.

Senhor Professor,

Em atenção à solicitação de Vossa Senhoria para alterações no projeto de pesquisa anteriormente intitulado AVALIAÇÂAO DA REABSORÇÃO RADICULAR EXTERNA CONSECUTIVA AO USO DO SISTEMA DAMON POR MEIO DA TOMOGRAFIA COMPUTADORIZADA DO FEIXE CÔNICO, de autoria de Roberta Heiffig Handem, sob sua orientação foram aprovadas por este Colegiado em reunião realizada no dia 29 de fevereiro de 2012, quais sejam:

- alteração na metodologia do diagnóstico das reabsorções radiculares, não sendo mais por meio de tomografias computadorizadas e somente por meio de radiografias periapicais;

- alteração no título da pesquisa para "Avaliação da reabsorção radicular externa consecutiva ao uso do Sistema Autoligável Damon".

No entanto, lembramos aos pesquisadores:

- que sejam encaminhados ao CEP-FOB/USP relatórios anuais sobre o andamento da pesquisa (parciais e finais), conforme ô cronograma apresentado;

- que sejam notificados ao CEP-FOB/USP, com a devida justificativa, qualquer modificação na metodologia e/ou título e a inclusão ou exclusão de autores;

- na apresentação do relatório final, sejam incluídos todos os TCLEs devidamente assinados e rubricados, se for o caso.

Atenciosamente,

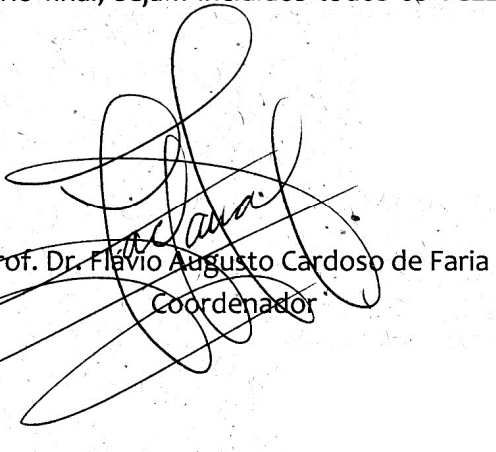

Prof. Dr. Marcos Roberto de Freitas

Docente do Departamento de Odontopediatria, Ortodontia e Saúde Coletiva

Al. Dr. Octávio Pinheiro Brisolla, 9-75 - Bauru-SP - CEP 17012-101 - C.P. 73

e-mail: cep@fob.usp.br - Fone/FAX (0xx14) 3235-8356

http://www.fob.usp.br 